CARLOS AUGUSTO CAMINADA FAGUNDES FILHO

\title{
ANÁLISE DA ESTRATÉGIA DE CONTRATAÇÃO DE CONSUMIDORES LIVRES, TENDO COMO BALIZAMENTO A FORMAÇÃO DE PREÇOS NO MERCADO CATIVO
}


CARLOS AUGUSTO CAMINADA FAGUNDES FILHO

\section{ANÁLISE DA ESTRATÉGIA DE CONTRATAÇÃO DE CONSUMIDORES LIVRES, TENDO COMO BALIZAMENTO A FORMAÇÃO DE PREÇOS NO MERCADO CATIVO}

Dissertação apresentada à Escola Politécnica da Universidade de São Paulo para obtenção do título de Mestre em Engenharia Elétrica

São Paulo 
CARLOS AUGUSTO CAMINADA FAGUNDES FILHO

\section{ANÁLISE DA ESTRATÉGIA DE CONTRATAÇÃO DE CONSUMIDORES LIVRES, TENDO COMO BALIZAMENTO A FORMAÇÃO DE PREÇOS NO MERCADO CATIVO}

Dissertação apresentada à Escola Politécnica da Universidade de São Paulo para obtenção do título de Mestre em Engenharia Elétrica

Área de Concentração: Sistemas de Potência

Orientador: Prof. Dr. Dorel Soares Ramos

São Paulo

2009 
Este exemplar foi revisado e alterado em relação à versão original, sob responsabilidade única do autor e com a anuência de seu orientador.

São Paulo, 31 de agosto de 2009.

Carlos Augusto C. Fagundes Filho

Dorel Soares Ramos

FICHA CATALOGRÁFICA

Fagundes Filho, Carlos Augusto Caminada

Análise da estratégia de contratação de consumidores livres tendo como balizamento a formação de preços no mercado cativo / C.A.C. Fagundes Filho. - ed.rev. - São Paulo, 2009.

$132 \mathrm{p}$.

Dissertação (Mestrado) - Escola Politécnica da Universidade de São Paulo. Departamento de Engenharia de Energia e Automação Elétricas.

1. Energia elétrica 2. Tarifas públicas 3 . Preço ao consumidor I. Universidade de São Paulo. Escola Politécnica. Departamento de Engenharia de Energia e Automação Elétricas II. t. 
Carlos Augusto Caminada Fagundes Filho

Análise da Estratégia de Contratação de Consumidores Livres, tendo como balizamento a Formação de Preços no Mercado Cativo

Dissertação apresentada à Escola Politécnica da Universidade de São Paulo para obtenção do título de Mestre em Engenharia Elétrica Área de Concentração: Sistemas de Potência

Aprovado em:

Banca Examinadora

Prof. Dr. Dorel Soares Ramos - Orientador

Instituição: Escola Politécnica da USP Assinatura:

Prof. Dr. Hector Arango

Instituição: Universidade Federal de Itajubá Assinatura:

Prof. Dr. Carlos Márcio Vieira Tahan

Instituição: Escola Politécnica da USP Assinatura: 
Aos meus avós, Aos meus pais, Ao meu irmão e À minha namorada, Ana 


\section{AGRADECIMENTOS}

Ao professor e orientador Dorel Soares Ramos, pela orientação e atenção dispensada durante a execução deste trabalho.

Aos professores e colegas Carlos Tahan e Hector Arango, pelas oportunidades proporcionadas, ensinamentos e exemplos de profissionalismo e dignidade que são.

Aos amigos e companheiros da ABRACE, em especial à Denise Teixeira e Patrícia Arce, pelo suporte e constantes contribuições ao longo do desenvolvimento deste trabalho.

À Ecom Energia, pelo apoio na conclusão dessa etapa de minha vida.

Aos eternos amigos e irmãos da EFEl, pelo companheirismo e amizade.

À minha namorada Ana pelo amor, apoio e companheirismo no tempo em que me dediquei a esta tarefa.

A meus pais, por me darem a Vida, muitas vezes sacrificando as suas para fazer da minha a melhor possível, e a meu irmão, pela amizade. 


\section{RESUMO}

A disponibilidade de energia a preços competitivos é fundamental para a competitividade dos produtos da indústria nacional, que está imersa num ambiente concorrencial interno e externo. Essa indústria tem inserção maciça no cotidiano de toda sociedade, contribuindo decisivamente para o bom andamento da economia brasileira. O Modelo Setorial permite a um grande consumidor optar pela contratação de energia de forma regulada ou livre, pelo que a análise da melhor estratégia de contratação torna-se fundamental. No presente trabalho, é realizado o mapeamento da composição dos preços praticados no Ambiente de Contratação Livre ( $A C L$ ) e Ambiente de Contratação Regulado (ACR). As regras são definidas através da análise da legislação setorial e do comportamento observado dos agentes de mercado. Após essa etapa, são realizadas simulações, partindo de premissas macroeconômicas e setoriais, que fornecem projeções de preços para ambos os ambientes e, por fim, realizadas comparações entre as diversas estratégias de contratação.

Palavras chave: Estratégia de contratação. Consumidores de energia. Projeção de preços. Contratos bilaterais. Tarifa de energia. 


\begin{abstract}
The availability of electrical energy at competitive prices is of fundamental importance for the competitiveness of products in each industry field, considering the strong competition in internal and external markets. The industry production plays an important role in society everyday life, contributing decisively to the smooth running of the Brazilian economy. Taking into account this perspective, the Brazilian electrical sector institutional model allows a big consumer to have the option to satisfy his energy needs in the regulated or free market. Therefore, the analysis of the best contracting strategy becomes crucial. In this work, the energy pricing in Regulated Contracting Market (ACR) and in the Free Contracting Market $(A C L)$ is deeply analyzed. The rules are defined through the analysis of the electrical sector legislation and the observed behavior of market players. After this stage, simulations are performed considering sector and macroeconomic assumptions, which provide spot prices forecast and long term energy prices forecast for both environments and, finally, comparisons between the different contracting strategies are established.
\end{abstract}

keywords: Contracting Strategies; Wholesale Energy Market; Spot Prices Forecast; Bilateral Agreements; Electricity Tariffs. 


\section{LISTA DE ILUSTRAÇÕES}

Figura 1 - Os Ambientes de Contração ........................................................ 26

Figura 2 - Estrutura Organizacional Novo Modelo.......................................... 28

Figura 3 - Processo de Decisão para Sistemas Hidrotérmicos ............................ 36

Figura 4 - Funções de Custo Imediato e Futuro ………...................................... 37

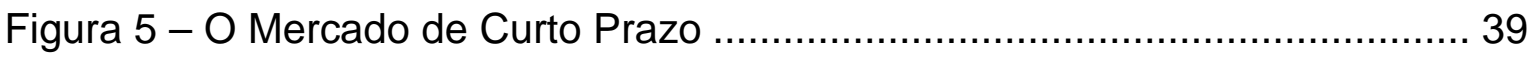

Figura 6 - Histórico mensal de Preços .......................................................... 40

Figura 7 - Momentos de Contratação …………………............................... 42

Figura 8 - Composição do Custo das UTE's com contrato por disponibilidade .... 43

Figura 9 - Montantes e preços negociados nos LEN e Fonte Alternativa (base

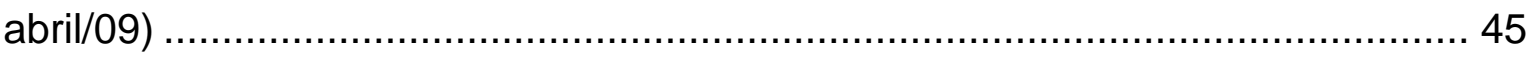

Figura 10 - Repasse dos níveis de contratação ............................................. 50

Figura 11 - Regime de Regulação por Incentivos........................................... 51

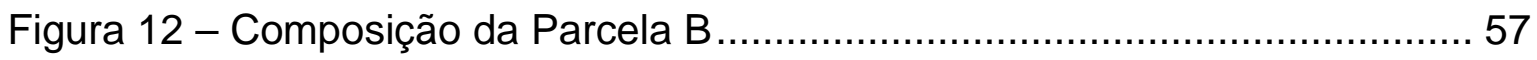

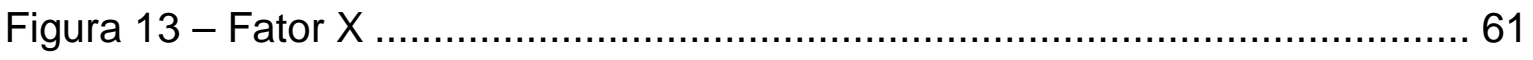

Figura 14 - Composição da TUSD P da classe A2 .............................................. 70

Figura 15 - Composição da TUSD FP da classe A2 ………………………... 71

Figura 16 - Composição da TUSD Energia da classe A2 .................................. 71

Figura 17 - Composição da TE FP U da CEMIG ............................................... 73

Figura 18 - Comparativo entre a estrutura da TE e o equivalente no ACL ........... 76

Figura 19 - Portfólio de Contratos CEMIG ......................................................... 80

Figura 20 - Correlação do Produto com entrega em 2008 do 1ํ LEN .................. 85

Figura 21 - PLD médio SE/CO para os Cenários 1 e 4 …................................. 87

Figura 22 - Fator de Capacidade adotado para as usinas eólicas........................ 88 
Figura 23 - PLD médio SE/CO para os Cenários 2 e 3

Figura 24 - Custo Esperado do Produto com entrega em 2009 do 1은...... 90

Figura 25 - Composição da TE no Cenário 1 para o Consumidor 1 .................... 92

Figura 26 - Projeção da TE para o Consumidor 1 ........................................... 92

Figura 27 - Projeção da TE para o Consumidor 2 ........................................... 93

Figura 28 - Projeção do preço médio de compra da CEMIG ................................. 94

Figura 29 - Preços Hipotéticos dos contratos de Curto Prazo ............................. 96

Figura 30 - Formação do preço dos contratos de um ano .................................. 99

Figura 31 - Formação do preço dos contratos de dois anos .............................. 99

Figura 32 - Formação do preço dos contratos de três anos .............................. 101

Figura 33 - Formação do preço dos contratos de quatro anos ........................... 101

Figura 34 - Dados de Entrada do Modelo de Simulação ...................................... 102

Figura 35 - Séries de preços utilizadas pelo modelo de simulação .................... 103

Figura 36 - Séries Hidrológicas vinculadas às séries de preços........................ 103

Figura 37 - Comportamentos dos contratos bilaterais de 1 ano ........................ 105

Figura 38 - Comportamentos dos contratos bilaterais de 2 anos ..................... 105

Figura 39 - Comportamentos dos contratos bilaterais de 3 anos ..................... 106

Figura 40 - Comportamentos dos contratos bilaterais de 4 anos ..................... 106

Figura 41 - Distribuições de Preços de Renovação - Cenário 1 ........................ 108

Figura 42 - Distribuições de Preços de Renovação - Cenário 2 ....................... 109

Figura 43 - Distribuições de Preços de Renovação - Cenário 3 ....................... 109

Figura 44 - Distribuições de Preços de Renovação - Cenário 4 ........................ 110

Figura 45 - Distribuições do PLD médio em 2016 .......................................... 111 


\section{LISTA DE TABELAS}

Tabela 1 - Critérios vigentes para se tornar Consumidor Livre. (CCEE, 2008)...... 34

Tabela 2 - Restrições ao Volume de Contratação de Energia ........................................ 48

Tabela 3 - Restrições ao Repasse Tarifário .................................................................. 49

Tabela 4 - Composição da Receita de uma distribuidora ............................................53

Tabela 5 - Classe de Consumidores do Grupo A …………………………………...... 63

Tabela 6 - Estrutura da tarifa horo-sazonal azul........................................................ 65

Tabela 7 - Estrutura da tarifa horo-sazonal verde …………………………………..... 65

Tabela 8 - Classe de Consumidores do Grupo B ...................................................... 66

Tabela 9 - Estimativa de duração da RTE.................................................................. 77

Tabela 10 - Taxas de crescimento de mercado ........................................................... 78

Tabela 11 - Critério de atualização de preços por tipo de contrato ............................ 81

Tabela 12 - Custo Médio Anual recalculado a partir do PMO de Nov/2008 ….......84

Tabela 13 - Taxas de crescimento anual da Carga do SIN ......................................... 86

Tabela 14 - Alterações da data de entrada em operação ........................................... 87

Tabela 15 - Acréscimos Anuais de Potência Eólica.................................................... 88

Tabela 16 - Perfis de Consumo Adotados ...............................................................90

Tabela 17 - Ponderações anuais para os contratos bilaterais .................................. 104

Tabela 18 - Resultado Financeiro para o Consumidor I (bilhões) ……………….... 107

Tabela 19 - Resultado Financeiro para o Consumidor II (bilhões) .......................... 107 


\section{LISTA DE ABREVIATURAS E SIGLAS}

\begin{tabular}{|c|c|}
\hline ACL & Ambiente de Contratação Livre \\
\hline ACR & Ambiente de Contratação Regulada \\
\hline ANEEL & Agência Nacional de Energia Elétrica \\
\hline BNDES & Banco Nacional de Desenvolvimento Econômico e Social \\
\hline BRR & Base de Remuneração Regulatória \\
\hline CCC & Conta de Consumo de Combustível Fósseis \\
\hline CCEAR & Contrato de Comercialização de Energia no Ambiente Regulado \\
\hline CCEE & Câmara de Comercialização de Energia Elétrica \\
\hline CDE & Conta de Desenvolvimento Energético \\
\hline CEC & Valor Esperado do Custo Econômico de Curto Prazo \\
\hline CEMIG & Companhia Energética de Minas Gerais \\
\hline CEPEL & Centro de Pesquisa de Energia Elétrica \\
\hline CFURH & Compensação Financeira pelo Uso de Recursos Hídricos \\
\hline CMSE & Comitê de Monitoramento do Setor Elétrico \\
\hline CME & Custo Marginal de Expansão \\
\hline CMO & Custo Marginal de Operação \\
\hline CNAE & Conselho Nacional de Águas e Energia \\
\hline CNPE & Conselho Nacional de Política Energética \\
\hline COP & Valor Esperado do custo de Operação \\
\hline CVA & Conta de Compensação de Variação de Valores de Itens da "Parcela \\
\hline A" & \\
\hline CVU & Custo Variável Unitário \\
\hline DNAEE & Departamento Nacional de Águas e Energia Elétrica \\
\hline EPE & Empresa de Pesquisa Energética \\
\hline ESS & Encargo de Serviço do Sistema \\
\hline FCF & Função de Custo Futuro \\
\hline $\mathrm{FCl}$ & Função de Custo Imediato \\
\hline FP & Horário Fora Ponta \\
\hline ICB & Índice de Custo Benefício \\
\hline IGP-M & Índice Geral de Preços de Mercado \\
\hline IPCA & Índice de Preços ao Consumidor Amplo \\
\hline IRT & Índice de Reajuste Tarifário \\
\hline LEE & Leilão de Energia Existente \\
\hline LEN & Leilão de Energia Nova \\
\hline LER & Leilão de Energia de Reserva \\
\hline MAE & Mercado Atacadista de Energia \\
\hline MCSD & Mecanismo de Compensação de Sobras e Déficits \\
\hline MME & Ministério de Minas e Energia \\
\hline MUST & Montante de Uso de Sistema de Transmissão \\
\hline ONS & Operador Nacional do Sistema \\
\hline $\mathrm{P}$ & Horário de Ponta \\
\hline $\mathrm{PCH}$ & Pequena Central Hidrelétrica \\
\hline PDE & Plano Decenal de Expansão de Energia \\
\hline PIE & Produtor Independente de Energia \\
\hline PLD & Preço de Liquidação das Diferenças \\
\hline PMO & Programa Mensal de Operação \\
\hline
\end{tabular}


PROINFA Programa de Incentivo às Fontes Alternativas de Energia Elétrica

P\&D Pesquisa e Desenvolvimento

RB Rede Básica

RE-SEB Projeto de Reestuturação do Setor Elétrico

RGR Reserva Global de Reversão

RTE Recomposição Tarifária Extraordinária

$S \quad$ Período Seco

SIN Sistema Interligado Nacional

TE Tarifa de Energia

TFSEE Taxa de Fiscalização de Energia Elétrica

TUSD Tarifa de Uso do Sistema de Distribuição

TUST Tarifa de Uso do Sistema de Transmissão

U

Período Úmido

UTE Usina Termelétrica

UHE Usina Hidrelétrica

VR Valor de Referência

WACC Weighted Average Cost of Capital 


\section{SUMÁRIO}

1 INTRODUÇÃO

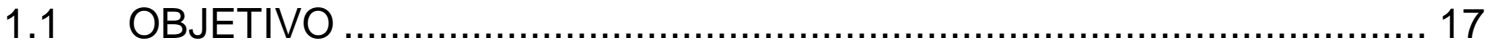

1.2 ESTRUTURA DA DISSERTAÇÃO............................................... 18

2 O AMBIENTE REGULATÓRIO DO SETOR ELÉTRICO BRASILEIRO ........ 20

2.1 HISTÓRICO DO SETOR ELÉTRICO BRASILEIRO …......................... 20

2.2 O MODELO ATUAL DO SETOR ELÉTRICO ..................................... 24

2.3 INSTITUIÇÕES DO SETOR ELÉTRICO E SUAS ATRIBUIÇÕES ......... 27

2.3.1 Conselho Nacional de Pesquisa Energética - CNPE ..................... 28

2.3.2 Ministério de Minas e Energia - MME ………............................ 29

2.3.3 Agência Nacional de Energia Elétrica - ANEEL …......................... 29

2.3.4 Operador Nacional do Sistema Elétrico - ONS ……...................... 29

2.3.5 Empresa de Pesquisa Energética - EPE.................................... 30

2.3.6 Câmara de Comercialização de Energia Elétrica - CCEE............... 30

2.3.7 Comitê de Monitoramento do Setor Elétrico - CMSE ...................... 31

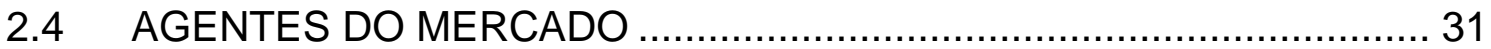

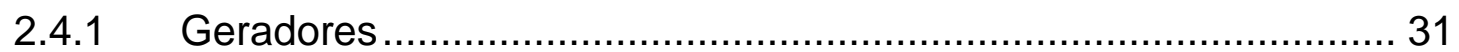

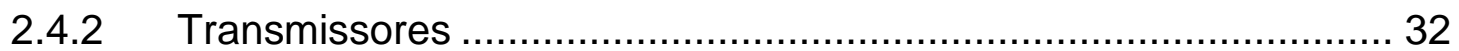

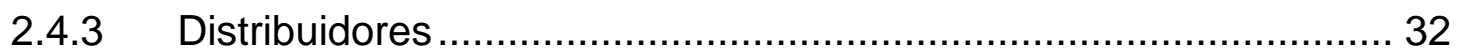

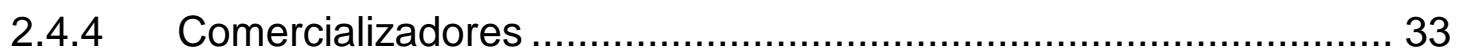

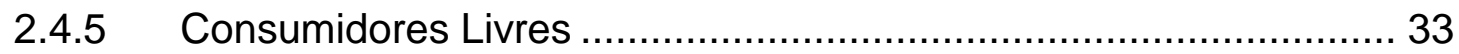

2.4.6 Importadores e Exportadores....................................................... 35

3 SISTEMAS HIDROTÉRMICOS E O MERCADO DE CURTO PRAZO .......... 36

4 COMPRA DE ENERGIA NO ACR …....................................................... 41

4.1 COMPRA DE ENERGIA ATRAVÉS DE LEILÕES REGULADOS ......... 41

4.1.1 Contratos por Disponibilidade ................................................... 42

4.1.2 Contratos por Quantidade de Energia ........................................ 44

4.1.3 Resultados dos Leilões de Energia Nova ................................... 44

4.2 CONTRATOS DO PROINFA ............................................................ 45

4.3 CONTRATOS DE ITAIPU ..................................................... 46

4.4 CONTRATOS DE GERAÇÃO DISTRIBUIDA …............................ 47

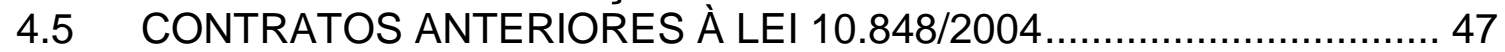

4.6 RESTRIÇÕES AO VOLUME DE CONTRATAÇÃO E AO REPASSE

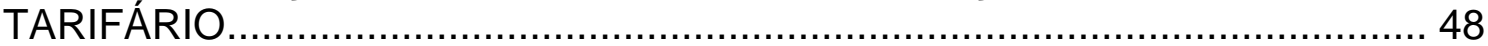

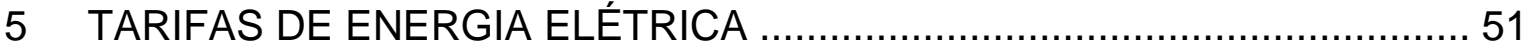

5.1 COMPOSIÇÃO DA RECEITA REQUERIDA.................................... 52

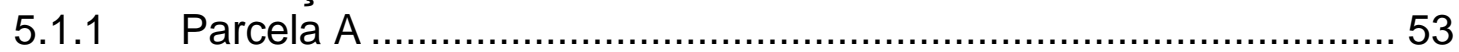

5.1.1.1 Compra de Energia Elétrica ............................................... 54

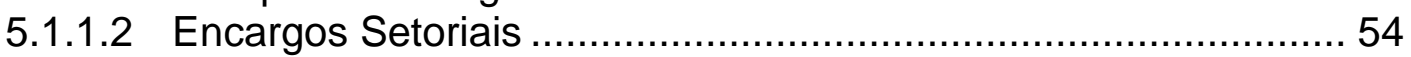

5.1.1.3 Custos com Transporte de Energia ........................................ 56

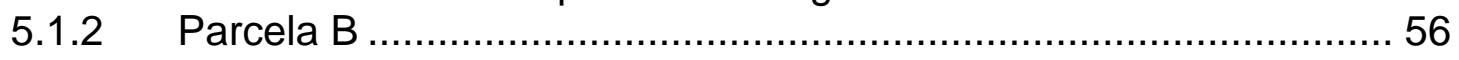

5.1.3 Componentes Financeiros ....................................................... 58

5.2 MECANISMOS DE ALTERAÇÃO DAS TARIFAS............................ 58

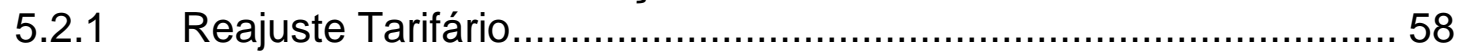

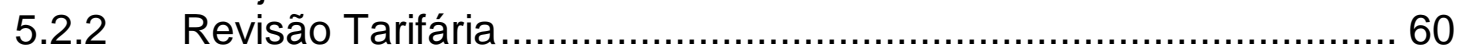

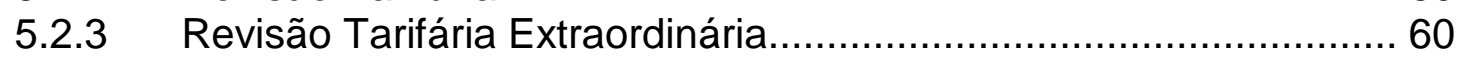


5.2.4 Fator X

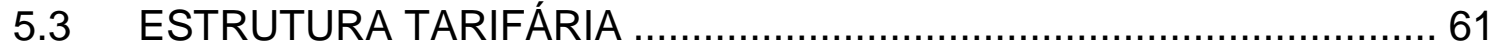

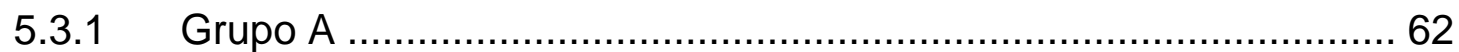

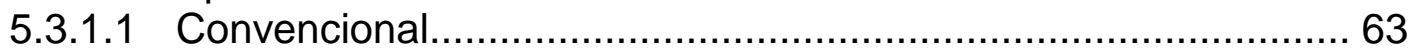

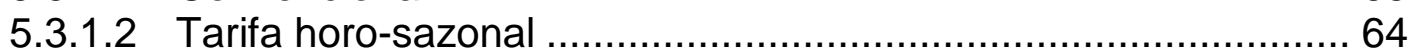

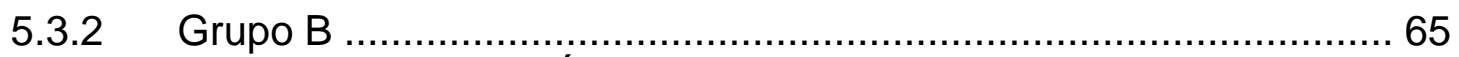

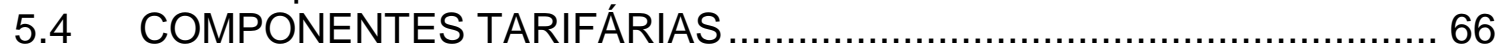

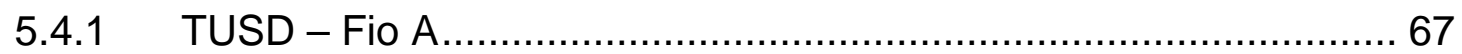

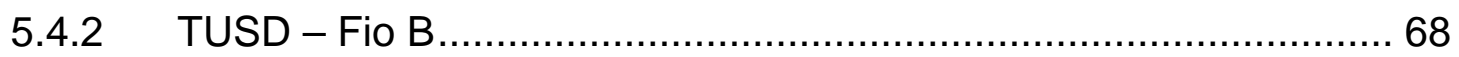

5.4.3 TUSD - Encargos do Serviço de Distribuição ............................... 68

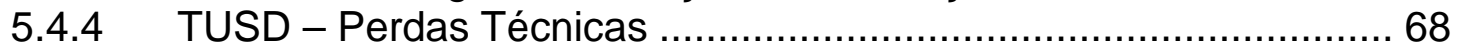

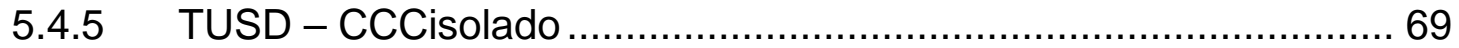

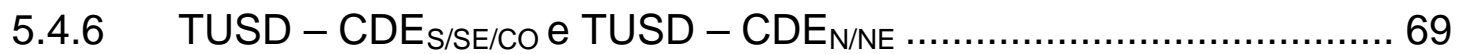

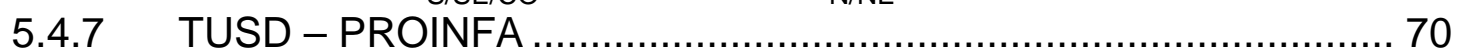

5.4.8 TUSD - Perdas Não Técnicas...................................................... 70

5.4.9 TE - Tarifa de Energia …...................................................... 72

6 EXPECTATIVA DE EVOLUÇÃO DA TARIFA DE ENERGIA ……............... 74

6.1 METODOLOGIA PARA A PREVISÃO DA TARIFA DE ENERGIA ........ 75

6.1.1 A base de comparação com o mercado livre ................................ 75

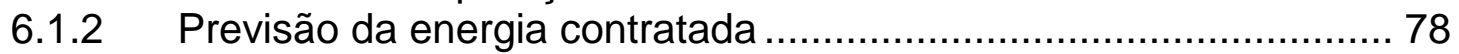

6.1.3 Previsão do preço de recontratação ............................................ 79

6.1.4 O preço dos Contratos ............................................................. 81

6.1.5 O preço dos Contratos por Disponibilidade .................................. 81

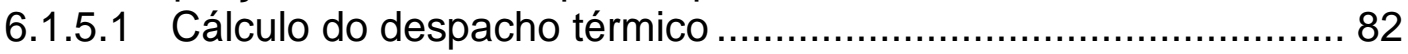

6.1.5.2 Identificação dos montantes despachados acima da inflexibilidade 83

6.1.5.3 Identificação do Custo Econômico de Curto Prazo ...................... 83

6.1.5.4 Conversão da Receita em preço ............................................ 83

6.1.5.5 Correlação Custo do Contrato por Disponibilidade com o PLD... 84

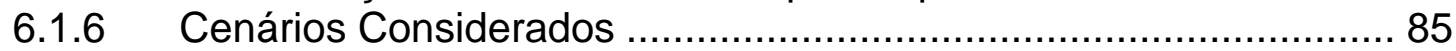

6.2 RESULTADOS DA TARIFA DE ENERGIA …................................ 90

7 EXPECTATIVA DOS PREÇOS DOS CONTRATOS BILATERAIS DE

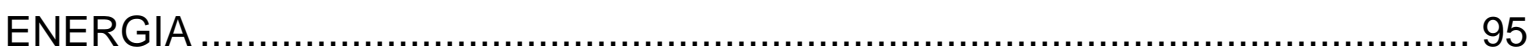

7.1 MODELAGEM DOS CONTRATOS BILATERAIS ……........................ 96

7.1.1 Contratos de Curto Prazo ………………............................... 96

7.1.2 Contratos de Médio e Longo Prazo ………................................ 99

7.2 CARACTERÍSTICAS DO MODELO DE SIMULAÇÃO........................... 102

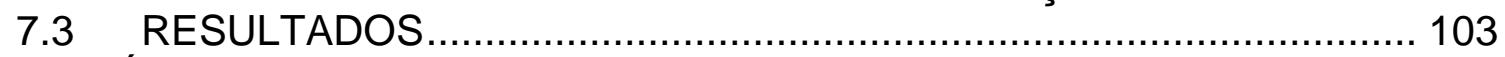

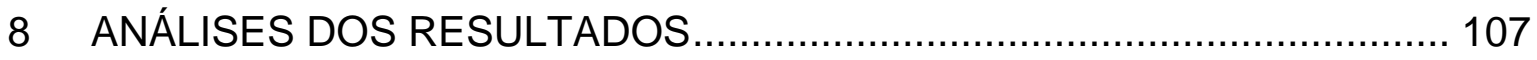

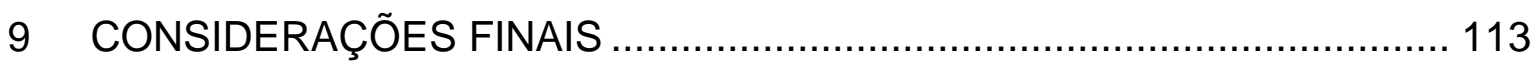

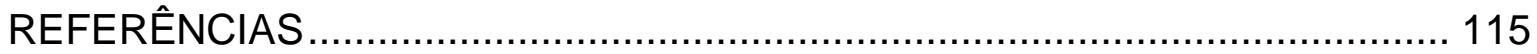

ANEXO 1 - DADOS UTILIZADOS NA PROJEÇÃO DA TARIFA DE ENERGIA 117

ANEXO 2 - CARACTERÍSTICAS DAS USINAS TÉRMICAS …........................ 122

ANEXO 3 - RESULTADOS DOS CONTRATOS BILATERAIS.......................... 125 


\section{INTRODUÇÃO}

O Marco Regulatório brasileiro sofreu importantes alterações no ano de 2004, em função da ocorrência de um severo racionamento de energia em 2001/2002, motivado essencialmente pela atração insuficiente de novos investimentos para a expansão da oferta.

Nessa perspectiva, foram introduzidos novos dispositivos no modelo vigente à época, com destaque da subdivisão do ambiente de contratação de energia em duas vertentes distintas, a saber: Ambiente de Contratação Regulada (ACR) e o Ambiente de Contratação Livre (ACL).

No ACR, atuam as Distribuidoras de energia que atendem o mercado cativo, as quais passaram a ter a obrigação de contratar sua necessidade futura de energia com antecedência de 5 anos, sempre através de Leilão promovido pelo Governo (Leilão A-5), com forte penalização na hipótese de exposição ao mercado de curto prazo, aferida em um período de 1 ano. Os preços obtidos nos Leilões de compra de energia "nova", via contratos de longo prazo, são repassados às tarifas e compõem parcela importante da tarifa de fornecimento ao mercado cativo.

Já no ACL, atuam os comercializadores, geradores e consumidores que atendem a certas condições físicas impostas pela legislação, denominados consumidores livres. Nesse ambiente, os agentes realizam contratos bilaterais, cujos preços variam conforme a conjuntura e a estratégia de contratação.

Assim, como o aparato legal e regulatório não determina em qual ambiente de contratação o consumidor deve participar, cria-se a necessidade de uma análise quantitativa sobre as opções disponíveis e os riscos inerentes a essas. 


\subsection{OBJETIVO}

O presente trabalho tem como objetivo avaliar as opções de contratação de um grande consumidor de energia no Ambiente de Contratação Livre, tendo como balizador o preço da energia praticada no Ambiente de Contratação Regulado.

Para definir qual será o provável preço da energia no ACR, faz-se necessária a avaliação do portfólio de contratos de uma distribuidora, assim como realizar suposições quanto aos montantes e preços da recontratação da energia proveniente de empreendimentos existentes (energia velha), que deverá ocorrer a partir de 2013. Nesta fase também será definido o provável custo dos contratos provenientes de novos empreendimentos de fonte térmica, que passaram a compor de forma representativa o mix de compra das concessionárias de distribuição a partir de 2009.

Além do custo de aquisição da energia por parte das distribuidoras, deve-se avaliar os outros custos que compõem a Tarifa de Energia (TE) regulada e a forma de tarifação. Para os grandes consumidores conectados em níveis de tensão superiores a $69 \mathrm{kV}$, é aplicada a tarifação horo-sazonal azul, que impacta a tarifa final de energia de acordo com a curva de carga do consumidor.

Os preços praticados no ACL variam de maneira significativa com a estratégia de contratação do consumidor. Assim, para equacionar esse desafio, propõe-se a modelagem da formação dos preços dos contratos tendo como base o Custo Marginal de Expansão e o Custo Marginal de Operação, obtido através de simulações do modelo Newave.

Ao término deste trabalho, procura-se avançar conclusões com o auxílio das análises e estudos supracitados, de modo a permitir tecer considerações sobre a estratégia de contratação de um grande consumidor de energia. 


\subsection{ESTRUTURA DA DISSERTAÇÃO}

No capítulo 2 é feito um breve descritivo do ambiente regulatório no qual encontra-se inserido o Setor Elétrico Brasileiro (SEB). Nesse contexto, inicialmente apresenta-se uma retrospectiva histórica sucinta, focando a evolução do SEB desde seu princípio até o modelo vigente. Nesse momento, também são descritas as principais atribuições das instituições do setor, assim como os papéis que os agentes do mercado desempenham.

No capítulo 3 apresenta-se a formação do preço de curto-prazo no SEB, assim como o Mercado de Curto-Prazo. Também serão abordados os impactos causados pela formação de preços na contratação de um consumidor livre.

Já no capítulo 4, tomando como aspecto focal a compra de energia no Ambiente de Contratação Regulado, descreve-se os tipos de contratos utilizados pelo agente distribuidor para lastrear a totalidade da sua carga, assim como os riscos incorridos por esse agente na compra de energia.

No capítulo seguinte, enfoca-se as Tarifas de Energia Elétrica. Para isso, é descrita a composição da Receita Requerida de um agente de distribuição, os mecanismos de alteração das tarifas, a estrutura tarifária vigente e as componentes tarifárias.

Em seguida, a partir de uma análise prospectiva, evidencia-se a expectativa de evolução da Tarifa de Energia no ACR. Nesse contexto, é descrita a metodologia utilizada e são apresentados os resultados obtidos.

No capítulo 7 é apresentada a metodologia utilizada para previsão do preço dos contratos firmados no $\mathrm{ACL}$, para diferentes estratégias de contratação do consumidor. Também é descrito o simulador utilizado e apresentados os resultados obtidos. 
Já no capítulo 8, realiza-se a comparação das estratégias de contratação emuladas e analisam-se os resultados obtidos, apontando os possíveis riscos inerentes à tomada de decisão.

Por fim, no capítulo 9 apresenta-se as considerações finais e as recomendações para trabalhos futuros. 


\section{O AMBIENTE REGULATÓRIO DO SETOR ELÉTRICO BRASILEIRO}

\subsection{HISTÓRICO DO SETOR ELÉTRICO BRASILEIRO}

Durante o século XIX o café se tornou o principal produto de geração de renda no Brasil. Sua valorização, ocorrida em meados desse século, associada às medidas protecionistas, à extinção do tráfico negreiro, ao aumento da imigração estrangeira, bem como aos superávits na balança comercial, produziram as precondições para os avanços rumo à modernização e urbanização do país.

O crescimento das cidades levava a uma expansão da indústria de construção civil e da oferta de infra-estrutura urbana. É nesse movimento que se inserem as primeiras iniciativas de uso da energia elétrica no país, à mesma época que essa inovação tecnológica era introduzida na Europa e nos Estados Unidos. (BNDES, 2002).

O marco inicial do setor elétrico brasileiro é 1879 , quando foi inaugurado, no Rio de Janeiro, o serviço permanente de iluminação elétrica interna na estação central da ferrovia Dom Pedro II.

Até a promulgação do Código de Águas (1934), o setor se desenvolveu através do aporte de capital privado nacional e estrangeiro, que visava atender principalmente à crescente demanda por iluminação pública.

Entre outros fatores, a crise de 1929 culminou na desvalorização do café e deixou claro que havia a necessidade de redefinir as políticas econômicas que objetivassem diversificar a estrutura produtiva do país. Isso gerou uma crescente 
onda de intervenção do Estado, que foi formalizada com a edição do Código de Águas (Decreto 24.643, de 10 de julho de 1934).

O Código definiu a política tarifária do serviço pelo custo e transferiu para a União a competência de legislar e outorgar concessões de serviços públicos de energia elétrica, antes regidos apenas por contratos assinados com os estados, os municípios e o Distrito Federal. Dado o poder de mercado que as empresas estrangeiras detinham numa atividade que assumia crescente importância para o desenvolvimento econômico, também foi estabelecido que as autorizações ou concessões somente fossem conferidas a brasileiros ou a empresas organizadas no Brasil.

As medidas adotadas provocaram incertezas regulatórias que desencorajaram investimentos dos grandes grupos estrangeiros instalados no país, causando limitações de oferta e degradação do atendimento.

De modo a viabilizar a implantação da indústria pesada, da indústria de bens intermediários e da indústria de bens de capital, o Estado passou a ser o principal empreendedor do setor elétrico, tirando o foco de sua função clássica, que é ser Poder Concedente, Regulador, Mediador, Fiscalizador e Formulador de Políticas. O fato marcante dessa mudança de política é a criação da Companhia Hidroelétrica do São Francisco (CHESF), em 1945.

A década de 60 foi marcada pelo aumento significativo da capacidade instalada e da malha de transmissão de energia elétrica e pela criação do Ministério de Minas e Energia - MME, do Departamento Nacional de Águas e Energia - DNAE, e da Eletrobrás.

No período compreendido entre as décadas de 70 e 80 , o setor elétrico atingiu seu ápice, representado pelo "milagre econômico", e experimentou também o início de seu declínio, passando incólume pela crise do petróleo em 1973. Nesse período foi consolidada a estrutura básica do sistema Eletrobrás, composta pela Eletronorte, Eletrosul, Furnas e Chesf e praticamente todos os segmentos do Setor Elétrico eram de propriedade pública, federal ou estadual. 
No inicio dos anos 80 o Governo optou por uma redução artificial das tarifas em termos reais ${ }^{1}$, com o objetivo de frear a inflação, tendo como conseqüência uma grave crise econômico-financeira das empresas do setor. Nesse período também ocorreu a corrida de algumas empresas, já endividadas pelas obras da década anterior, aos suppliers credits, complicando ainda mais sua saúde financeira. Houve também o RENCOR e o frustrado Projeto de Revisão do Setor Elétrico REVISE. Essa década foi marcada pelos blecautes e a inadimplência setorial, 0 famoso "calote".

Com o esgotamento da capacidade de investimento do Estado, em meados de 1990, deu-se o processo de reforma institucional do Setor Elétrico, que teve como objetivo assegurar a expansão da oferta e a atratividade econômica do setor, garantindo um suprimento confiável ao menor custo.

A reestruturação no Brasil ocorreu inicialmente através de uma série de mudanças na legislação, com o objetivo de se transferir do Estado para a iniciativa privada a responsabilidade pelos investimentos no sistema. Nesse momento o Estado passaria a desenvolver apenas os papéis de fiscalizador e regulador.

As atividades de transmissão e distribuição continuaram enquadradas como monopólios naturais, enquanto as atividades de geração e comercialização passam a ser enxergadas como atividades propícias à concorrência. Executou-se um processo de segmentação do Setor Elétrico e também de privatizações de grande parte das empresas de distribuição, algumas empresas de geração e mais recentemente empresas de transmissão.

No bojo do processo de reforma do setor, houve também a criação do consumidor livre e do produtor independente de energia, que passaram a assumir os riscos da comercialização de energia, introduzindo assim um caráter mais competitivo ao setor.

\footnotetext{
${ }^{1}$ Com a inflação muito alta, as correções tarifárias para preservar o valor da receita tinham que ser mensais, mas o governo decidiu manter as tarifas congeladas.
} 
Entre agosto de 1996 e novembro de 1998, foi executado um extenso projeto para a Reestruturação do Setor Elétrico Brasileiro, coordenado pelo Ministério das Minas e Energia (MME) contando com a participação de consultores da Coopers \& Lybrand, denominado RE-SEB (Eletrobrás, 1998). Um grande número de trabalhos foi produzido irradiando uma série de sugestões práticas para a reestruturação desse setor no Brasil, inclusive a criação de um mercado atacadista de energia, substituindo o sistema de preços regulamentados de geração.

A adoção do modelo proposto passou pela criação dos três pilares institucionais: o Operador Nacional do Sistema (ONS), o Mercado Atacadista de Energia (MAE) e a Agência Nacional de Energia Elétrica (ANEEL).

O modelo proposto para o setor elétrico brasileiro seguiu os padrões dos modelos internacionais com adaptações às características locais, onde é possível destacar a predominância de geração hidroelétrica com a interdependência espacial e temporal das usinas.

Neste novo modelo, para que pudesse ocorrer a competição, fazia-se necessária à introdução de um mercado livre para elaboração de Contratos de Compra e Venda de Energia entre geradores, comercializadores e distribuidores. Os preços e os montantes de energia a serem contratados passam a ser negociados bilateralmente entre os agentes. A comercialização passou a representar uma atividade muito importante para as empresas.

Dessa forma, os agentes passam a negociar a maior parcela de sua demanda através de contratos bilaterais com o objetivo de proteger as partes contra a exposição ao risco representado pela potencial volatilidade do preço spot de energia.

Com o racionamento ocorrido entre 2001 e 2002, o modelo ora em implantação demonstrou suas fragilidades e o governo federal, através da Câmara de Gestão da Crise de Energia, mais tarde Comitê de Revitalização do Modelo do Setor 
Elétrico, identificou pontos de aperfeiçoamento do modelo, que foram de fundamental importância para as mudanças verificadas nos anos seguintes.

\subsection{O MODELO ATUAL DO SETOR ELÉTRICO}

No início do governo do Presidente Luiz Inácio Lula da Silva, mudanças no modelo do Setor Elétrico foram estudadas por um grupo de trabalho ligado ao Ministério de Minas e Energia. Em julho de 2003, foram aprovadas as diretrizes básicas para implementação de mudanças no modelo institucional do setor por intermédio da Resolução № 5 do Conselho Nacional de Política Energética (CNPE).

O documento "Proposta de Modelo Institucional do Setor Elétrico", de julho de 2003, elaborado pelo Ministério de Minas e Energia, apresenta os objetivos das mudanças: "assegurar o atendimento da demanda de energia elétrica de forma confiável, com racionalidade e sustentabilidade econômica" (MME, 2003). O planejamento do Setor Elétrico voltaria a ser centralizado e elaborado por uma nova entidade, a Fundação de Estudo e Planejamento Energético. A expansão se daria a partir de licitações, onde cada usina teria assegurado contratos de venda de energia.

O mercado seria dividido em dois ambientes de comercialização. As distribuidoras somente poderiam comprar energia no Ambiente de Contratação Administrada por meio de leilões públicos e atender consumidores apenas com tarifas reguladas. No Ambiente de Livre Contratação, os produtores independentes e comercializadores venderiam energia aos consumidores livres. $\mathrm{O}$ limite de tensão de fornecimento para o consumidor ser elegível para o mercado livre foi eliminado e a demanda contratada deveria ser igual ou superior a três mil quilowatts. Os consumidores livres poderiam retornar à condição de cativo, desde que notificassem a distribuidora com antecedência mínima de cinco anos, sendo 
prerrogativa da Distribuidora atender a solicitação em menor tempo. As distribuidoras e consumidores livres seriam obrigados a contratar cem por cento de sua carga, sendo que no caso das concessionárias de distribuição, com antecedência de cinco anos. Diferenças entre contratos e produção pelo lado dos geradores e entre contratos e carga verificada seriam contabilizados e liquidados como vinha acontecendo.

Essa proposta foi discutida durante vários meses com "representantes dos diversos níveis de governo, de empresas, dos consumidores e dos sindicatos" (MME, 2003) absorvendo algumas mudanças. Em 10 de dezembro de 2003, o governo federal baixou a Medida Provisória nำ 144, que foi convertida na Lei no 10.848, em 15 de março de 2004, estabelecendo mudanças no Setor. A referida lei foi regulamentada pelo Decreto no 5.163, de 30 de junho de 2004.

Para viabilizar, entre outros, os estudos de planejamento do Setor Elétrico, foi instituída a Empresa de Pesquisa Energética (EPE), a partir da Medida Provisória n`145, convertida na Lei n¹0.847, em 15 de março de 2004.

A relação comercial entre os agentes do setor elétrico para a compra e venda de energia ocorre através de contratos. A Lei no 10.848/2004 estabeleceu a criação de dois ambientes de contratação para os agentes. Um destinado às empresas que atendem aos consumidores finais de maneira regulada - Ambiente de Contratação Regulada (ACR) e outro, onde alguns agentes podem exercer a livre negociação - Ambiente de Contratação Livre (ACL).

No ACR, a comercialização de energia elétrica acontece por meio de leilões. Todos os agentes vendedores (geradores, importadores e comercializadores) podem vender a todos os distribuidores, segundo procedimentos específicos (Decreto no 5.163, de 30 de julho de 2004). Quando um gerador vende sua energia no ACR, assinará contratos com cada uma das distribuidoras que apresentaram necessidades de energia.

O ACL é o ambiente onde comercializadores, geradores e consumidores livres realizam negócios entre si. As regras são praticamente as mesmas das 
estabelecidas antes da Lei $n^{\circ} 10.848$, de 2004. Fora $m$ acrescentadas algumas restrições que não existiam anteriormente quanto ao nível de contratação e penalidades, e também passou a ser obrigatório a adesão à CCEE para todo o consumidor livre.

Através da ilustração abaixo, visualizam-se o Ambiente de Contratação Regulada (ACR) e o Ambiente de Contratação Livre (ACL), bem como os agentes que participam destes ambientes e suas relações.

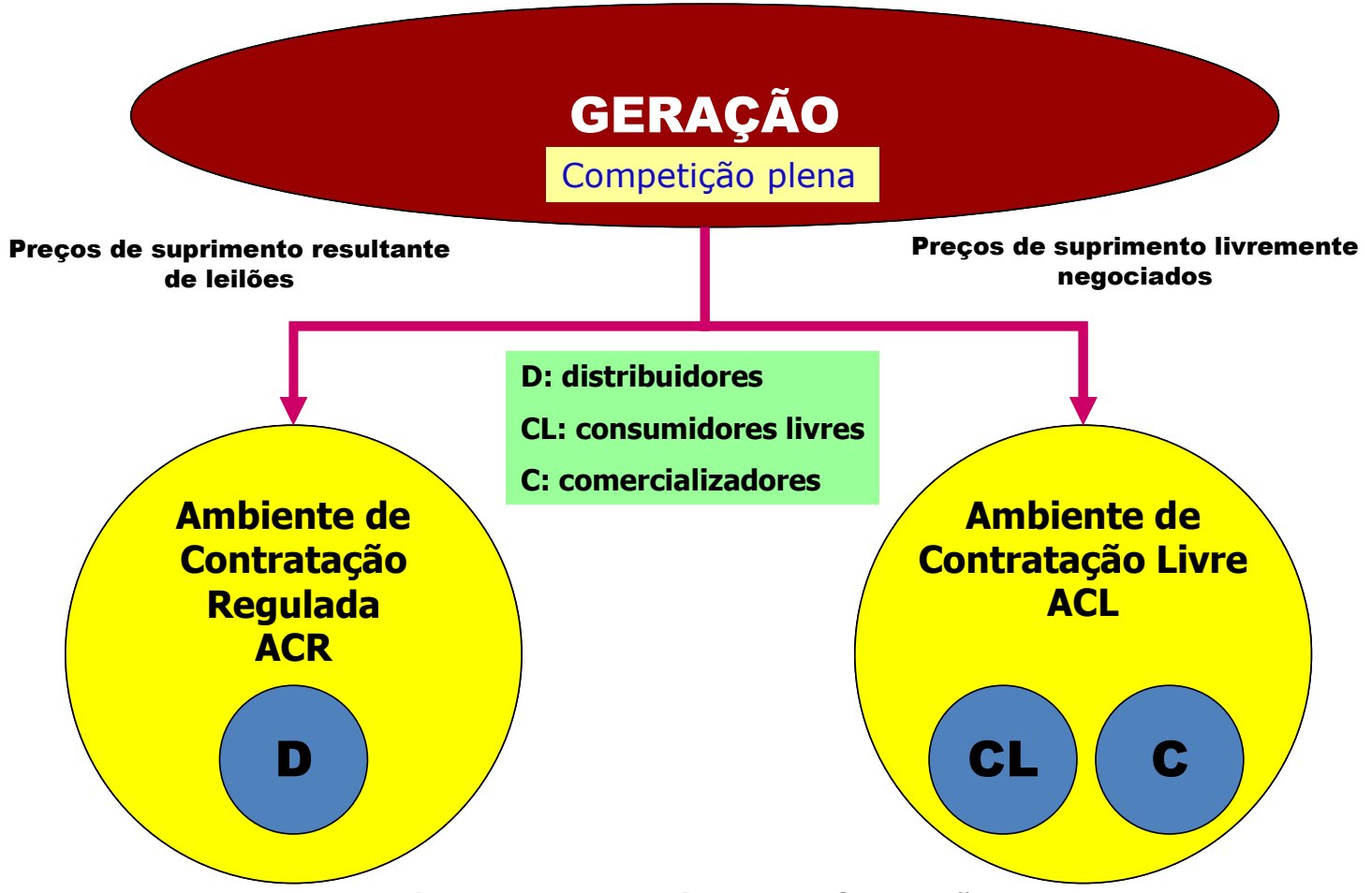

Figura 1 - Os Ambientes de Contração

O modelo vigente dá ênfase à expansão do sistema de geração e à garantia do suprimento através do binômio planejamento/contratação. No que se refere ao planejamento, obriga os agentes de consumo (distribuidores, vendedores, autoprodutores e consumidores livres) a preverem suas necessidades para um horizonte relativamente longo, sendo que no caso das distribuidoras o horizonte de previsão de carga para efeito de contratação de energia foi estabelecido de forma compulsória e é de cinco anos. Estas previsões servem para sinalizar a 
necessidade de construção de usinas, em tempo hábil para que estes empreendimentos possam ser licitados e construídos.

Os agentes de geração vencedores destes processos de licitação ganham, além do direito de explorar comercialmente o empreendimento que construirão, contratos de longo prazo (mínimo de quinze anos) de venda de energia, celebrados com os agentes de distribuição.

\subsection{INSTITUIÇÕES DO SETOR ELÉTRICO E SUAS ATRIBUIÇÕES}

A estabilidade do marco regulatório é essencial onde existem falhas de mercado, monopólios naturais e os investimentos exijam um longo prazo de maturação. Para a atração de investimentos e segurança do fornecimento, é fundamental que exista uma regulação com autonomia e independência, e isso passa por uma definição clara das atribuições dos diversos agentes institucionais (MME, 2003). A Figura 2 ilustra o diagrama das instituições do setor elétrico. 


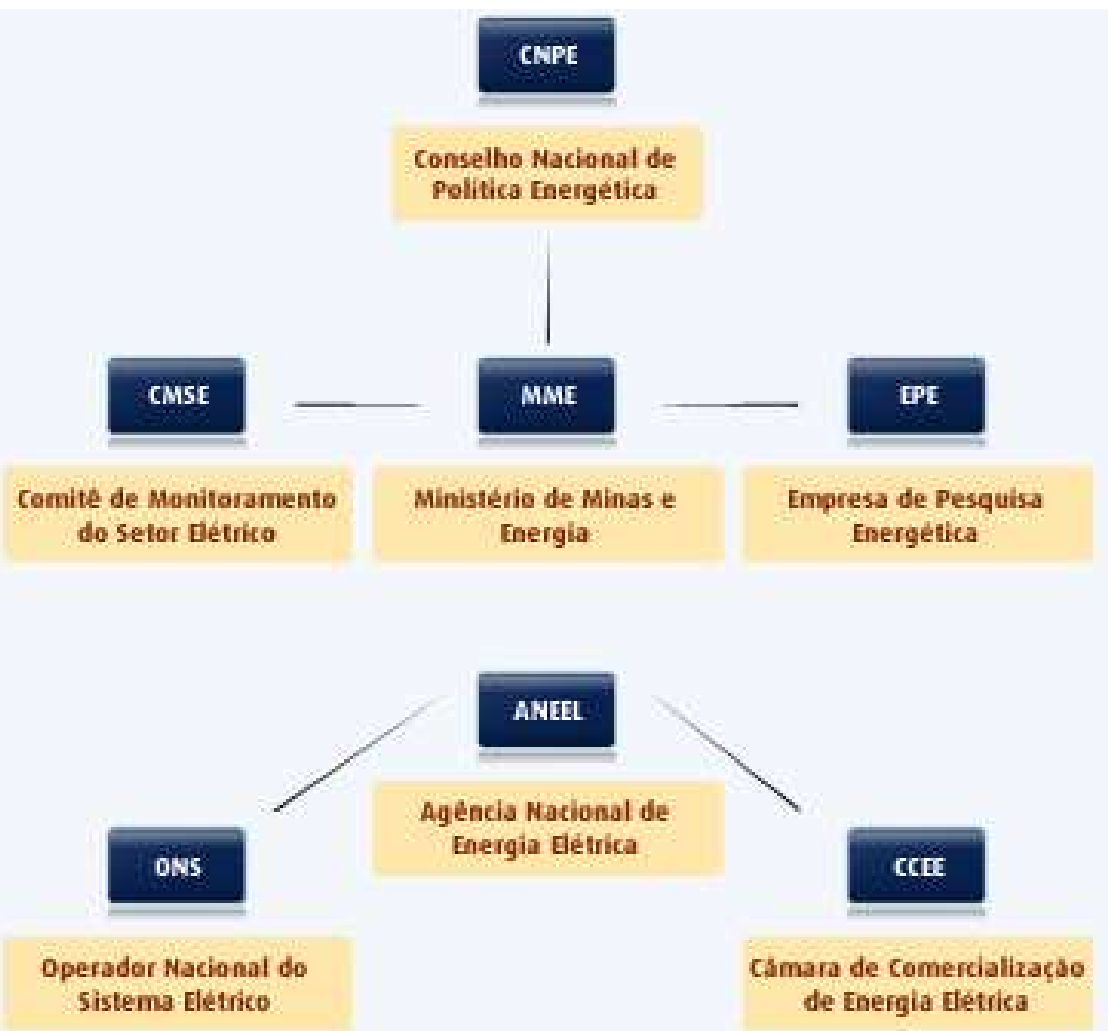

Figura 2 - Estrutura Organizacional Novo Modelo

\subsubsection{Conselho Nacional de Pesquisa Energética - CNPE}

O CNPE é um órgão interministerial de assessoramento à Presidência da República, tendo como principais atribuições formular políticas e diretrizes de energia e assegurar o suprimento de insumos energéticos às áreas mais remotas ou de difícil acesso país.

É também responsável por revisar periodicamente as matrizes energéticas aplicadas às diversas regiões do país, estabelecer diretrizes para programas específicos, como os de uso do gás natural, do álcool, de outras biomassas, do carvão e da energia termonuclear, além de estabelecer diretrizes para a importação e exportação de petróleo e gás natural. 


\subsubsection{Ministério de Minas e Energia - MME}

O MME é o órgão do Governo Federal responsável pela condução das políticas energéticas do país. Suas principais obrigações incluem a formulação e implementação de políticas para o setor energético, de acordo com as diretrizes definidas pelo CNPE. O MME é responsável por estabelecer o planejamento do setor energético nacional, monitorar a segurança do suprimento do Setor Elétrico Brasileiro e definir ações preventivas para restauração da segurança de suprimento no caso de desequilíbrios conjunturais entre oferta e demanda de energia.

\subsubsection{Agência Nacional de Energia Elétrica - ANEEL}

A ANEEL foi instituída pela Lei ํㅜ 9.427/96 e constituída pelo Decreto ํㅜ 2.335/97, com as atribuições de regular e fiscalizar a produção, transmissão, distribuição e comercialização de energia elétrica, zelando pela qualidade dos serviços prestados, pela universalização do atendimento e pelo estabelecimento das tarifas para os consumidores finais, sempre preservando a viabilidade econômica e financeira dos Agentes e da indústria.

As alterações promovidas em 2004 pelo novo modelo do setor estabeleceram como responsabilidade da ANEEL, direta ou indiretamente, a promoção de licitações na modalidade de leilão, para a contratação de energia elétrica pelos Agentes de Distribuição do Sistema Interligado Nacional (SIN).

\subsubsection{Operador Nacional do Sistema Elétrico - ONS}

O ONS foi criado pela Lei ำ 9.648 , de 27 de maio de 1998, e regulamentado pelo Decreto $\mathrm{n}^{\circ} \mathbf{2 . 6 5 5}$, de 2 de julho de 1998, com as alterações do Decreto ํㅜ 5.081 , de 14 de maio de 2004, para operar, supervisionar e controlar a geração de energia elétrica no SIN, bem como administrar a rede básica de transmissão de energia elétrica no Brasil. 
Tem como objetivo principal, atender os requisitos de carga, otimizar custos e garantir a confiabilidade do sistema, definindo ainda, as condições de acesso à malha de transmissão em alta-tensão do país.

\subsubsection{Empresa de Pesquisa Energética - EPE}

Instituída pela Lei ํㅜ 10.847/04 e criada pelo Decreto № 5.184/04, a EPE é uma empresa vinculada ao MME, cuja finalidade é prestar serviços na área de estudos e pesquisas destinadas a subsidiar o planejamento do setor energético.

Suas principais atribuições incluem a realização de estudos e projeções da matriz energética brasileira, execução de estudos que propiciem o planejamento integrado de recursos energéticos, o planejamento de expansão da geração e da transmissão de energia elétrica de curto, médio e longo prazos, realização de análises de viabilidade técnico-econômica e sócio-ambiental de usinas, bem como a obtenção da licença ambiental prévia para aproveitamentos hidrelétricos e de transmissão de energia elétrica.

\subsubsection{Câmara de Comercialização de Energia Elétrica - CCEE}

A CCEE, instituída pela Lei $n^{\circ}$ 10.848/04 e criada pelo Decreto ํo 5.177/04, absorveu as funções do MAE e suas estruturas organizacionais e operacionais. Entre suas principais obrigações estão: a apuração do Preço de Liquidação de Diferenças (PLD), utilizado para valorar as transações realizadas no mercado de curto prazo; a realização da contabilização dos montantes de energia elétrica comercializados; a liquidação financeira dos valores decorrentes das operações de compra e venda de energia elétrica realizadas no mercado de curto prazo e a realização de leilões de compra e venda de energia no $A C R$, por delegação da ANEEL. 


\subsubsection{Comitê de Monitoramento do Setor Elétrico - CMSE}

O CMSE é um órgão criado no âmbito do MME, sob sua coordenação direta, com a função de acompanhar e avaliar a continuidade e a segurança do suprimento elétrico em todo o território nacional.

Suas principais atribuições incluem: acompanhar o desenvolvimento das atividades de geração, transmissão, distribuição, comercialização, importação e exportação de energia elétrica; avaliar as condições de abastecimento e de atendimento; realizar periodicamente a análise integrada de segurança de abastecimento e de atendimento; identificar dificuldades e obstáculos que afetem a regularidade e a segurança de abastecimento e expansão do setor e elaborar propostas para ajustes e ações preventivas que possam restaurar a segurança no abastecimento e no atendimento elétrico

\subsection{AGENTES DO MERCADO}

A seguir são descritos os papéis que os agentes de mercado desempenham.

\subsubsection{Geradores}

Os agentes geradores atuam no mercado competitivo e podem negociar energia tanto no ACR como no ACL. Esses agentes também possuem livre acesso aos sistemas de transmissão e distribuição de energia elétrica podendo ser classificados em:

- Concessionários de Serviço Público de Geração: Agente titular de Serviço Público Federal delegado pelo Poder Concedente mediante licitação, na modalidade de concorrência, à pessoa jurídica ou consórcio de Empresas 
para exploração e prestação de serviços públicos de energia elétrica, nos termos da Lei 8.987, de 13 de fevereiro de 1995.

- Produtores Independentes de Energia Elétrica: são Agentes individuais ou reunidos em consórcio que recebem concessão, permissão ou autorização do Poder Concedente para produzir energia elétrica destinada à comercialização por sua conta e risco.

- Auto-Produtores: são Agentes com concessão, permissão ou autorização para produzir energia elétrica destinada a seu uso exclusivo, podendo comercializar eventual excedente de energia, desde que autorizado pela ANEEL.

\subsubsection{Transmissores}

A transmissão de energia é um monopólio natural e fortemente regulamentado. A outorga de concessão de Transmissão é precedida por licitação ou autorização, sendo a primeira predominante. O Agente de Transmissão tem como obrigação disponibilizar as suas instalações de maneira a assegurar a otimização dos recursos eletroenergéticos, sendo responsável pela operação e manutenção de seus ativos. O ONS é o órgão responsável por supervisionar e coordenar suas ações de acordo com regras operativas, aprovadas pela ANEEL.

\subsubsection{Distribuidores}

Assim como a atividade de transmissão, a distribuição de energia elétrica é regulada técnica e economicamente. Os agentes de distribuição prestam o serviço mediante concessão ou permissão em regiões geográficas específicas, disponibilizando suas redes a todos os acessantes localizados dentro da área de concessão. São responsáveis pela operação, manutenção e expansão dessas redes.

A Lei $n^{0}$ 10.848, de 2004, restringiu a atuação das distribuidoras ao ACR. Em função das novas regras, as distribuidoras são obrigadas a realizar previsões de 
seu mercado com antecedência e firmar contratos de longo prazo através dos leilões realizados pela CCEE.

\subsubsection{Comercializadores}

Os agentes comercializadores atuam no segmento de mercado onde há competição e podem estabelecer-se após autorização da ANEEL.

Sua principal função está relacionada com a compra e venda de energia no ACL e também é usual fornecer assessoria quanto ao gerenciamento de contratos de energia e de uso dos sistemas de distribuição ou transmissão.

No ACR, a atuação dos comercializadores é restrita aos leilões de ajuste, onde podem participar como vendedores por meio de contratos com duração máxima de dois anos.

\subsubsection{Consumidores Livres}

O Decreto $n^{\circ} 5.163$, de 2004, alterado pelo Decreto $n^{\circ} 5.249$, de 12 de agosto de 2004, define o consumidor livre como aquele que exerceu a opção pela livre contratação e o potencialmente livre como aquele que, mesmo podendo escolher seu fornecedor de energia, opta por adquirir energia da concessionária de distribuição a qual está conectado.

As prerrogativas para se enquadrar como consumidor livre são resumidas na Tabela 1. 
Tabela 1 - Critérios vigentes para se tornar Consumidor Livre. (CCEE, 2008)

\begin{tabular}{|ccc|}
$\begin{array}{c}\text { Demanda Mínima } \\
\text { Contratada }\end{array}$ & $\begin{array}{c}\text { Tensão de } \\
\text { Fornecimento }\end{array}$ & $\begin{array}{c}\text { Data de Ligação } \\
\text { do Consumidor }\end{array}$ \\
\hline $3 \mathrm{MW}$ & Qualquer tensão & Após $08 / 07 / 1995$ \\
$3 \mathrm{MW}$ & $69 \mathrm{kV}$ & Antes de $08 / 07 / 1995$ \\
\hline
\end{tabular}

A partir de 1998, conforme regulamenta a Lei oㅜ 9.427, de 26 de dezembro de 1996, os consumidores com demanda mínima de $500 \mathrm{~kW}$, atendidos em qualquer tensão de fornecimento, têm também o direito de adquirir energia de qualquer fornecedor, desde que a energia adquirida seja oriunda de Pequenas Centrais Hidrelétricas (PCHs) ou de fontes alternativas (eólica, biomassa ou solar). Esses consumidores são usualmente denominados Consumidores Especiais.

Conforme disposto no Decreto oㅜ 5.163/2004, os consumidores livres e especiais devem garantir o atendimento a $100 \%$ de seu consumo verificado, através de geração própria ou de contratos bilaterais celebrados no ACL.

Desde a Lei $\mathrm{n}^{\circ}$ 10.848, de 2004, é permitido ao cons umidor livre voltar a ser suprido em condições reguladas pela concessionária local, assumindo a condição de consumidor potencialmente livre. Para isto, o consumidor terá de avisar à distribuidora com cinco anos de antecedência. A concessionária local pode reduzir este prazo, a seu critério. 


\subsubsection{Importadores e Exportadores}

Os importadores e exportadores de energia são os Agentes do setor que detêm autorização do Poder Concedente para realizar importação e exportação de energia elétrica para abastecimento do mercado nacional e de países vizinhos.

É obrigatória a participação na CCEE dos autorizados para importação ou exportação de energia elétrica com intercâmbio igual ou superior a $50 \mathrm{MW}$. 


\section{SISTEMAS HIDROTÉRMICOS E O MERCADO DE CURTO PRAZO}

Na maioria dos países que passaram pelo processo de reestruturação, o preço de curto-prazo, ou preço "spot" da energia elétrica é obtido através do equilíbrio entre oferta e demanda, em geral a partir de um processo de leilão.

Já no Brasil, o preço de curto-prazo é baseado no custo marginal de operação, que é obtido através da utilização de modelos computacionais de planejamento da operação, que utilizam processos de otimização.

O processo de otimização consiste na decisão de quanto turbinar de água dos reservatórios e quanto gerar através de usinas térmicas, de modo que o custo total até o final do horizonte de estudo seja minimizado.

Em um sistema hidrotérmico é de extrema importância à decisão tomada em um estágio qualquer da operação energética, pois existe relação direta com as consequências no futuro. Esta situação está ilustrada na Figura 3.

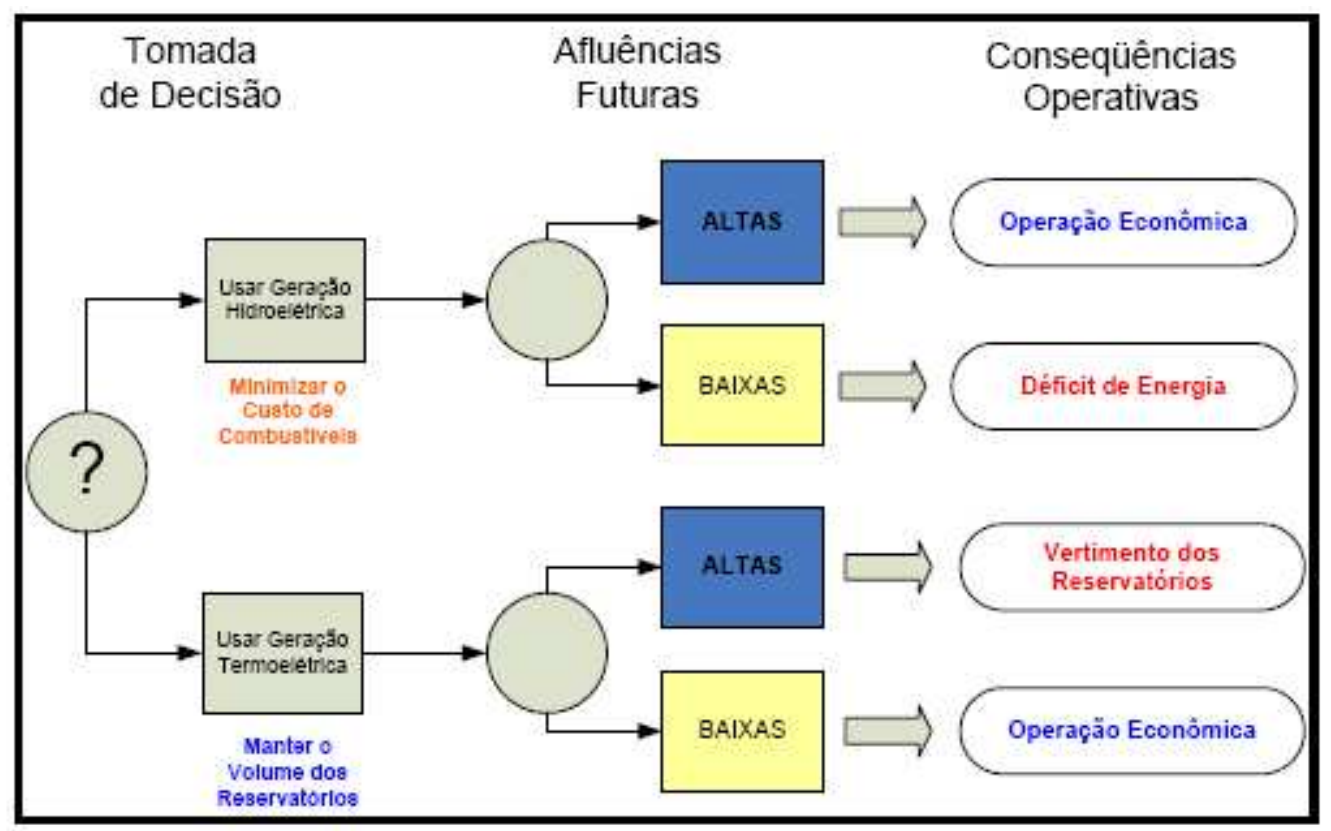

Figura 3 - Processo de Decisão para Sistemas Hidrotérmicos 
Para definição da política ótima de operação, o operador deve considerar não apenas os custos de geração térmica em um estágio $t$, mas também, o custo esperado dessa geração e do déficit no final desse estágio $t$ (início de $t+1$ ). Matematicamente, esta lógica é expressa pela "Função de Custo Imediato" (FCl), representando o benefício do uso imediato da água, e pela "Função de Custo Futuro" (FCF), representando o benefício de armazená-la hoje para seu uso no futuro (Kelman et al, 1999).

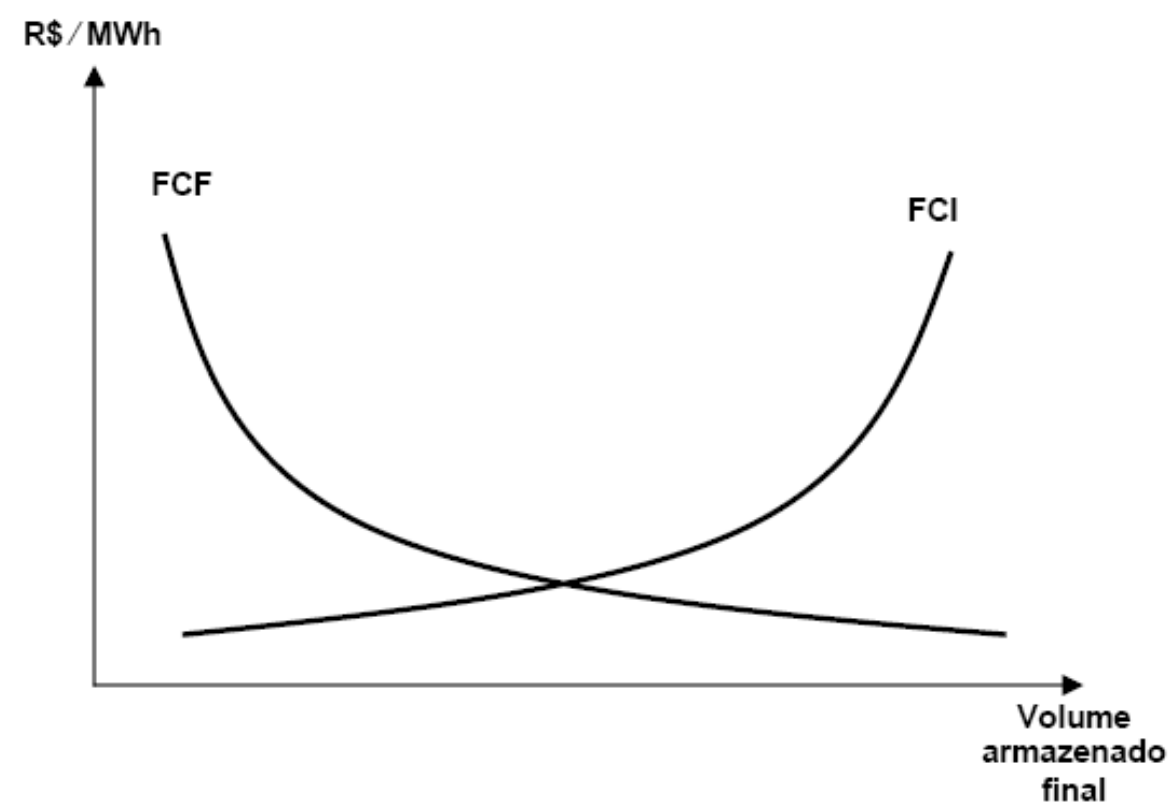

Figura 4 - Funções de Custo Imediato e Futuro

É possível entender a $\mathrm{FCl}$ como o custo de geração térmica necessária para complementar o atendimento à demanda no estágio $t$, e é representada por uma função linear por partes. A FCF de cada estágio t, por sua vez, pode ser definida como sendo o custo esperado de geração térmica ao longo do período de planejamento em função do volume armazenado ao final do estágio. À medida que se aumenta o volume armazenado final, diminui a função de custo futuro, pois mais capacidade hidráulica existirá no futuro. O uso ótimo da água será, pois, aquele que minimiza a soma do custo de geração térmica no presente e o valor esperado do custo de geração até o fim do período de estudo (Medeiros et al, 2004). 
Conseqüentemente, o problema de encontrar o menor custo global se resume a encontrar o ponto de mínimo da "Função de Custo Total" (FCT) - dada pela soma das FCF e FCl. Este ponto é onde a derivada de FCT em relação ao volume final é igual a zero ou, ainda, onde as derivadas de FCF e $\mathrm{FCl}$ em relação ao volume final são iguais em módulo. Assim, o chamado "valor da água" pode ser calculado pela inclinação da $\mathrm{FCl}$ (ou da FCF) no ponto de decisão ótimo correspondente ao nível de armazenamento ao final do estágio t. Para alcançar os objetivos do planejamento da operação em sistemas hidrotérmicos e para obter uma boa representação do sistema, não é razoável a utilização de um único modelo, dada a sua complexidade. Faz-se, então, um desdobramento do problema em vários subproblemas com horizontes de planejamento (ou de otimização) diferentes (Medeiros et al, 2004).

Cada subproblema utiliza um modelo desenvolvido pelo Centro de Pesquisas de Energia Elétrica - CEPEL para solucionar a decisão operativa:

- NEWAVE: modelo estratégico de geração hidrotérmico a subsistemas equivalentes com horizonte de cinco anos discretizado em bases mensais, com representação agregada do parque hidroelétrico e cálculo da política ótima baseado em Programação Dinâmica Dual Estocástica;

- DECOMP: modelo de determinação da coordenação da operação mensal com discretização semanal, desenvolvido para otimizar o planejamento da operação a curto prazo de um sistema hidrotérmico, sujeito à afluências estocásticas.

O DECOMP recebe do NEWAVE a FCF, que adicionada às projeções diárias de demanda e afluências, possibilita a definição do despacho do sistema. Este despacho é realizado pelo modelo DECOMP que também fornece os Custos Marginais de Operação (CMO).

O processo descrito acima é realizado pelo ONS e visa definir o despacho do sistema ao menor custo total possível, e é também utilizado para calcular o Preço 
de Liquidação das Diferenças (PLD) da Câmera de Comercialização de Energia Elétrica, a fim de promover a contabilização e liquidação do mercado de energia.

Sob a ótica dos consumidores, a contabilização do Mercado de Curto Prazo consiste na comparação entre os montantes de energia contratados e consumidos. Após conhecida essa diferença, estabelece-se sua valoração ao PLD, que é liquidada pelo agente.

Assim, os agentes que apresentarem consumo menor que o montante contratado receberão essa diferença valorada ao PLD. De maneira similar, os agentes que consumirem um montante maior do que 0 apresentado por seus contratos pagarão a energia adicional valorada ao PLD (Figura 5).

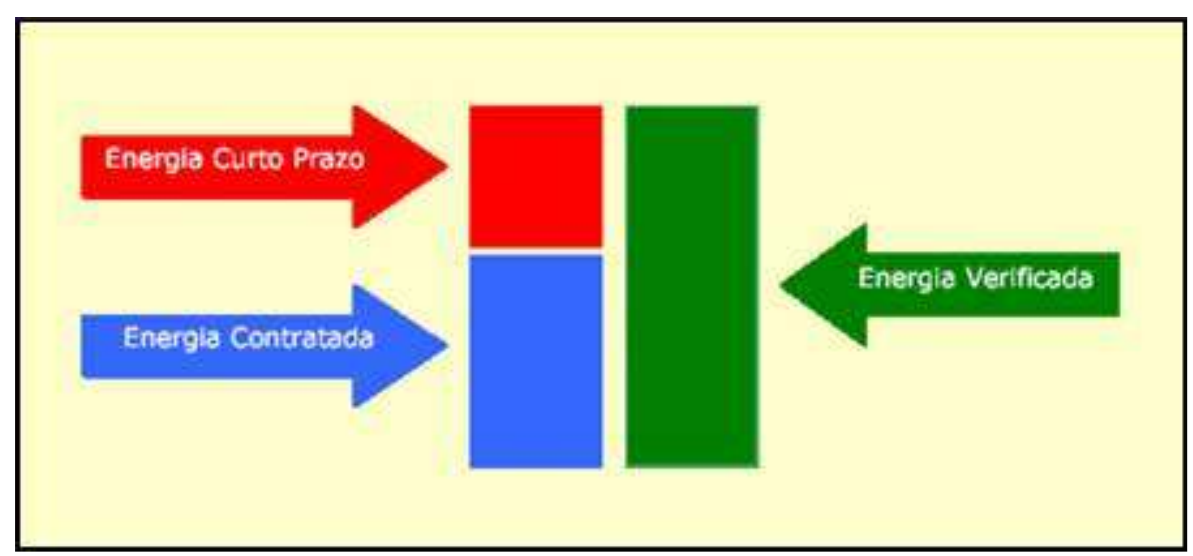

Figura 5 - 0 Mercado de Curto Prazo

A atuação dos agentes no mercado de curto prazo é limitada, pois existem mecanismos que inibem a subcontratação, sendo inclusive aplicadas penalidades para alguns tipos de comportamentos. Adicionalmente, o risco da subcontratação é elevado, pois, tendo em vista que as características do NEWAVE e do parque gerador, os valores de CMO, e conseqüentemente de PLD, são extremamente voláteis e sujeitos à sazonalidade das chuvas. Esse fato pode ser observado na Figura 6. 


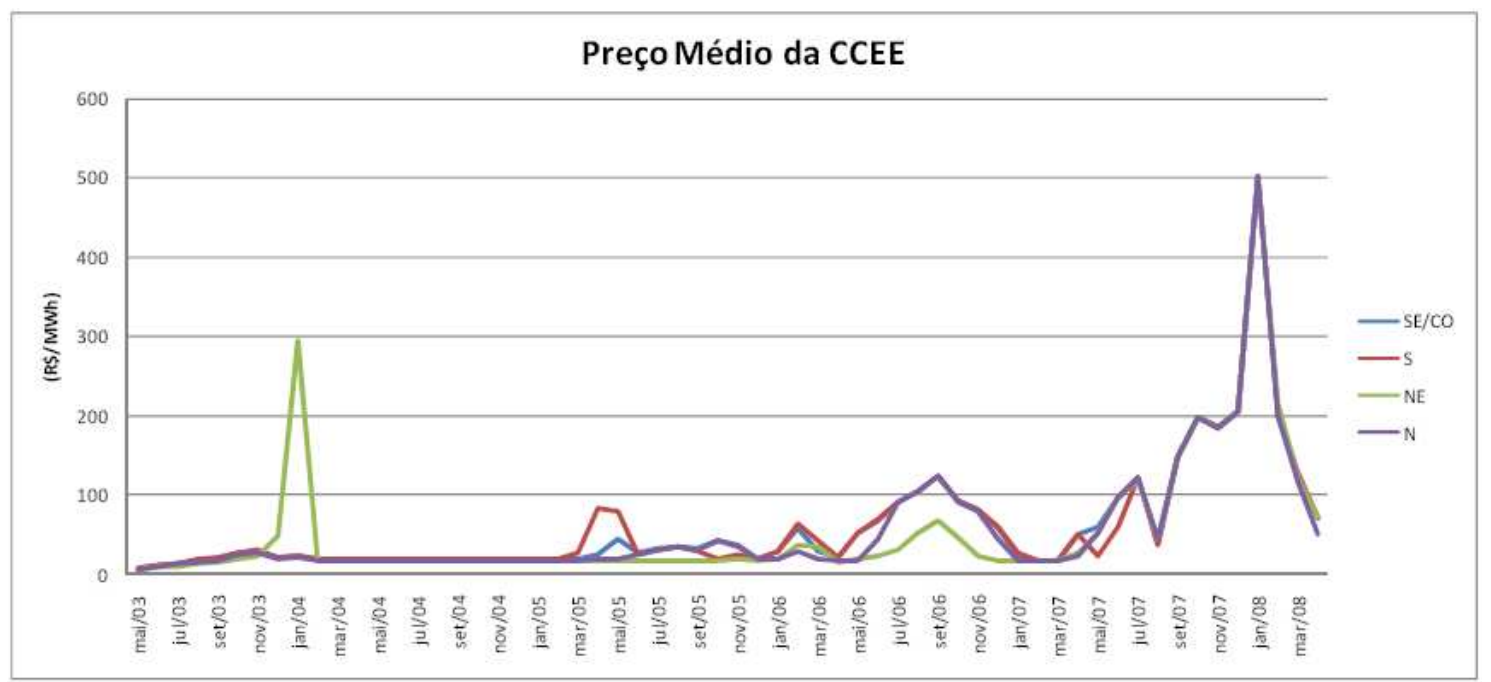

Figura 6 - Histórico mensal de Preços

A dificuldade de previsibilidade do PLD tem como conseqüência direta o aumento do preço dos contratos negociados no ACL e também é um grande obstáculo para a formação de um mercado futuro de energia. 


\section{COMPRA DE ENERGIA NO ACR}

Conforme descrito no decreto $5.163 / 2004$, as distribuidoras de energia devem possuir lastro contratual para atender à totalidade de seu mercado e estão sujeitas à penalidade, caso isso não ocorra. Para atender a necessidade descrita, as concessionárias de distribuição dispõem dos seguintes mecanismos: contratos provenientes de leilões regulados, contratos do Programa de Incentivo às Fontes Alternativas de Energia Elétrica (PROINFA), contratos de ITAIPU, contratos de energia de geração distribuída e aquisições realizadas antes da edição da Lei $10.848 / 2004$.

\subsection{COMPRA DE ENERGIA ATRAVÉS DE LEILÕES REGULADOS}

Nos leilões regulados, os agentes vendedores (geradores, importadores e comercializadores) vencedores devem assinar contratos bilaterais, denominados Contratos de Compra de Energia no Ambiente Regulado (CCEARs) com todas as distribuidoras que declaram necessidade de energia. Esses leilões são realizados pela ANEEL ou CCEE e podem ser subdivididos em:

- Leilões de Energia Nova, realizados com cinco (A-5) ou três (A-3) anos de antecedência do início de suprimento e caracterizados pela participação de empreendimentos ainda não construídos.

- Leilões de Energia Existente, realizados com um ano (A-1) ou quatro meses (Ajuste) de antecedência do início de suprimento e caracterizados pela participação de empreendimentos existentes.

A figura a seguir ilustra as opções de contratação das distribuidoras. 


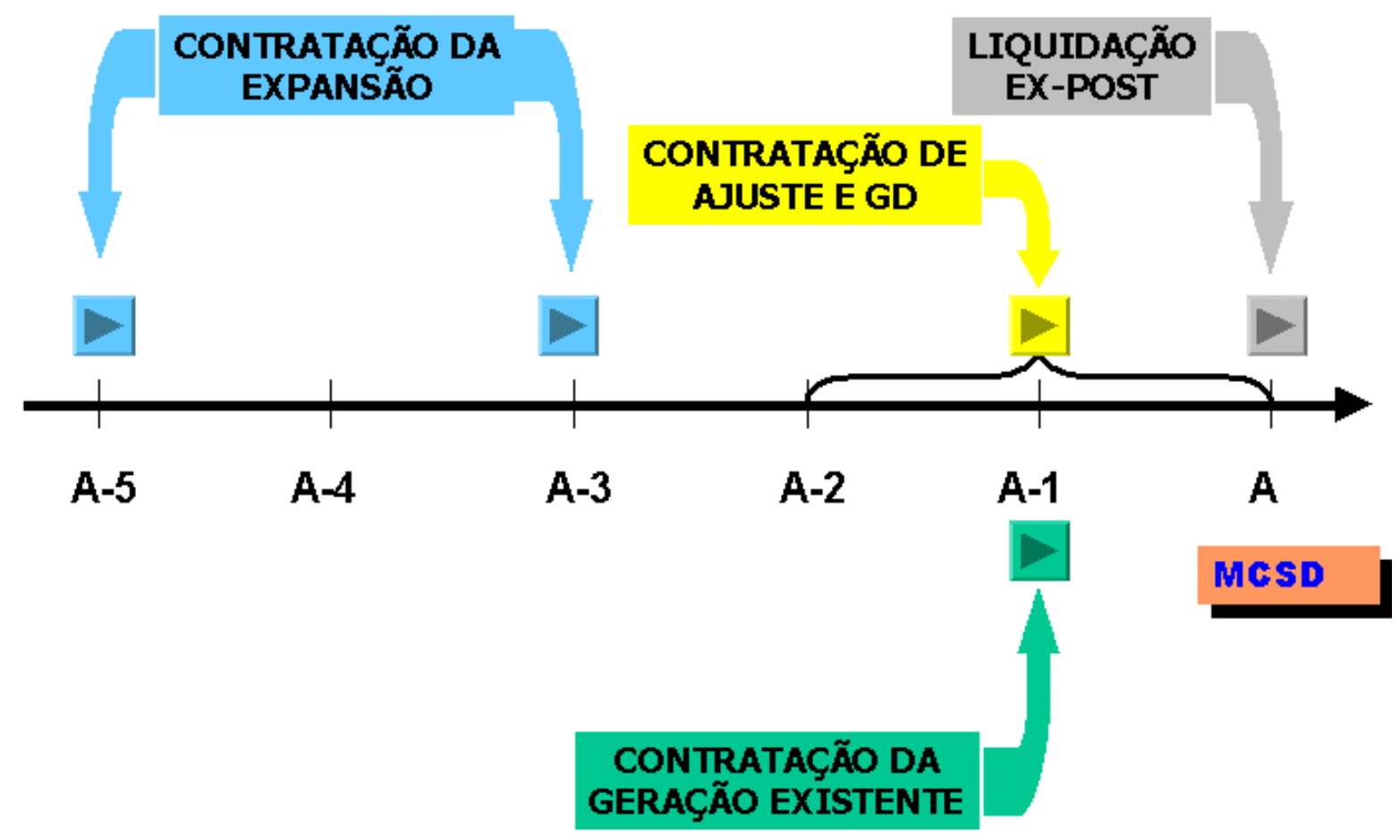

Figura 7 - Momentos de Contratação

Nos leilões A-5 e A-3 ocorrem distinções entre os empreendimentos de fonte térmica e hidráulica. Os vencedores do leilão, que apresentam empreendimentos de fonte térmica firmam contratos por disponibilidade, enquanto os de fonte hidráulica contratos por quantidade.

\subsubsection{Contratos por Disponibilidade}

Tendo em vista os riscos associados ao despacho térmico e à volatilidade do PLD, foram constituídos os Contratos por Disponibilidade. Esse tipo de contrato tem como característica intrínseca o fato de que o vendedor somente é responsável pelos custos associados à disponibilidade de seu empreendimento e 
à geração inflexível declarada no momento do leilão. Assim, os custos devidos ao despacho (COP) e à liquidação da diferenças (CEC) são de responsabilidade do comprador. De modo geral, o custo associado aos contratos por disponibilidade é ilustrado a seguir.

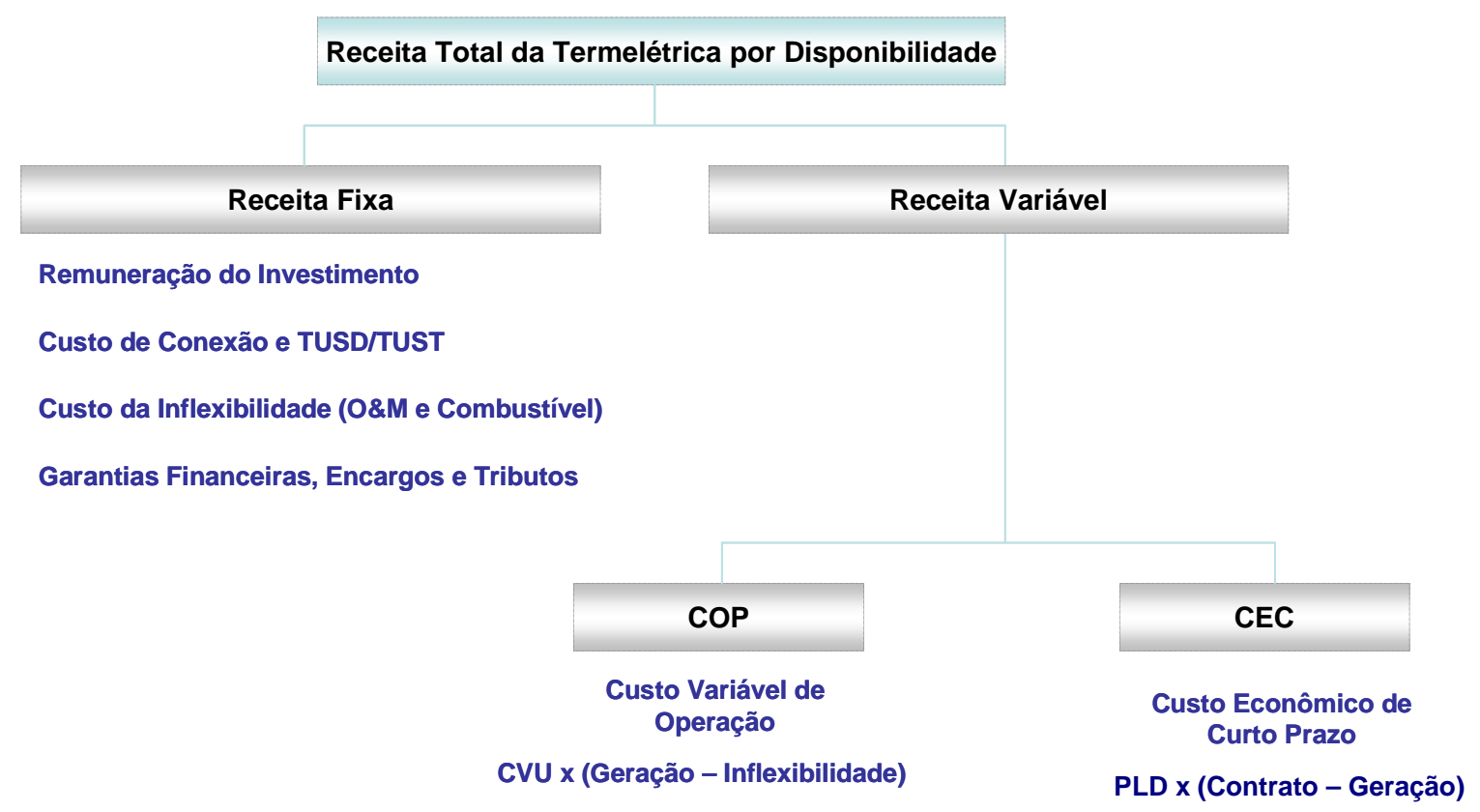

Figura 8 - Composição do Custo das UTE's com contrato por disponibilidade

Através da ilustração acima e pelo exposto anteriormente, pode-se concluir que os custos da Parcela Variável são totalmente alocados ao comprador. Assim, o custo de um eventual despacho por ordem de mérito será completamente assumido pelos consumidores cativos, o que pode se tornar um fator de dificuldade para previsão dos custos totais desse contrato. 


\subsubsection{Contratos por Quantidade de Energia}

Os contratos por quantidade são associados aos leilões de energia existente e aos leilões de energia nova proveniente de fonte hidrelétrica. Diferentemente dos contratos por disponibilidade, estes contratos alocam os custos decorrentes dos riscos hidrológicos ao vendedor e os riscos financeiros, decorrentes de diferenças de preços entre o submercado de venda e compra, são assumidos pelo comprador.

\subsubsection{Resultados dos Leilões de Energia Nova}

Com vistas a promover a expansão da oferta, o modelo setorial prevê a realização de Leilões de Energia Nova (LEN), onde são ofertados empreendimentos cuja operação não foi iniciada.

O 1 LEN foi realizado em 2005 e nessa ocasião foram ofertados produtos na modalidade quantidade e disponibilidade, com início de suprimento em 2008, 2009 e 2010, e vigência de trinta e quinze anos respectivamente.

Até maio de 2009 foram realizados sete leilões de energia nova, além do primeiro leilão de fontes alternativas e os dos leilões das usinas do Rio Madeira (Santo Antônio e Jirau). A figura a seguir ilustra a energia contratada por meio dos leilões supracitados, com distinção entre fonte hidráulica e térmica, e os respectivos preços. 


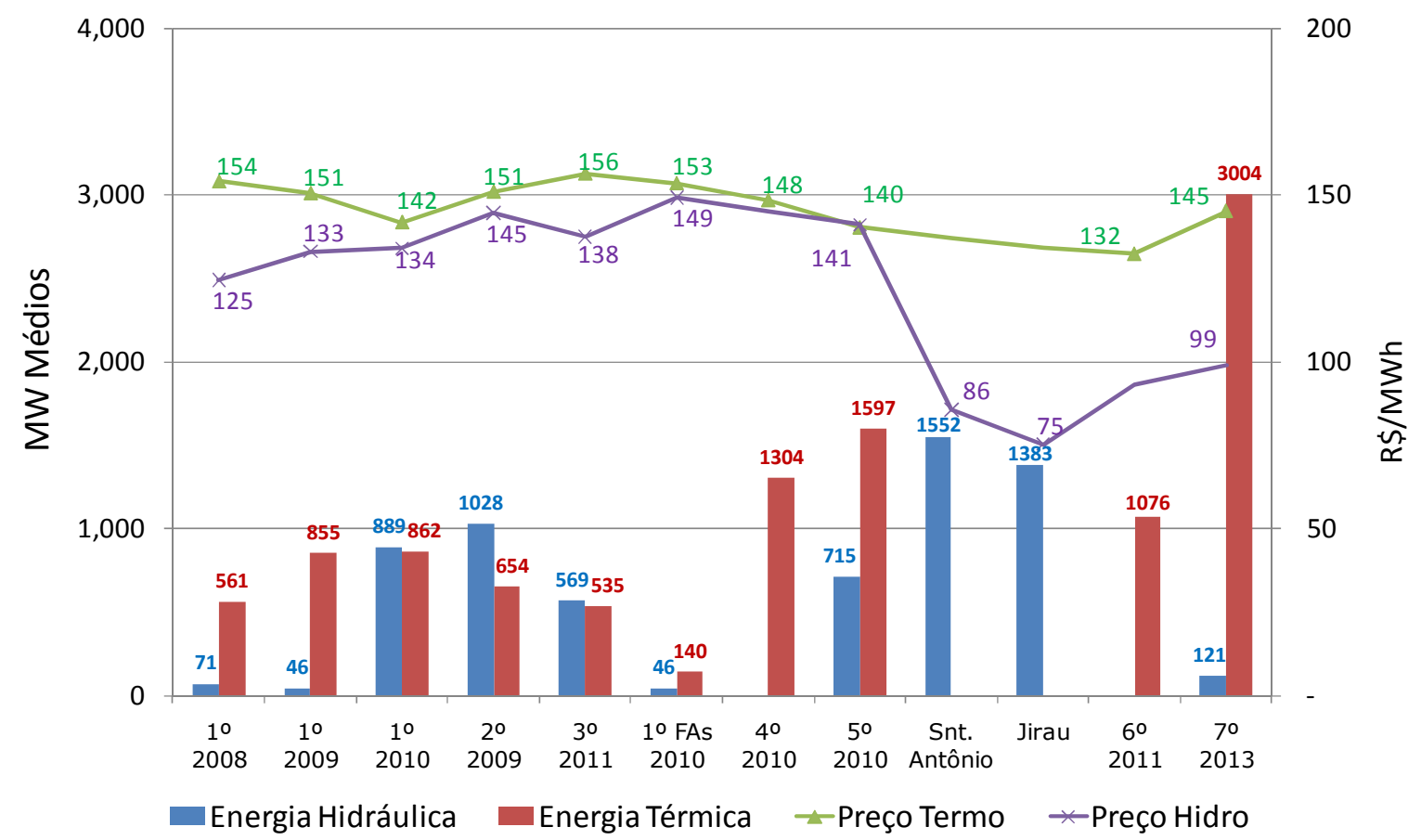

Figura 9 - Montantes e preços negociados nos LEN e Fonte Alternativa (base abril/09)

Os resultados dos leilões indicam a participação significativa de empreendimentos de fonte térmica, com destaque ao óleo combustível, cuja participação no comparativo entre os empreendimentos termelétricos supera $30 \%$. Se por um lado a diversificação da matriz é bem-vinda, pois no caso de séries precárias de afluências tem-se a opção de utilizar os recursos térmicos disponíveis para garantir o suprimento energético, por outro sua contratação aloca os riscos hidrológicos aos compradores, trazendo imprevisibilidade à tarifa de energia dos consumidores cativos.

\subsection{CONTRATOS DO PROINFA}

A Lei $n^{\circ} 10.438$ de 26 de abril de 2002, instituiu o PROINFA com o objetivo de aumentar a participação da energia elétrica produzida por empreendimentos de 
Produtores Independentes Autônomos, concebidos com base em fontes Eólicas, Pequenas Centrais Hidrelétricas - PCHs e Biomassa, no SIN.

Os custos desse programa são rateados entre todos os consumidores do SIN, de forma compulsória, e cada consumidor detém um contrato que corresponde a uma parcela de energia desses empreendimentos.

\subsection{CONTRATOS DE ITAIPU}

O acordo internacional entre o Brasil e Paraguai viabilizou a construção da usina hidrelétrica de Itaipu, que atualmente apresenta potência instalada de 14.000 MW e responde por cerca de $20 \%$ da energia elétrica produzida no SIN. A energia assegurada da hidroelétrica de Itaipu é disponibilizada à todas as distribuidoras dos submercados Sudeste/Centro-Oeste e Sul na forma de quotas da potência da usina e proporcional ao mercado faturado dessas distribuidoras.

O pagamento pela potência disponibilizada pela usina é efetuado mensalmente e baseado no produto da parcela da demanda atribuída a cada agente, em kilowatt (kW), por uma tarifa determinada em dólar por kilowatt (US\$/kW) convertida em moeda nacional pela taxa de câmbio do último dia útil do mês de competência.

Adicionalmente, aloca-se às distribuidoras quotistas o custo do Transporte da energia dessa usina até a fronteira com a Rede Básica, assim como Tarifa de Uso do Sistema de Transmissão (TUST) incorrida pela mesma.

A demanda e a energia assegurada de Itaipu são definidas pela ANEEL e, em 2004, o MME publicou a Portaria 303 que fixa, além da energia assegurada das usinas do SIN, a assegurada de Itaipu para o período de 2005 a 2014. Em 2006, as quotas foram revistas e fixadas, através da Resolução ANEEL 218/06, de 2008 a 2011. 


\subsection{CONTRATOS DE GERAÇÃO DISTRIBUIDA}

A concessionária de distribuição possui a prerrogativa de adquirir contratos de energia provenientes de empreendimentos conectados diretamente à rede de distribuição, denominados Geração Distribuída, desde que sejam realizados mediante chamada pública.

O Decreto 5.163/04 estabelece o limite de $10 \%$ do mercado da concessionária para aquisição desse tipo de contrato e define o repasse integral do custo de até o Valor de Referência (VR).

\subsection{CONTRATOS ANTERIORES À LEI 10.848/2004}

Com a edição da Lei 10.848/04, os contratos bilaterais, como definidos, ficaram restritos aos relacionamentos comerciais entre agentes comercializadores, geradores e consumidores livres.

Contudo, os contratos bilaterais firmados pelas distribuidoras e aprovados pela ANEEL até 16 de março de 2004 permanecem válidos até o término do período de suprimento. 


\subsection{RESTRIÇÕES AO VOLUME DE CONTRATAÇÃO E AO REPASSE TARIFÁRIO}

Como apresentado em 4.1, existem vários momentos que a empresa de distribuição dispõe para contratar energia a fim de atender o seu mercado. No entanto, os arcabouços legais e regulatórios impõem restrições ao volume de compra e ao repasse tarifário dos custos associados, com o objetivo de garantir a modicidade tarifária e prover sinalização antecipada para a expansão da geração.

As tabelas a seguir apresentam os principais momentos de contratação das empresas de distribuição associados às restrições de volume e de repasse tarifário respectivamente.

Tabela 2 - Restrições ao Volume de Contratação de Energia

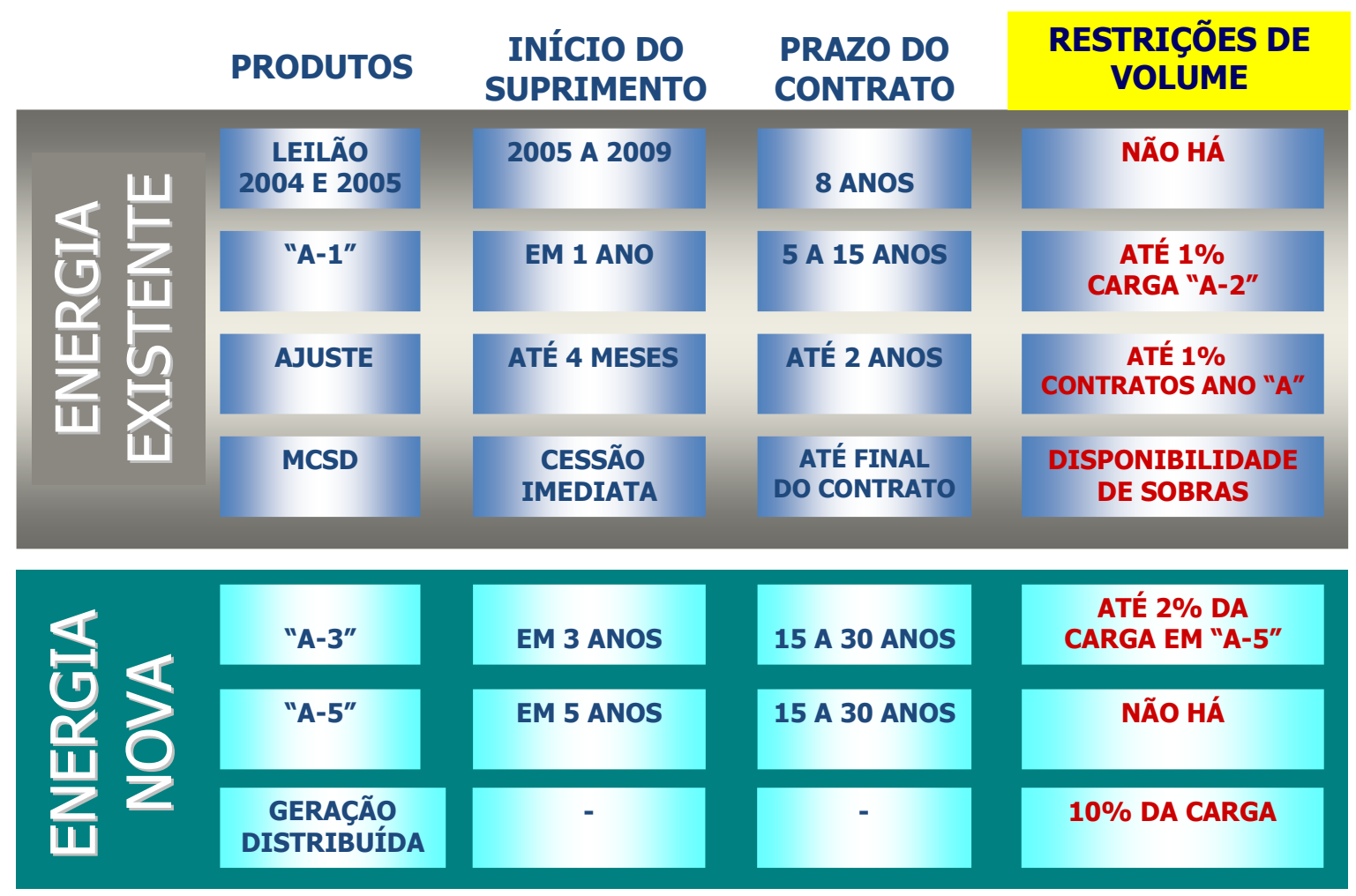


Tabela 3 - Restrições ao Repasse Tarifário

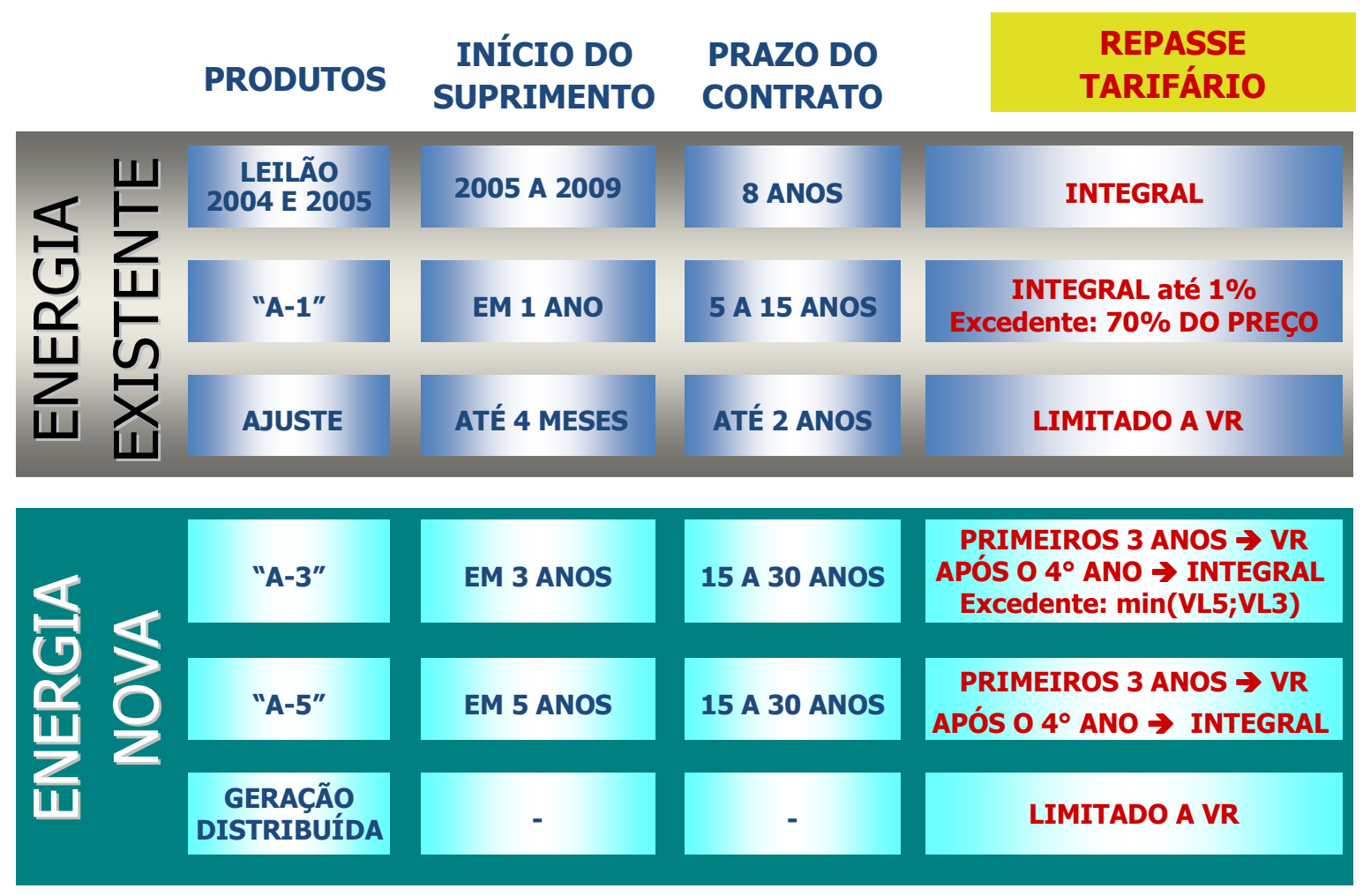

Como pode ser observado na Tabela 3 , foram criados alguns mecanismos indutores à contratação eficiente nos leilões de A-5 e A-3, tendo em mente o objetivo de contribuir para a expansão do parque gerador do país.

Assim, o modelo setorial prevê que a distribuidora que obtiver um custo individual de contratação nos leilões "A-3" e "A-5" inferior ao Valor Anual de Referência (VR) terá um ganho na contratação, pois poderá repassar à tarifa durante três anos um valor superior ao efetivamente despendido com essas contratações.

$\mathrm{Na}$ prática, esse mecanismo estimula a contratação nos leilões de A-5, cujos preços tendem a serem inferiores aos dos leilões $A-3$, e, consequentemente, à expansão do sistema.

Outro fator que induz a contratação em "A-5" é o que limita o repasse dos custos dos leilões "A-3" ao menor valor dentre os custos relativos á "A-5" e "A-3", quando a declaração em "A-3" exceder $2 \%$ da demanda. 
A fim de coibir a contratação excessiva nos Leilões de Energia Existente (A-1) e garantir a expansão da oferta foi necessária a limitação da contratação adicional ao montante em renovação nesse tipo de certame. O valor estipulado foi de $1 \%$ da carga verificada no ano anterior à realização do respectivo leilão e seu repasse limitado a VR.

Embora existam mecanismos de gerenciamento do risco de mercado, o atendimento a $100 \%$ da carga da distribuidora torna-se uma tarefa inviável, dadas as variações que ocorrem entre o momento da declaração da necessidade e a efetiva realização de sua carga. Assim, a legislação prevê que as distribuidoras podem repassar às tarifas dos consumidores finais os montantes contratados até $103 \%$ de sua carga. Como pode ser observado na figura a seguir, após esse limite a empresa de distribuição está sujeita aos riscos do Mercado de Curto Prazo, sendo que suas perdas ou ganhos apropriados não repassados aos consumidores.

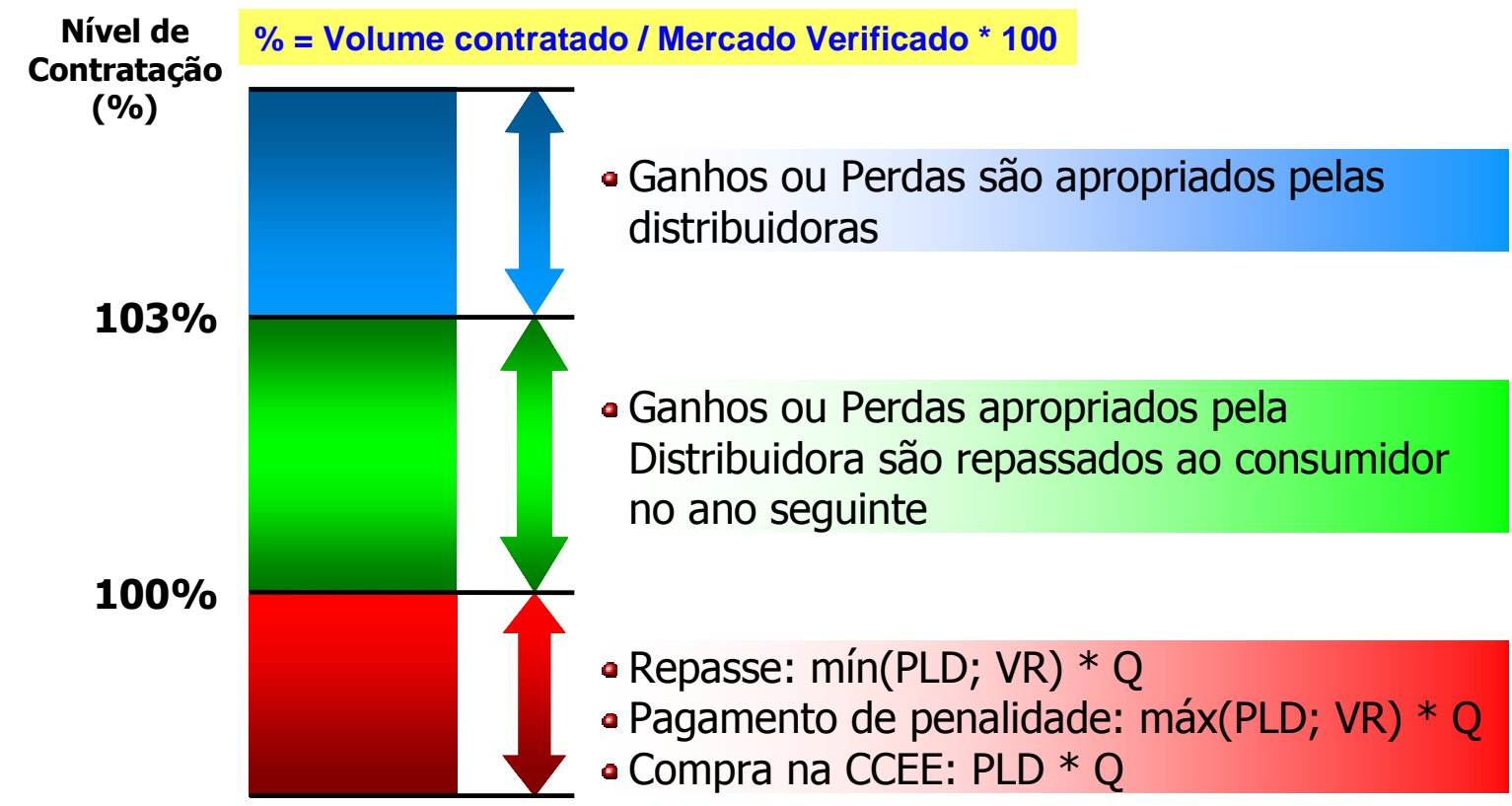

Figura 10 - Repasse dos níveis de contratação 


\section{TARIFAS DE ENERGIA ELÉTRICA}

O regime a que estão submetidos os contratos de concessão das distribuidoras de energia elétrica é o chamado Regime de Regulação por Incentivos. Este regime prevê que as tarifas estabelecidas pela ANEEL representam um preço-teto que a concessionária pode aplicar, sendo que no período entre Revisões Tarifárias os ganhos de eficiência (redução de custos) obtidos em seus processos não implicarão redução imediata da tarifa praticada. Pelo contrário, a redução de custos da concessionária representa maior margem de ganho para os acionistas, até que a próxima Revisão Tarifária aconteça (normalmente 4 anos). Para a concessionária, a possibilidade de apropriar-se dos ganhos decorrentes da redução de custos, entre duas Revisões Tarifárias, representa 0 incentivo à eficiência inerente ao Regime de Regulação por Incentivos. A contrapartida para o consumidor é a possibilidade de ter tarifas menores quando a Agência Reguladora realizar o novo cálculo da receita necessária para prestação do serviço de distribuição, denominada Receita Requerida, que tende a ser menor por refletir uma empresa mais eficiente.

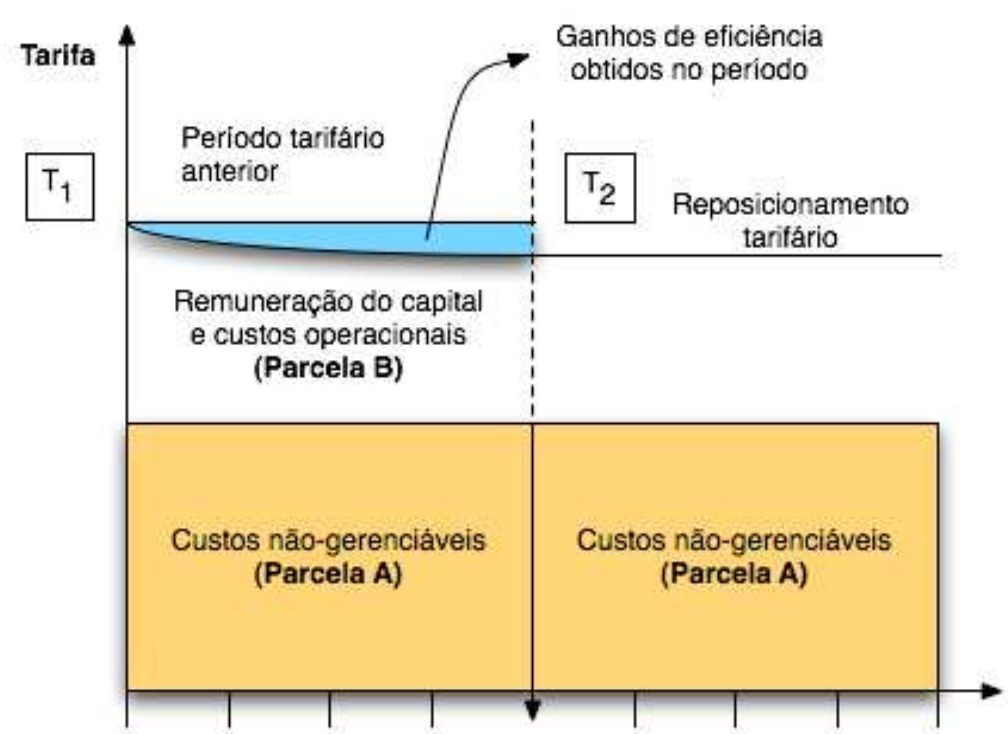

Figura 11 - Regime de Regulação por Incentivos 
Outro aspecto fundamental do regime de regulação por incentivos é a atuação da Agência Reguladora no que diz respeito à exigência dos níveis de qualidade dos serviços prestados. Isto porque a concessionária tem forte incentivo à redução de custos, podendo exceder-se a ponto de degradar a qualidade do atendimento. Portanto, o equilíbrio entre redução de custos por incremento de eficiência e a qualidade do serviço prestado deve ser monitorado pela ANEEL.

Com base nesse contexto, o presente capítulo visa apresentar a estrutura dos custos regulatórios de uma concessionária de energia e suas formas de revisão. Além disso, serão abordados os meios de conversão desses custos nas tarifas aplicadas às várias classes de consumidores.

\subsection{COMPOSIÇÃO DA RECEITA REQUERIDA}

O contrato de concessão firmado entre a concessionária de distribuição e o poder concedente estabelece que a receita requerida pela distribuidora é composta de duas parcelas: Parcela A e Parcela B. A primeira refere-se aos custos nãogerenciáveis de concessionária, tais como: compra de energia, encargos setoriais e encargos de transmissão. Já a segunda é composta pelas despesas gerenciáveis que podem ser resumidas em despesas de capital e custos de operação e manutenção. A Tabela 4 apresenta essa composição 
Tabela 4 - Composição da Receita de uma distribuidora

\begin{tabular}{|c|c|}
\hline \multicolumn{2}{|c|}{ Composição da Receita Requerida } \\
\hline Parcela A & Parcela B \\
\hline (custos não-gerenciáveis) & (custos gerenciáveis) \\
\hline Encargos Setoriais & Despesas de Operação e \\
\hline Custo com Transporte de & Manutenção \\
\hline Energia & $\begin{array}{c}\text { Remuneração para os } \\
\text { Investidores }\end{array}$ \\
\hline Compra de Energia Elétrica \\
para Revenda
\end{tabular}

A seguir serão abordadas de forma superficial as componentes das Parcelas A e B.

\subsubsection{Parcela A}

Como descrito anteriormente, a Parcela A da Receita Requerida é formada pelos custos considerados não gerenciáveis pela concessionária. Estes custos são relativos à compra de energia, à transmissão até as redes de distribuição e aos encargos setoriais. De maneira geral, pode-se dizer que as concessionárias têm direito ao repasse integral destas despesas. A seguir serão detalhados os componentes supracitados. 


\subsubsection{Compra de Energia Elétrica}

O custo referente à compra de energia é a despesa gerada referente ao atendimento da Energia Requerida, que é composta pelas seguintes parcelas: Mercado Cativo, Suprimento, Perdas Técnicas e Perdas Não-Técnicas. Para atender a esses componentes, as concessionárias podem dispor dos seguintes tipos de contratos: Contratos Bilaterais, Contratos de Leilões, Contratos de ITAIPU e Contratos de Comercialização de Energia no Ambiente Regulado (CCEARs).

\subsubsection{Encargos Setoriais}

Os Encargos Setoriais são definidos em Leis e resultam de políticas governamentais. Os encargos que atualmente compõem a Parcela $A$ são: Reserva Global de Reversão (RGR), Conta de Consumo de Combustíveis Fósseis (CCC), Conta de Desenvolvimento Energético (CDE), Compensação Financeira pelo Uso de Recursos Hídricos (CFURH), Taxa de Fiscalização de Energia Elétrica (TFSEE), Contribuição ao ONS, Programa de Incentivo às Fontes Alternativas de Energia Elétrica (Proinfa), Encargo de Serviços do Sistema (ESS), Pesquisa e Desenvolvimento (P\&D) e Eficiência Energética.

A RGR é um encargo setorial e foi criada pelo Decreto n. 41.019 , de 26 de fevereiro de 1957. A RGR tem como principais objetivos prover recursos para reversão, encampação, expansão e melhoria do serviço público de energia elétrica. A Quota de RGR fixada anualmente é paga mensalmente em duodécimos pelas concessionárias à ELETROBRÁS, que é a gestora dos recursos arrecadados para esse fim. 
A Taxa de Fiscalização de Serviços de Energia Elétrica (TFSEE) foi instituída pela Lei n. 9 9.427, de 26 de dezembro de 1996, e tem seu valor fixado anualmente pela ANEEL. Sua receita destina-se à cobertura do custeio das atividades da ANEEL.

O encargo referente à Pesquisa e Desenvolvimento Energético (P\&D) foi criado pela Lei n. ${ }^{\circ}$ 9.991, de 24 de julho de 2000, que estabelece que as concessionárias e permissionárias de serviços públicos de distribuição de energia elétrica ficam obrigadas a aplicar anualmente o montante de, no mínimo, 0,75\% e 0,25\% de sua receita operacional líquida, respectivamente, em projetos de pesquisa e desenvolvimento e em programas de eficiência energética.

A contribuição para o Operador Nacional do Sistema (ONS) tem como finalidade prover recursos para o custeio das atividades dessa instituição.

A CCC é um encargo pago por todas as empresas concessionárias de distribuição e de transmissão de energia elétrica do Brasil. Este encargo é utilizado para cobrir os custos anuais da geração termelétrica de áreas ainda não interligadas ao SIN, chamadas de "sistemas isolados", sendo o montante anual fixado pela ANEEL para cada concessionária, em função do seu mercado de referência.

A CDE foi criada pela Lei $n^{\circ} 10.438$ de 26 de abril de 2002 , e pode-se afirmar que dentro de seu escopo encontram-se duas finalidades distintas; a primeira está relacionada à diversificação e expansão da matriz energética, enquanto a segunda diz respeito à universalização e ampliação das redes de atendimento.

A Lei $n^{\circ} 10.438$ de 26 de abril de 2002, instituiu o PROINFA com o objetivo de aumentar a participação da energia elétrica produzida por empreendimentos de Produtores Independentes Autônomos, concebidos com base em fontes Eólicas, Pequenas Centrais Hidrelétricas - PCHs e Biomassa, no SIN.

O ESS representa o custo incorrido para manter a segurança, confiabilidade e a estabilidade do Sistema para o atendimento da carga. Esse encargo, 
praticamente em sua totalidade, é pago pelos consumidores aos agentes de geração que prestarem serviços não remunerados pelo Preço de Liquidação de Diferenças (PLD).

\subsubsection{Custos com Transporte de Energia}

Os Custos com Transporte de Energia são fixados pela ANEEL e referem-se aos valores incorridos pela concessionária de distribuição ao acessar a Rede Básica ou a rede de outra distribuidora. A seguir são descritos os componentes que compõem essa parcela.

Os custos Rede Básica e Rede Básica Fronteira referem-se a valores pagos pelas concessionárias de distribuição às Transmissoras pertencentes à rede básica do SIN. O primeiro é referente ao acesso à Rede Básica enquanto o segundo é responsável pelo custo de uso dos equipamentos de utilização específica da concessionária de distribuição. Os montantes a serem recuperados com essas componentes são calculados mensalmente pelo ONS, com base nos dados de demanda contratada e tarifa específica do ponto de conexão.

Já o Uso das Instalações de Conexão, usualmente denominado Conexão, referese ao uso, pelas distribuidoras, das instalações de conexão não integrantes da rede básica e pertencentes às transmissoras.

O Uso das Instalações de Distribuição refere-se ao custo associado ao uso da rede de outra distribuidora.

\subsubsection{Parcela B}

Como mencionado anteriormente, a Parcela B representa os custos gerenciáveis da concessionária. Essa parcela é composta pela Remuneração dos Ativos, Quota de Reintegração Regulatória e Custos Operacionais. 


\section{Parcela B (Custos Gerenciáveis )}

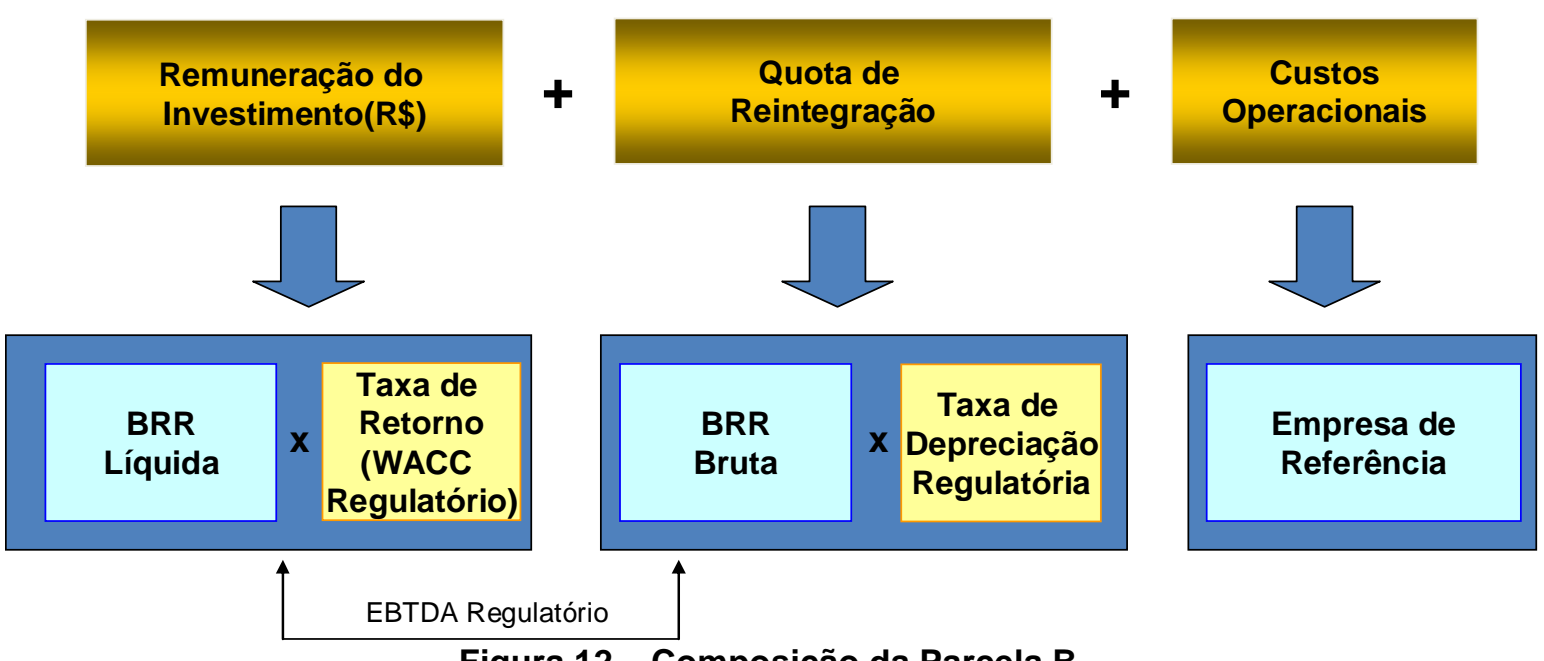

Figura 12 - Composição da Parcela B

A Remuneração dos Ativos é obtida pela aplicação da taxa de retorno adequada para a atividade de distribuição no Brasil sobre o valor líquido dos ativos a serem remunerados, que são aqueles apresentados pelos investimentos prudentes realizados pela Concessionária.

A taxa de retorno adequada é definida pela ANEEL para cada ciclo de revisão tarifária. Assim como em outros países, a metodologia empregada pelo regulador brasileiro utiliza o Custo Médio Ponderado de Capital (Weighted Average Cost of Capital - WACC), incluindo o efeito dos impostos sobre a renda.

Já a Quota de Reintegração Regulatória é composta das quotas de depreciação e de amortização e representa a forma de recomposição dos investimentos realizados para prestação do serviço de distribuição ao longo da vida útil desses bens.

A construção dos custos operacionais passa pela elaboração dos custos de referência utilizando-se a ferramenta da Empresa de Referência, que determina os custos operacionais eficientes para prestação do serviço de distribuição, tendo em vista as condições geo-econômicas do ambiente no qual a concessionária desenvolve sua atividade. 


\subsubsection{Componentes Financeiros}

Como no momento do reajuste/revisão tarifária alguns itens de custos apresentam valores provisórios, a agência reguladora realiza uma projeção dos valores a serem repassados às tarifas e, no momento do próximo reajuste/revisão, é realizada a compensação das diferenças verificadas.

Vale destacar que os componentes tarifários financeiros não fazem parte da base tarifária, ou seja, não fazem parte da tarifa econômica, pois se referem a valores pagos pelos consumidores em cada período de 12 meses subseqüentes aos reajustes ou revisões tarifárias.

\subsection{MECANISMOS DE ALTERAÇÃO DAS TARIFAS}

A fim de manter o equilíbrio econômico financeiro da concessão, o contrato firmado entre o poder concedente e a empresa de distribuição prevê três mecanismos de alteração das tarifas: Reajuste Tarifário Anual, Revisão Tarifária e Revisão Tarifária Extraordinária. A seguir são descritos os três mecanismos.

\subsubsection{Reajuste Tarifário}

Os reajustes tarifários ocorrem anualmente, exceto nos anos que acontecem as revisões tarifárias, tendo por objetivo ajustar as tarifas aos níveis de despesas não gerenciáveis (Parcela $A$ ) da distribuidora e atualizar monetariamente seus custos gerenciáveis (Parcela B) capturando uma parcela de seus ganhos de escala.

O resultado do reajuste tarifário culmina na aplicação do Índice de Reajuste Tarifário (IRT) sobre as tarifas praticadas pela concessionária. O IRT é composto de duas parcelas: IRT econômico e IRT financeiro, onde o primeiro representa o 
repasse dos custos que permanecem na tarifa no próximo reajuste/revisão, e o segundo o repasse dos custos temporários (não compõem base tarifária).

Nesse cálculo, são levadas em consideração as duas (2) parcelas: A parcela composta pela evolução dos custos que independem de decisões das concessionárias (Parcela $A$ ), e a parcela composta pelos custos que dependem essencialmente da eficácia da gestão empresarial (Parcela B). O índice geral de preços de mercado (IGP-M) da Fundação Getúlio Vargas é utilizado como indexador de custos para os custos controláveis, e " $X$ " é o fator de indução à melhoria da eficiência econômica das atividades monopolistas. Além disso, é levada em consideração a receita anual da concessionária correspondente ao ano em que a tarifa será aplicada e ao ano imediatamente anterior.

$$
I R T=\frac{V_{P A 1}+V_{P B 0} \times(I G P M-X)}{R A_{0}}
$$

onde:

$\mathrm{IRT}$ = reajuste tarifário que deve ser aplicado anualmente.

VPA1 = Valor da Parcela A para o ano teste.

VPBO $=$ Valor da Parcela B no ano anterior ao do reajuste tarifário.

IGPM = índice geral de preços de mercado da Fundação Getúlio Vargas.

$\mathrm{X}=$ Fator $\mathrm{X}$.

RA0 = Receita Verificada da concessionária no ano anterior à data do reajuste em processamento. 


\subsubsection{Revisão Tarifária}

Sumariamente, o processo de revisão tarifária consiste em uma série de metodologias necessárias ao cálculo da receita requerida, representando uma reconstrução da tarifa que assegura o equilíbrio econômico e financeiro da concessão.

Diferentemente do reajuste tarifário, além dos custos não gerenciáveis, na Revisão Tarifária os custos gerenciáveis da concessionária são redefinidos e nesse momento é assegurado que os ganhos de eficiência empresarial, obtidos pela concessionária ao longo do último ciclo tarifário, sejam revertidos à modicidade tarifária.

Após a definição dos custos regulatórios eficientes, a concessionária tem a possibilidade de apropriar-se dos ganhos decorrentes da redução de custos, entre duas Revisões Tarifárias, representando incentivo à eficiência inerente ao Regime de Regulação por Incentivos. A contrapartida para o consumidor é a possibilidade de ter tarifas menores quando a Agência Reguladora realiza o novo cálculo da Receita Requerida, que deverá refletir uma empresa mais eficiente.

\subsubsection{Revisão Tarifária Extraordinária}

A revisão tarifária extraordinária é um mecanismo por meio do qual a ANEEL poderá, a qualquer tempo, por solicitação da empresa de distribuição e quando devidamente comprovado, proceder à revisão das tarifas, visando manter o equilíbrio econômico-financeiro do contrato, caso algum custo da empresa de distribuição tenha apresentado modificações significativas que comprometam sua "saúde" financeira.

\subsubsection{Fator $X$}

Além dos ganhos decorrentes do incremento na eficiência dos processos ocorridos entre as Revisões Tarifárias, as concessionárias podem obter ganhos em função do crescimento do mercado faturado. Ou seja, as tarifas são 
calculadas tomando a premissa que o "mercado pagante" será aquele projetado no momento da Revisão Tarifária (mercado do ano teste ${ }^{2}$ ). Ocorre que este mercado tende a crescer ao longo dos anos e a tarifa inicialmente estabelecida, quando aplicada ao incremento do mercado, poderá resultar em receita adicional. Para capturar este ganho em favor da modicidade das tarifas, o contrato de concessão prevê a existência do Fator $\mathrm{X}$, que é calculado durante o processo de Revisão e aplicado nos reajustes anuais subsequentes.

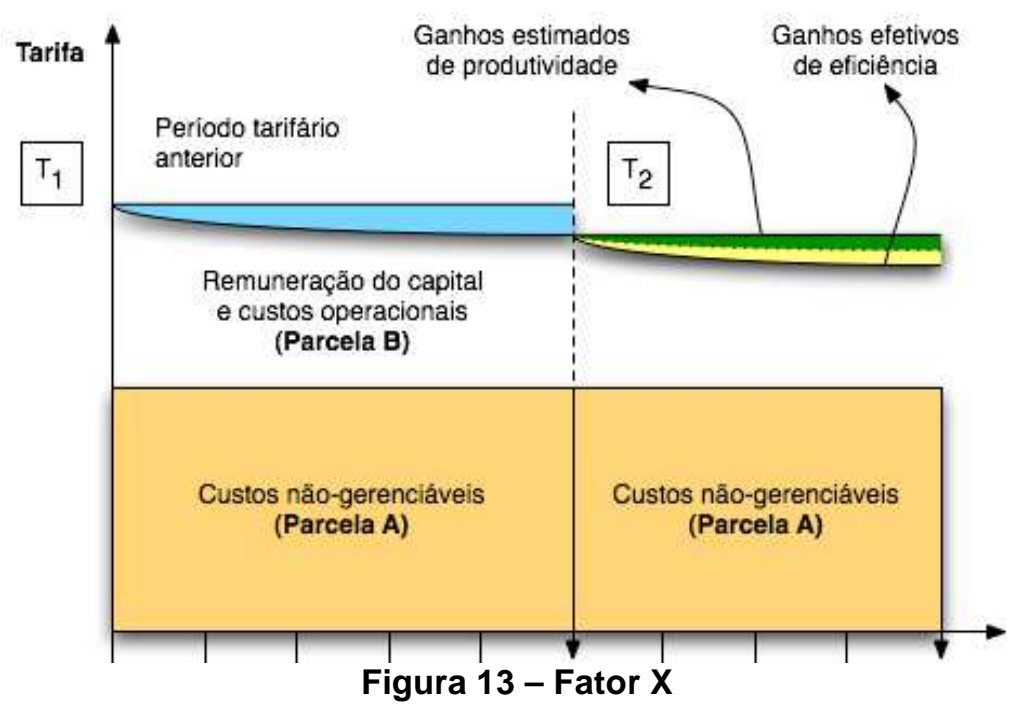

\subsection{ESTRUTURA TARIFÁRIA}

A prestação de serviço de eletricidade requer uma tarifa que, ao mesmo tempo, promova o uso racional por parte do consumidor e a eficiência da empresa prestadora do serviço, com o máximo de qualidade e produtividade. No Brasil optou-se pela adoção de uma estrutura tarifária baseada em custos marginais. A tarifa baseada nos custos marginais pode proporcionar resultados interessantes do ponto de vista do consumidor, que tem sua tarifa baseada nos custos que esse provoca ao sistema, interessantes também do ponto de vista da concessionária, que pode postergar investimentos, e, finalmente, do ponto de vista da própria sociedade.

\footnotetext{
${ }^{2}$ Mercado projetado para o período tarifário imediatamente subseqüente à data de revisão tarifária.
} 
Já o nível tarifário, pode ser definido como o valor médio global dos preços estabelecidos para o fornecimento de energia elétrica, o qual, por sua vez, define a receita total auferida pela concessionária.

Basicamente, o nível tarifário ideal é aquele no qual a concessionária obtém uma receita que cubra os custos e remunere adequadamente os respectivos investimentos, em conformidade com os preceitos regulatórios. Por sua vez, a estrutura tarifária é o parâmetro que define a relatividade de preços praticados nas diversas categorias de consumidores. No Brasil, em termos tarifários, esta classificação considera o nível de tensão de atendimento dos clientes, a intensidade da demanda requerida, a caracterização da utilização da energia e a sazonalidade do consumo.

Conforme definido na Resolução ANEEL № 456, de 29 de novembro de 2000, que estabelece as Condições Gerais de Fornecimento de Energia Elétrica, no

Brasil as tarifas estão estruturadas em dois grandes grupos, a saber: "Grupo A" e "Grupo B".

\subsubsection{Grupo A}

Fazem parte do grupo $A$ os consumidores atendidos pelas redes de alta tensão. A Tabela 5 apresenta as classes pertencentes ao referido grupo e as respectivas faixas de tensão.

As tarifas do "Grupo A" são construídas em duas modalidades de fornecimento: convencional e horo-sazonal. 
Tabela 5 - Classe de Consumidores do Grupo A

\begin{tabular}{|cc|}
\hline Classe & Tensão \\
\hline A1 & $>230 \mathrm{kV}$ \\
A2 & 88 a $138 \mathrm{kV}$ \\
A3 & $69 \mathrm{kV}$ \\
A3A & 30 a $44 \mathrm{kV}$ \\
A4 & 2,3 a $25 \mathrm{kV}$ \\
AS & \\
\hline
\end{tabular}

\subsubsection{Convencional}

Os consumidores atendidos com tensão de fornecimento inferiores a $69 \mathrm{kV}$ e que apresentem demanda inferior a $300 \mathrm{~kW}$ podem optar pela estrutura tarifária convencional. Essa estrutura é caracterizada pela aplicação de tarifas de consumo de energia e demanda de potência independentes das horas de utilização do dia e dos períodos do ano. 


\subsubsection{Tarifa horo-sazonal}

De acordo com a Resolução 456/2000, a tarifa horo-sazonal é caracterizada pela aplicação de tarifas diferenciadas de consumo de energia elétrica e de demanda de potência de acordo com as horas de utilização do dia e dos períodos do ano. As tarifas horo-sazonais podem ser divididas em dois subgrupos: Tarifa Azul e Tarifa Verde.

\subsection{Tarifa azul}

As unidades consumidoras conectadas em tensão inferior a $69 \mathrm{kV}$ e demanda contratada inferior a $300 \mathrm{~kW}$ podem optar pelo enquadramento na Tarifa Azul ou Verde. Já para as unidades com tensão de fornecimento igual ou superior a $69 \mathrm{kV}$ é obrigatório a aplicação da Tarifa Azul.

Para os consumidores enquadrados nessa categoria os períodos do dia são divididos em horário de ponta (P) e fora ponta (FP). De acordo com a Resolução ANEEL 456/2000 o horário de ponta é definido pela concessionária e composto por 3 (três) horas diárias consecutivas, exceção feita aos sábados, domingos e feriados nacionais. Complementarmente, o horário fora de ponta é o período composto pelo conjunto das horas diárias consecutivas e complementares àquelas definidas no horário de ponta.

Quanto à sazonalidade, a resolução mencionada acima classifica o ano em dois períodos: período úmido (U) e seco (S). O período úmido compreende meses de dezembro de um ano a abril do ano seguinte, e o período seco os meses de maio a novembro.

A Tabela 6 sintetiza a estrutura de aplicação da tarifa horo-sazonal azul. 
Tabela 6 - Estrutura da tarifa horo-sazonal azul

\begin{tabular}{|l|c|c|c|c|c|}
\hline \multicolumn{2}{|c|}{ Demanda (R\$/kW) } & \multicolumn{4}{|c|}{ Energia (R\$/MW) } \\
\hline P & FP & PS & P U & FP S & FP U \\
\hline
\end{tabular}

\subsection{Tarifa verde}

Como informado anteriormente, as unidades consumidoras atendidas pelo SIN com tensão de fornecimento inferior a $69 \mathrm{kV}$ e demanda contratada inferior a 300 kW podem optar pela tarifa horo-sazonal, seja na modalidade azul ou verde.

Assim como a tarifa horo-sazonal azul, a tarifa verde é composta por tarifas diferenciadas de consumo de energia elétrica, de acordo com as horas de utilização do dia e dos períodos do ano. Já para a demanda de potência é aplicada uma única tarifa, independente das horas do dia e do período do ano. A Tabela 7 sintetiza a estrutura de aplicação da tarifa horo-sazonal verde.

Tabela 7 - Estrutura da tarifa horo-sazonal verde

\begin{tabular}{|c|c|c|c|c|}
\hline Demanda (R\$/kW) & \multicolumn{4}{|c|}{ Energia (R\$/MW) } \\
\hline Único valor & PS & P U & FP S & FP U \\
\hline
\end{tabular}

\subsubsection{Grupo B}

O grupo B é formado por consumidores atendidos por tensão inferior a 2,3kV. As tarifas deste grupo são monômias e aplicadas apenas para a componente de consumo de energia ( $R \$ / M W$ ). De acordo com a Resolução 456/2000, esses consumidores são classificados nas seguintes classes e sub-classes: 
Tabela 8 - Classe de Consumidores do Grupo B

\begin{tabular}{|cc|}
\hline Classe & Tensão \\
\hline B1 & Residencial \\
B2 & Rural \\
B3 & Outras \\
B4 & Iluminação Pública \\
\hline
\end{tabular}

\subsection{COMPONENTES TARIFÁRIAS}

As tarifas aplicadas aos consumidores de energia conectados às concessionárias de distribuição podem ser dividas em duas grandes componentes: Tarifa de Energia (TE) e a Tarifa de Uso do Sistema de Distribuição (TUSD).

A Tarifa de Energia é o valor unitário aplicado ao consumo mensal da energia adquirida das distribuidoras por consumidores cativos atendidos em alta e em baixa tensão e, ainda, aplicável ao consumo de concessionárias ou permissionárias de distribuição com mercado anual inferior a 500 gigawatts-hora (GWh). De acordo com a Resolução Normativa ANEEL № 166, de 10 de outubro de 2005, a TE é formada por itens como o custo de aquisição de energia elétrica para revenda e os percentuais de perdas na Rede Básica do Sistema Interligado Nacional (SIN).

Já a TUSD, é a tarifa paga por todos os usuários conectados à rede das distribuidoras, entre estes os consumidores residenciais, comerciais e rurais, concessionárias de pequeno porte e geradores. A TUSD é dividida em dez partes - dentre estas as chamadas TUSD - Fio A e TUSD - Fio B. 
A seguir serão detalhados os componentes da TUSD e da TE e suas respectivas formas de aplicação aos consumidores.

\subsubsection{TUSD - Fio A}

A componente TUSD - Fio A engloba os custos correspondentes ao uso de redes de distribuição ou de transmissão de terceiros. Esse item apresenta valores idênticos para todas as faixas de tensão e é formada pelos seguintes parcelas: TUSTRB, TUSTFR, Conexão às Instalações da Rede Básica, Uso da Rede de Distribuição de outras concessionárias e perdas elétricas na Rede Básica causadas pelas perdas técnicas e não técnicas ${ }^{3}$. Todos os itens são calculados através da divisão de seu custo total pelo mercado de referência de demanda do horário da ponta, obtendo-se assim valores em $\mathrm{R} \$ /(\mathrm{kW}$.mês). Vale lembrar que os valores dessas componentes são idênticos para todos os níveis de tensão.

Já o Encargo de Uso das Instalações de Conexão, usualmente denominado Conexão, e o Custo de Uso da rede de Distribuição de outras concessionárias, são aplicados aos postos tarifários ponta e fora ponta, através da divisão de seus custos pelos mercados de referência dos postos citados.

A última parcela que compõem a TUSD - Fio A é a referente às perdas elétricas na Rede Básica causadas pelas perdas técnicas e não técnicas, que são definidas no momento da revisão ou do reajuste tarifário da concessionária de distribuição. Seu custo é definido valorando as perdas regulatórias ao custo médio ponderado de aquisição de energia da concessionária. $O$ valor resultante da operação é dividido pelo mercado de referência de demanda dos horários da ponta e fora da ponta, obtendo-se as respectivas tarifas em $\mathrm{R} \$ / \mathrm{kW}$.

\footnotetext{
${ }^{3} \mathrm{~A}$ soma dos montantes de perdas técnicas e não técnicas, admitidos para fins de repasse tarifário, é denominado de perdas regulatórias.
} 


\subsubsection{TUSD - Fio B}

A componente da tarifa de uso dos sistemas de distribuição, correspondente aos custos não gerenciáveis (Parcela B da Receita Requerida) é denominada TUSD Fio B. Essa componente é determinada por faixa de tensão, com valores aplicáveis às demandas máximas de potência ativa, para os postos tarifários ponta e fora da ponta.

\subsubsection{TUSD - Encargos do Serviço de Distribuição}

A componente da TUSD correspondente ao custo dos encargos vinculados ao serviço de distribuição de energia elétrica é denominada TUSD - Encargos do Serviço de Distribuição. Assim como a TUSD - Fio B, é determinada por faixa de tensão, com valores aplicáveis às demandas máximas de potência ativa, para os postos tarifários ponta e fora da ponta.

A TUSD - Encargos do Serviço de Distribuição é formada pela soma dos seguintes itens: Reserva Global de Reversão (RGR), Taxa de Fiscalização de Serviços de Energia Elétrica (TFSEE), Pesquisa e Desenvolvimento (P\&D) e contribuição para o Operador Nacional do Sistema Elétrico (ONS) .

\subsubsection{TUSD - Perdas Técnicas}

A TUSD - Perdas Técnicas representa o custo vinculado à energia elétrica dissipada entre os suprimentos de energia da distribuidora e os pontos de entrega nas instalações das unidades consumidoras ou distribuidoras supridas. Seu cálculo é realizado de forma similar ao da parcela TUSD - Fio B. 


\subsubsection{TUSD - CCCisolado}

A componente relativa ao custo da Conta de Consumo de Combustíveis dos Sistemas Isolados (CCCisol) é atribuída a todas as concessionárias de distribuição do Sistema Interligado e dos Sistemas Isolados, sendo denominada TUSD - CCCisolado.

Esta parcela corresponde à razão entre o custo total, em $\mathrm{R} \$$, definido no Plano Anual de Combustíveis para os Sistemas Isolados e o mercado total, em MWh, do Sistema Interligado Nacional e dos Sistemas Isolados, incluindo aquele referente aos consumidores livres. Sua aplicação é dada sobre a parcela do consumo mensal, que exceda o atendimento feito por empreendimento próprio de produção independente e/ou de autoprodução, considerando todas as unidades consumidoras dos sistemas interligado e isolados.

\subsubsection{TUSD - CDE $E_{S / S E / C O}$ e TUSD - CDE}

As parcelas TUSD - $C D E_{S / S E / C O}$ e TUSD - $C D E_{N / N E}$ são componentes relativas ao custo da Conta de Desenvolvimento Energético (CDE), que são definidas para as concessionárias de distribuição, conforme a respectiva localização.

Essas componentes são aplicadas sobre a parcela do consumo mensal que exceda 0 atendimento feito por empreendimento próprio de produção independente e/ou de autoprodução da unidade consumidora localizada nas respectivas regiões geoelétricas. 


\subsubsection{TUSD - PROINFA}

A componente relativa ao custo do Programa de Incentivo às Fontes Alternativas de Energia Elétrica - PROINFA é denominada TUSD - PROINFA. Sua forma de cálculo segue os mesmos procedimentos da TUSD - CCCisolado.

\subsubsection{TUSD - Perdas Não Técnicas.}

Refere-se à componente da tarifa de uso dos sistemas de distribuição, correspondente ao custo das perdas não técnicas e é estabelecida em duas subcomponentes, sendo uma em $\mathrm{R} \$ / \mathrm{MWh}$ e outra em $\mathrm{R} \$ / \mathrm{kW}$.

As figuras a seguir ilustram a composição da TUSD, sem os componentes financeiros, aplicável aos consumidores livres conectados ao sistema de distribuição da CEMIG, na classe A2, para o período de abril de 2008 a março de 2009.

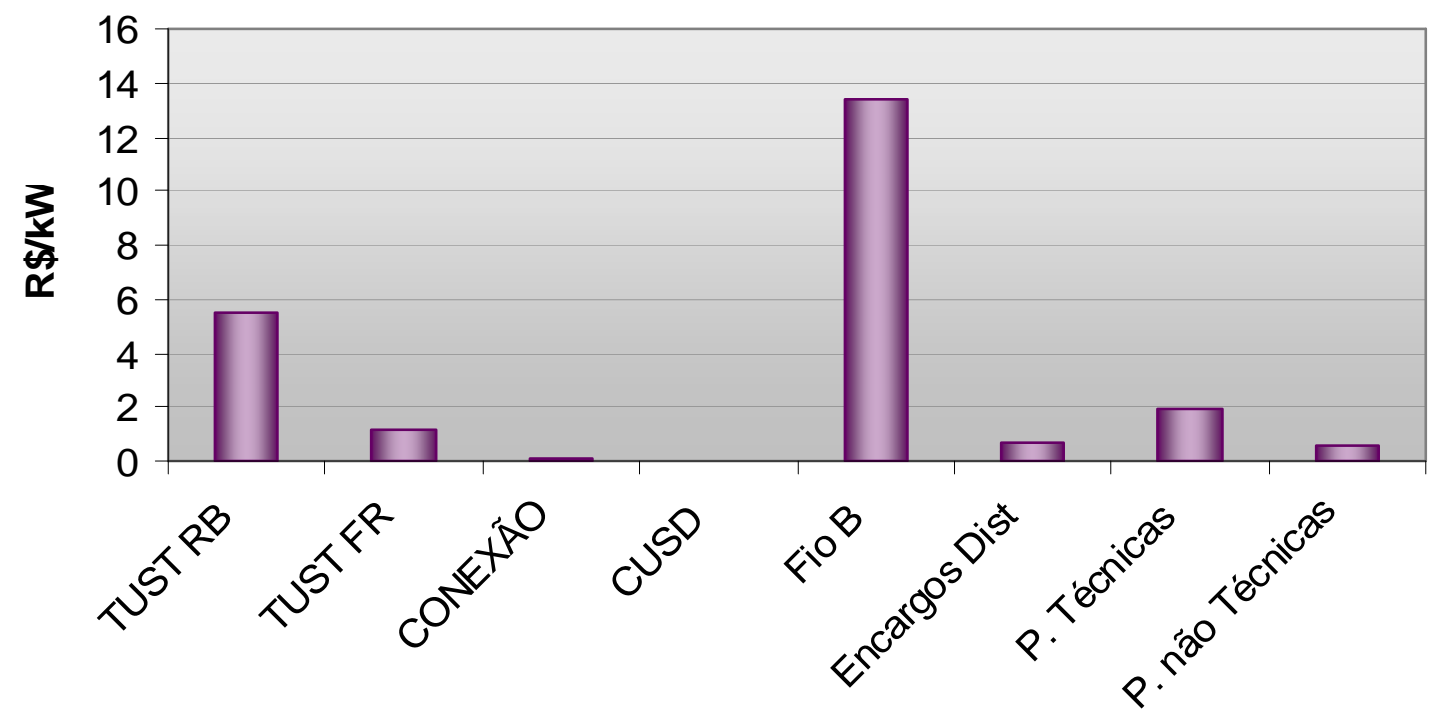

Figura 14 - Composição da TUSD P da classe A2 


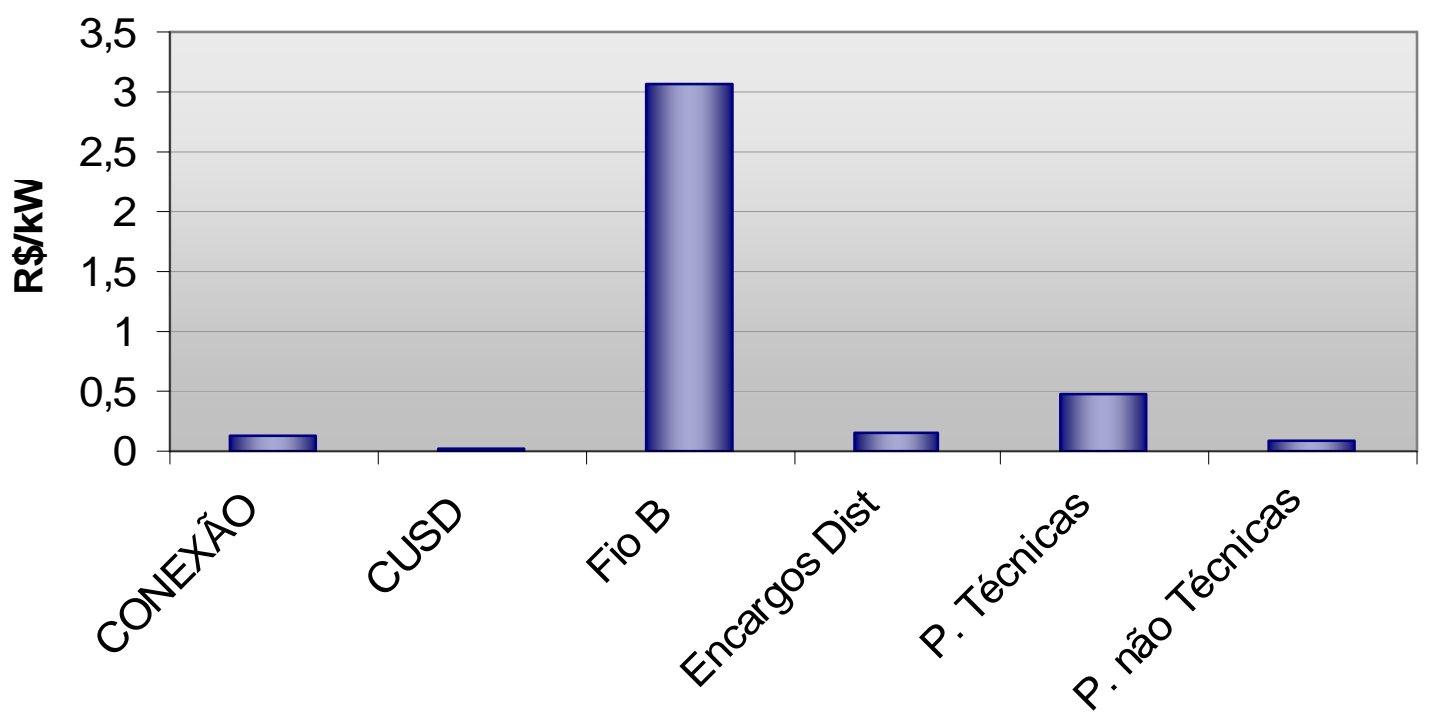

Figura 15 - Composição da TUSD FP da classe A2

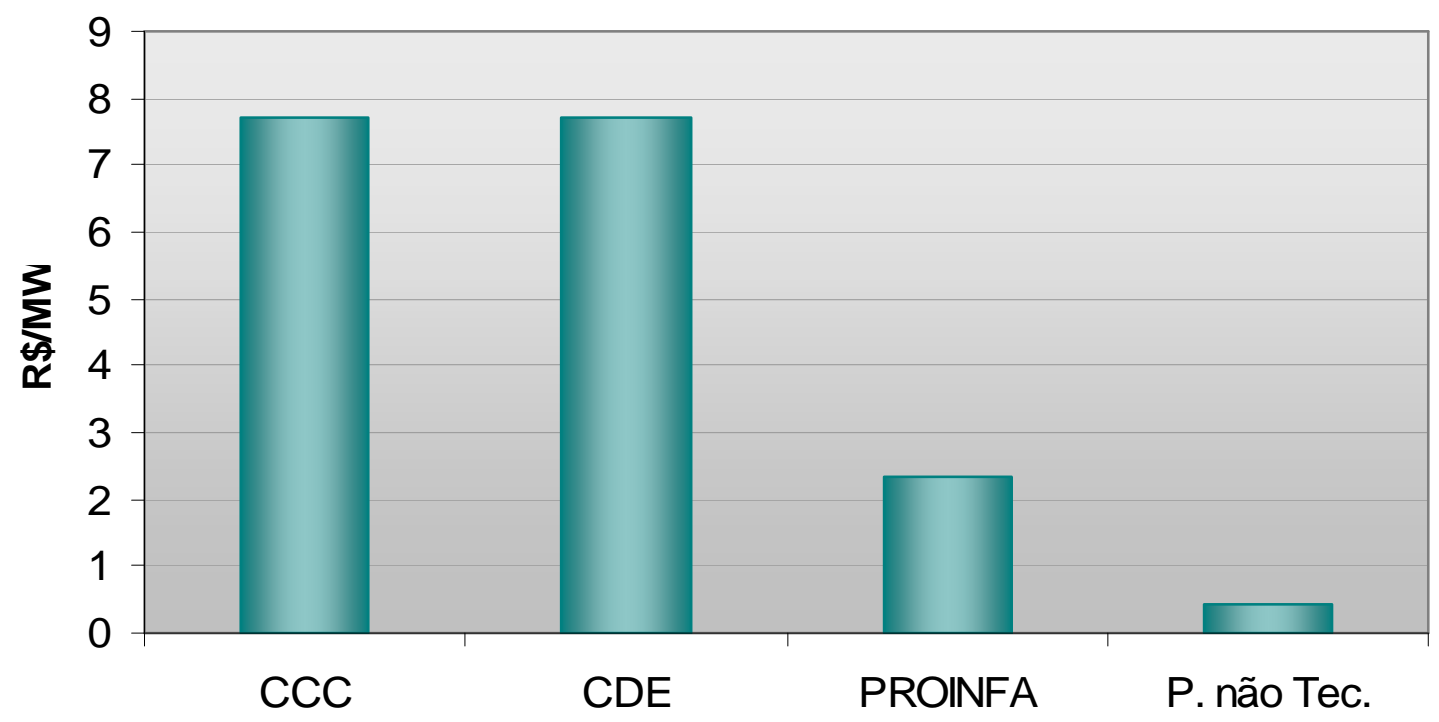

Figura 16 - Composição da TUSD Energia da classe A2 


\subsubsection{TE - Tarifa de Energia}

Como mencionado anteriormente, a Tarifa de Energia (TE) constitui-se a parcela referente aos custos de aquisição de energia para atendimento ao mercado cativo. Os custos incorridos pela concessionária de distribuição para esse fim são os seguintes: custos associados à compra de energia, custos associados à Itaipu, Perdas Elétricas na Rede Básica, Encargos de Serviços do Sistema (ESS), P\&D e Eficiência Energética, e TFSEE ${ }^{4}$.

Os custos associados à compra de energia para revenda são obtidos através da totalização do gasto com energia para atendimento ao mercado cativo e as Perdas de Rede Básica causada por este.

Já os custos associados à Itaipu são referentes à potência disponibilizada da usina, além do custo do Transporte da energia até a fronteira com a Rede Básica, assim como Tarifa de Uso do Sistema de Transmissão (TUST) incorrida pela mesma.

A figura a seguir ilustra a composição da Tarifa de Energia, sem os componentes financeiros, aplicada ao horário fora de ponta do período úmido da concessionária de distribuição CEMIG, para o ano tarifário de abril de 2008 a março de 2009.

\footnotetext{
${ }^{4}$ Dado que os valores a serem arrecadados pela empresa de distribuição referente aos itens P\&D, Eficiência Energética e TFSEE são vinculados à receita da distribuidora, esses custos são alocados tanto na TUSD quanto na TE.
} 


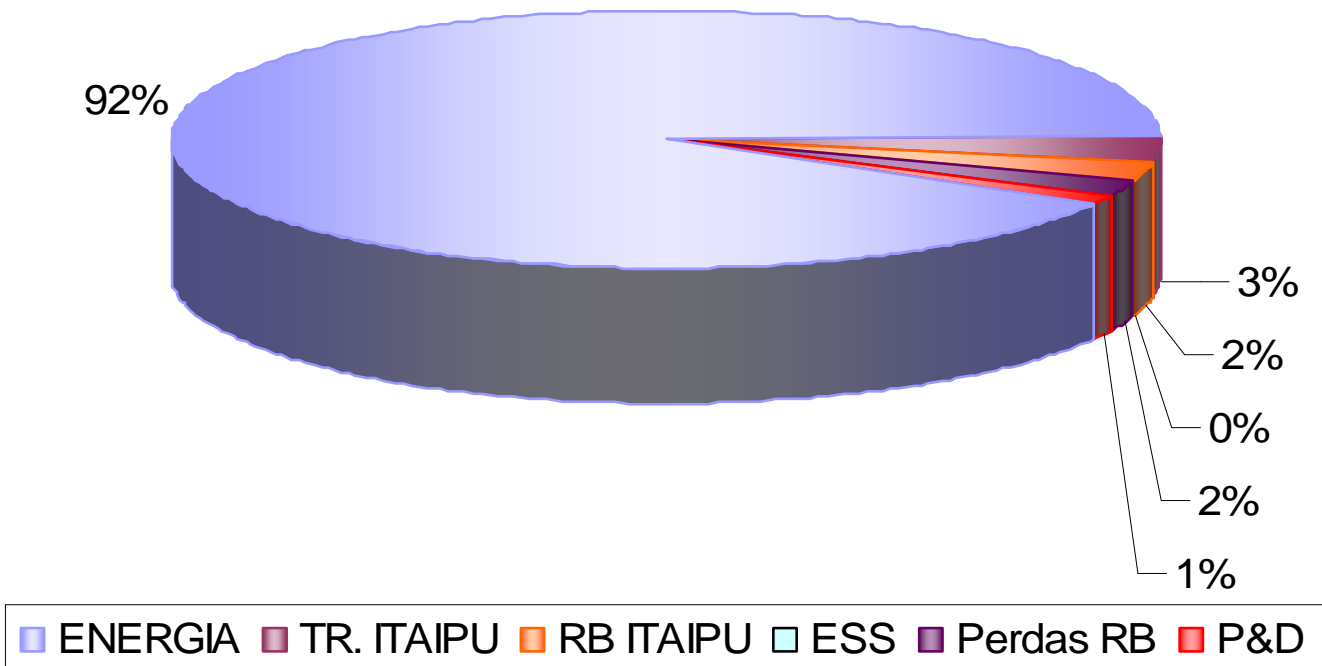

Figura 17 - Composição da TE FP U da CEMIG 


\section{EXPECTATIVA DE EVOLUÇÃO DA TARIFA DE ENERGIA}

Uma opção de contratação de energia de um grande consumidor é por meio da concessionária de distribuição que detém a área de concessão em que o mesmo encontra-se localizado. Assim, este capítulo visa prever a evolução da TE aplicada aos consumidores que adquirem energia através de uma concessionária de distribuição, considerando a previsão do custo dos contratos por disponibilidade, assim como uma expectativa de preço para recontratação da energia existente.

A previsão do custo dos contratos por disponibilidade é justificada pelo aumento de sua participação no portfólio de compra das distribuidoras, tendo em vista que os riscos associados à hidrologia são assumidos pelos consumidores.

Em síntese, para determinar a expectativa de evolução da Tarifa de Energia, fazse necessária uma análise mais focada nas particularidades do portfólio de contratos de cada concessionária. Assim, a concessionária escolhida para 0 estudo de caso foi a CEMIG Distribuição S.A, por apresentar em sua área de concessão um grande número de consumidores eletro intensivos. 


\subsection{METODOLOGIA PARA A PREVISÃO DA TARIFA DE ENERGIA}

\subsubsection{A base de comparação com o mercado livre}

Quando se trata de comparar as condições de preços da energia no mercado cativo e no mercado livre, é importante considerar a definição da TE e a partir daí estabelecer uma base de comparação. Em linhas gerais, sabe-se que qualquer consumidor, além dos encargos setoriais, está sujeito ao pagamento pelo uso das redes da distribuidora, independentemente de ser atendido no Ambiente de Contratação Regulada (ACR) ou no Ambiente de Contratação Livre (ACL). Assim, em tese, a diferença deve dar-se essencialmente no preço da energia adquirida nos dois ambientes.

No entanto, na prática existem outras diferenças em função da forma de cobrança ou do critério de tarifação. Um exemplo é o Encargo de Serviço do Sistema (ESS), que no caso de um cliente livre, o pagamento é realizado mensalmente no momento da liquidação na CCEE. Para um cliente cativo a cobrança por meio da tarifa inclui: (i) uma expectativa do custo econômico do ESS no período futuro; (ii) o custo do período passado não coberto pelas tarifas; e (iii) uma remuneração adicional à distribuidora pelas despesas de períodos passados pagas na CCEE sem a devida cobertura tarifária. Ou seja, este mecanismo equivale a um empréstimo que o consumidor cativo faz anualmente junto à concessionária de distribuição à taxa SELIC 5 .

Deve-se mencionar também que no ACR a estrutura tarifária reflete tarifas diferenciadas nos períodos seco e úmido, como também, nos horários de ponta e

\footnotetext{
${ }^{5}$ O ESS é uma das despesas da distribuidora sujeita ao mecanismo da Conta de Compensação de Valores da Parcela A - CVA, cujo índice de remuneração é a taxa SELIC.
} 
fora ponta para aqueles classificados nas Tarifas Verde ou Azul. Para se comparar ao ACL, seria o equivalente a firmar um contrato com preços diferentes conforme o horário ou data do consumo, o que geralmente não é uma prática do Mercado Livre.

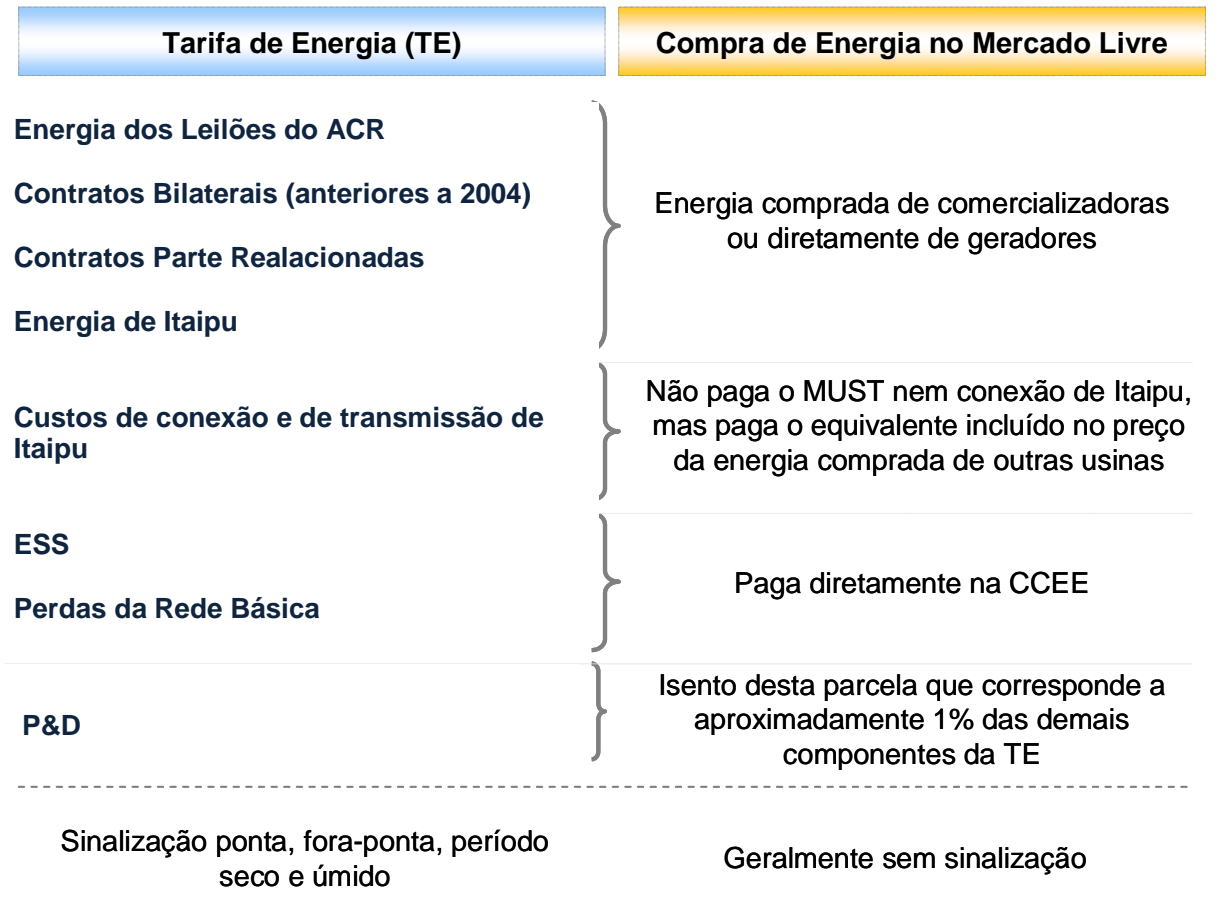

Figura 18 - Comparativo entre a estrutura da TE e o equivalente no ACL

Portanto, uma comparação mais precisa deve ser feita por consumidor em termos de custo da energia e não exatamente em termos de tarifas. Ou seja, é necessário avaliar o perfil de consumo, destacando o quanto se consome no período seco e úmido e também nos horários de ponta e fora ponta.

A figura acima mostra que exceto uma parcela do P\&D, as demais despesas incluídas na TE do consumidor cativo tem um equivalente na conta da energia paga pelo consumidor livre. 
A expectativa da TE futura requer uma previsão de todos seus itens formadores. Para cada item deve-se adotar um método para estimar o comportamento futuro dos valores, exceto para o ESS, que pode ser excluído da análise porque em ambos ambientes de contratação o Encargo estará presente e irá representar um mesmo montante a ser adicionado em cada caso de opção do consumidor.

Finalmente, no que diz respeito à base de comparação, é importante acrescentar o percentual de aumento referente à Recomposição Tarifária Extraordinária (RTE). Assim, a TE projetada deve ser acrescida do percentual de 7,9\% para os grandes consumidores, quando no mercado cativo, respeitados os prazos de duração deste adicional. Ainda a respeito da RTE, também deve-se considerar seu efeito quando aplicado às Tarifas de Uso do Sistema de Distribuição (TUSD), uma vez que os consumidores livres não estão sujeitos a essa cobrança. A expectativa de duração da $\mathrm{RTE}^{6}$ foi considerada conforme a tabela abaixo.

Tabela 9 - Estimativa de duração da RTE

\begin{tabular}{|cc|}
\hline Distribuidora & Prazo Final \\
\hline CEMIG & AGO/2010 \\
\hline
\end{tabular}

\footnotetext{
${ }^{6} \mathrm{O}$ adicional de 7,9\% não se refere exatamente à RTE que é a conta do racionamento de 2001. Na realidade, o prazo da RTE já se encerrou para a CEMIG, porém existiu uma negociação sobre o repasse de alguns itens da Parcela A no escopo do Acordo Geral do Setor Elétrico. Dessa forma, para a recuperação desta Parcela as distribuidoras estão autorizadas a aplicar os percentuais idênticos ao da RTE até que toda a receita seja recuperada
} 


\subsubsection{Previsão da energia contratada}

A primeira etapa da metodologia consiste em estabelecer qual a participação de cada contrato da distribuidora nos anos futuros. Para isso também deve ser realizada a previsão do mercado a ser atendido. Com relação a este tema, devese considerar valores que levam em conta a realidade da área de concessão da distribuidora.

Assim, entende-se por considerar as projeções apresentadas pela distribuidora à ANEEL em sua segunda revisão tarifária, que contempla o horizonte de 2008 a 2012. Para o período posterior, foi adotada uma leve redução nas trajetórias de crescimento. A tabela seguinte apresenta as taxas de crescimento do mercado utilizadas.

Tabela 10 - Taxas de crescimento de mercado

\begin{tabular}{|c|c|c|}
\hline Distribuidora & \multicolumn{2}{|c|}{ Período } \\
\cline { 2 - 3 } & $\mathbf{2 0 0 8 - \mathbf { 2 0 1 2 }}$ & $\mathbf{2 0 1 3 - \mathbf { 2 0 1 7 }}$ \\
\hline CEMIG & $3,20 \%$ & $3,00 \%$ \\
\hline
\end{tabular}

Considerando o portfólio atual de contratos, quando comparado ao mercado a ser atendido, constatam-se períodos de sobra e de déficit de contratação. Quando identificadas sobras que ultrapassam $103 \%$ de seu mercado, as despesas correspondentes devem ser excluídas. Ou seja, a energia contratada em excesso é valorada ao preço médio dos contratos regulados da distribuidora e o valor resultante deduzido das despesas referentes à compra de energia. Com respeito ao montante que está entre $100 \%$ e 103\%, deve-se considerar como receita o montante de energia a ser liquidado no Mercado de Curto Prazo.

Para os períodos onde há déficit, foram considerados dois aspectos: 
- Que a distribuidora irá participar dos próximos leilões de energia a fim de cumprir a obrigação de apresentar contratos para cem por cento de seu mercado; e

- Uma estimativa de preço para os montantes que ainda serão contratados, a partir de um dado cenário de oferta no futuro.

\subsubsection{Previsão do preço de recontratação}

A combinação dos atuais contratos com os preços considerados no cenário de contratações futuras determinará a tendência da Tarifa de Energia do consumidor cativo. Neste aspecto cabem algumas observações adicionais:

- Parte dos contratos decorrentes do $1^{\circ}$ Leilão de Empreendimentos Existentes se encerra ao final de 2012, e outra parcela representativa termina em dezembro de 2013. Desse modo, a partir de 2013 existirá um contexto importante de recontratação da "Energia Velha".

- A Energia oriunda das usinas do Rio Madeira começará a atender o mercado a partir de 2012, contribuindo em janeiro de 2014 com aproximadamente 2.000 MW médios de garantia física adicional no Sistema Interligado. A partir de janeiro de 2016 as duas usinas - Jirau e Santo Antônio - deverão adicionar mais de 4.000 MW médios ao cenário de oferta.

Diante das observações, espera-se que o cenário de oferta a partir de 2013 seja favorável. Assim, o caso apresentado considera que a "Energia Velha" apresentará 0 mesmo custo do $5^{\circ}$ Leilão de Energia Existente, cerca de $\mathrm{R} \$$ 92,00/MWh, e seu montante será de $70 \%$ daquele contratado anteriormente. 
Já o período de 2009 a 2011, reflete um cenário mais crítico de oferta de energia, onde os preços utilizados sinalizam tal situação. Os valores para a contratação desse período consideram o sinal do Custo Marginal de Operação (CMO) médio obtido através de análises críticas do Plano Decenal de Expansão de Energia (PDEE) 2008/2017, limitado aos valores do Preço de Liquidação das Diferenças (PLD) mínimo e máximo, que será denominado PLD para fins desse estudo. Os cenários de PLD serão detalhados à frente.

Deve-se considerar ainda que ocorrerão outros leilões de energia nova, e para isso, supõe-se que a energia negociada será $35 \%$ proveniente de usinas hidrelétricas com um custo de $R \$ 75,00 / \mathrm{MWh}$ e o restante de termelétricas a $R \$$ 150,00/MWh.

A figura a seguir ilustra o portfólio de contratos da CEMIG para o horizonte de 2008 a 2017.

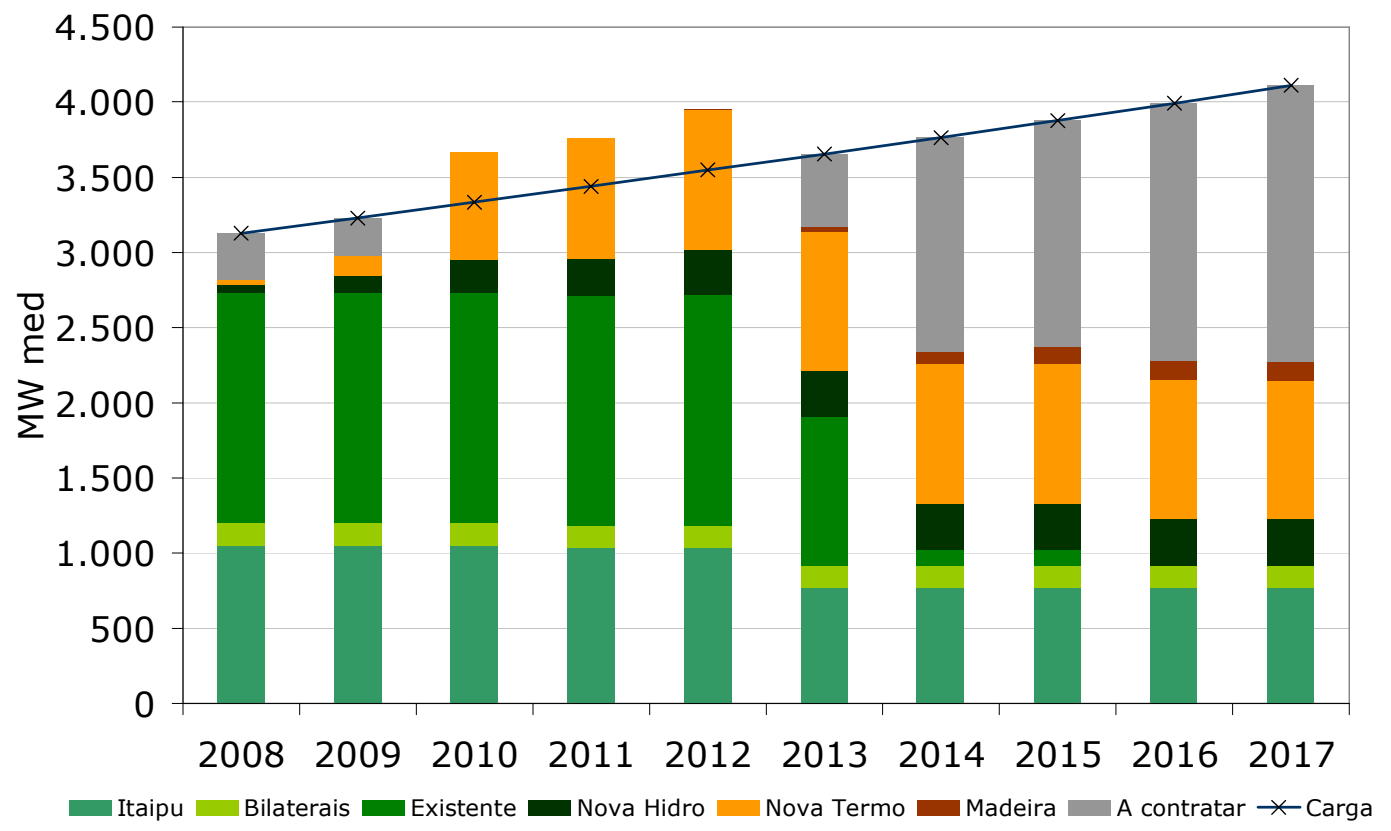

Figura 19 - Portfólio de Contratos CEMIG 


\subsubsection{O preço dos Contratos}

Com exceção aos contratos por disponibilidade, as informações sobre preço dos contratos vigentes são trazidas a valores presentes até a data da última revisão ou reajuste tarifário. Desse modo, foram adotados os seguintes critérios para considerar as despesas com compra de energia:

Tabela 11 - Critério de atualização de preços por tipo de contrato

\begin{tabular}{|c|c|}
\hline Tipo do Contrato & Critério \\
\hline Contratos Bilaterais anteriores a 2004 & Atualização do valor pelo IGP-M. \\
Energia de Itaipu & $\begin{array}{c}\text { Para o primeiro ano tarifário } \\
\text { considera-se o valor estipulado pela } \\
\text { Aneel e após isso a conversão de } \\
\text { sua tarifa pela taxa de câmbio de R\$ } \\
2,20 \text { por US\$. }\end{array}$ \\
\hline $\begin{array}{c}\text { Contratos por Quantidade dos Leilões de } \\
\text { Energia Nova }\end{array}$ & Atualização do valor pelo IPCA. \\
\hline $\begin{array}{c}\text { Contratos por Disponibilidade dos Leilões } \\
\text { de Energia Nova }\end{array}$ & Valores recalculados. \\
\hline
\end{tabular}

A seção a seguir aborda a metodologia empenhada para determinar os preços dos contratos por disponibilidade, oriundos dos leilões de Energia Nova, que serão considerados para projeção dos valores da Tarifa de Energia.

No Anexo 1 encontram-se os montantes e preços considerados para projeção da Tarifa de Energia.

\subsubsection{O preço dos Contratos por Disponibilidade}

Atualmente, o preço dos contratos por disponibilidade tem sido considerado nos processos tarifários como o valor do Índice de Custo Benefício $(\mathrm{ICB})^{7}$ estabelecido nos leilões de venda do ACR. Contudo sabe-se que o ICB, utilizado nos leilões, representa apenas uma estimativa do custo desses contratos para os

\footnotetext{
${ }^{7}$ O Índice de Custo Benefício é calculado no momento do leilão de energia nova e traz consigo a expectativa do custo de longo prazo do contrato por disponibilidade.
} 
consumidores, pois é calculado com base em previsões feitas quando da realização dos leilões.

Contudo, para determinar o custo previsto para esses contratos é necessário considerar um cenário para o PLD. Sabe-se que tal cenário é fortemente influenciado pelo mercado previsto e pelas condições de oferta no SIN, as quais sofreram mudanças significativas neste período. Portanto, para estabelecer um preço para os contratos de disponibilidade, deve-se realizar uma nova previsão de PLD e geração térmica a partir de premissas mais atuais.

Tendo em vista a formação do preço dos contratos por disponibilidade, a estimativa de seu custo deve considerar as seguintes etapas:

\subsubsection{Cálculo do despacho térmico}

A partir dos dados oficiais do PMO de novembro de 2008 foi simulado o despacho hidrotérmico para o período de novembro de 2008 a dezembro de 2012, utilizando o modelo Newave. Com isso foram quantificados os montantes que seriam produzidos em cada uma das térmicas contratadas no horizonte do estudo.

A mesma simulação fornece também a série de PLD mensal, sendo que os valores utilizados correspondem à média das 2.000 séries de cenários hidrológicos. 


\subsubsection{Identificação dos montantes despachados acima da inflexibilidade}

Os montantes despachados acima da inflexibilidade declarada não têm custos de geração cobertos pela receita fixa da usina. Assim, faz-se necessário calcular o custo da geração com base no Custo Variável Unitário (CVU), que representa essencialmente 0 custo do combustível e outras despesas operacionais necessárias para se produzir um MWh. Portanto, a parcela relativa ao COP foi apurada como o produto entre a geração acima da inflexibilidade e o CVU da usina.

\subsubsection{Identificação do Custo Econômico de Curto Prazo}

Considerando os valores de despacho em cada usina, é possível apurar a diferença entre a energia vendida em contratos de disponibilidade e a geração mensal indicada na simulação do Newave. Sobre o resultado aplica-se o valor do PLD, obtendo-se assim a receita correspondente ao CEC.

\subsubsection{Conversão da Receita em preço}

A receita fixa de cada empreendimento deve ser somada aos valores mensais apurados para COP e CEC obtendo-se assim uma receita mensal para cada usina. Este valor dividido pelo montante vendido resulta em referencial de preço mais atualizado. 


\subsubsection{Correlação Custo do Contrato por Disponibilidade com o PLD}

A simulação permite calcular o custo mensal dos vários contratos por disponibilidade, para o horizonte de 5 anos, em função do despacho previsto para cada usina, dada a configuração estabelecida anteriormente. Os resultados podem ser agregados de forma que o custo mensal de todas as usinas de um mesmo produto seja somado, formando uma seqüência de custos por produto oferecido no Leilão. Para ilustrar a ordem de grandeza, cada uma dessas séries mensais pode ser representada por um custo médio anual por produto conforme a tabela seguinte.

Tabela 12 - Custo Médio Anual recalculado a partir do PMO de Nov/2008

\begin{tabular}{|c|c|c|c|c|c|c|}
\hline Leilão & Produto & 2008 & 2009 & 2010 & 2011 & 2012 \\
\hline 1 & $2008-15$ & 115,85 & 175,49 & 205,58 & 242,61 & 260,99 \\
\hline 1 & $2009-15$ & & 185,01 & 208,99 & 243,00 & 261,61 \\
\hline 1 & $2010-15$ & & & 132,58 & 147,88 & 150,41 \\
\hline 2 & $2009-15$ & & 202,87 & 232,79 & 290,48 & 317,45 \\
\hline 3 & $2011-15$ & & & & 259,85 & 276,64 \\
\hline 4 & $2010-15$ & & & 245,46 & 299,30 & 326,66 \\
\hline 5 & $2012-15$ & & & & & 265,36 \\
\hline
\end{tabular}

Entretanto, os valores obtidos representam apenas um único cenário e não incluem as novas usinas que devem alterar as condições de oferta a partir dos próximos leilões. Portanto, considerar os valores apresentados na tabela acima, para fins de repasse do custo das térmicas é equivalente a trabalhar com um cenário bastante pessimista.

Para contornar este cenário pouco provável, as séries mensais de custos por produto do Leilão foram utilizadas para construção de correlações entre o PLD e o valor do custo previsto. Em tese, a relação entre eles é conhecida e pode até mesmo ser intuída. Ou seja, se existe oferta bastante superior ao mercado, então as térmicas mais caras terão maior probabilidade de permanecerem desligadas, 0 que reduziria o PLD e também o custo do contrato por disponibilidade. 
O inverso também pode ser utilizado como exemplo, quando o cenário de oferta é muito insatisfatório, as termelétricas terão maior probabilidade de serem despachadas e o PLD provavelmente será maior.

Considerando a correlação entre as séries de PLD e as séries de custo dos contratos, é possível obter as equações que definem o valor do custo por produto para qualquer cenário de PLD. A figura a seguir ilustra a correção obtida para o produto com entrega a partir de 2008 do 1ํ Leilão de Energia Nova.

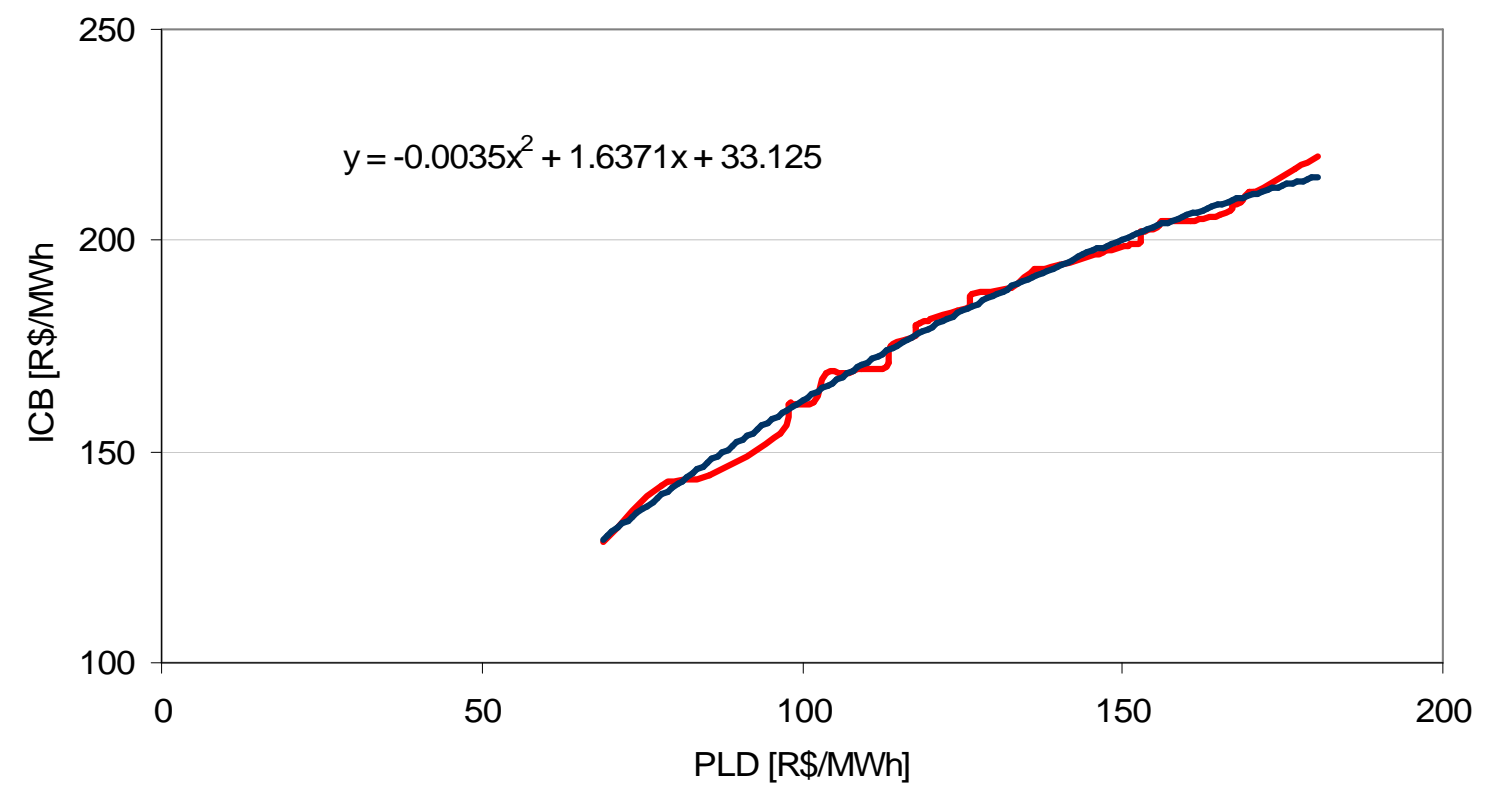

Figura 20 - Correlação do Produto com entrega em 2008 do $1^{\circ}$ LEN

O Anexo 2 traz as características das usinas térmicas vencedoras dos Leilões de Energia Nova.

\subsubsection{Cenários Considerados}

Os cenários referentes ao crescimento do mercado da distribuidora e à contratação futura de energia foram apresentados anteriormente. No entanto, como o preço dos contratos por disponibilidade é variável, faz-se necessário estabelecer alguns cenários sobre o impacto das usinas termelétricas no preço médio de compra de energia da concessionária de distribuição. 
Assim, foram considerados quatro cenários de preços tomando como base a análise crítica do Plano Decenal de Expansão de Energia (PDE) 2008/2017. A partir da definição do "Cenário 1" foram realizadas duas suposições a respeito do Leilão de Energia de Reserva (LER) proveniente de fonte eólica, cuja previsão de realização é novembro/2009, gerando assim os Cenários 2 e 3.

O Cenário 4 diferencia-se do Cenário 1 apenas pela projeção de carga utilizada e pela não utilização dos resultados do LER de fonte de biomassa, ocorrido em agosto de 2008, cujas usinas vencedoras totalizam potência instalada de 2.379 MW a energia assegurada em torno de 1 mil MWmed, posta a atual restrição de crédito afeta ao setor sucroalcooleiro.

Para definição do Cenário 1, a primeira análise crítica foi realizada na Carga de Energia Elétrica do SIN, tendo em vista que no momento em que a proposta do PDE 2008/2017 foi apresentada à sociedade, as projeções não levavam em consideração os efeitos da crise econômico-financeira deflagrada em meados de 2008.

Tomando como base as informações disponíveis na mídia especializada é possível inferir sobre a perspectiva de crescimento econômico do país e consequentemente da carga a ser atendida pelo Sistema Interligado Nacional. A tabela a seguir traz a comparação entre os crescimentos previstos pela EPE e os utilizados para construção do Cenário 1 e 4.

Tabela 13 - Taxas de crescimento anual da Carga do SIN

\begin{tabular}{|c|c|c|c|}
\hline Período & PDE & Cenário 1 & Cenário 4 \\
\hline 2009 & $5,4 \%$ & 0 & 0 \\
\hline 2010 & $5,4 \%$ & $3,5 \%$ & $6,5 \%$ \\
\hline $2011-2012$ & $5,4 \%$ & $4,5 \%$ & $5,4 \%$ \\
\hline $2013-2017$ & 4,7 & $4,5 \%$ & $4,7 \%$ \\
\hline
\end{tabular}

Já do ponto de vista da oferta, foram realizadas análises pontuais quanto à data de entrada em operação das principais obras de expansão que ainda não foram 
licitadas e apresentam o status de indicativas, conforme Tabela 13. Também foi considerada uma taxa de desistência de $15 \%$ para os empreendimentos termelétricos vencedores dos Leilões de Energia Nova que utilizam óleo combustível e diesel.

Tabela 14 - Alterações da data de entrada em operação

\begin{tabular}{|c|c|c|c|}
\hline Empreendimento & $\begin{array}{c}\text { Potência } \\
\text { (MW) }\end{array}$ & PDE & Cenário 1 \\
\hline UHE Marabá & 2.100 & Jan/2016 & Nov/2017 \\
\hline UHE Serra Quebrada & 1.328 & Jan/2017 & Nov/2017 \\
\hline UHE Torixoréu & 408 & Mar/2017 & Nov/2017 \\
\hline UHE Teles Pires & 1.820 & Jan/2016 & Nov/2017 \\
\hline UHE São Luiz dos Tapajós & 6.042 & Jan/2016 & Nov/2017 \\
\hline UHE Belo Monte & 11.000 & Out/2015 & Nov/2017 \\
\hline UTE Angra 3 & 1.350 & Jun/2014 & Jun/2016 \\
\hline
\end{tabular}

A partir das premissas descritas acima, o modelo NEWAVE foi executado considerando as séries históricas de afluência, e os Custos Marginais de Operação (CMO) resultantes foram limitados aos valores vigentes de Preço de Liquidação das Diferenças mínimo e máximo. A figura a seguir ilustra os valores médios obtidos para o subsistema Sudeste/Centro-Oeste.

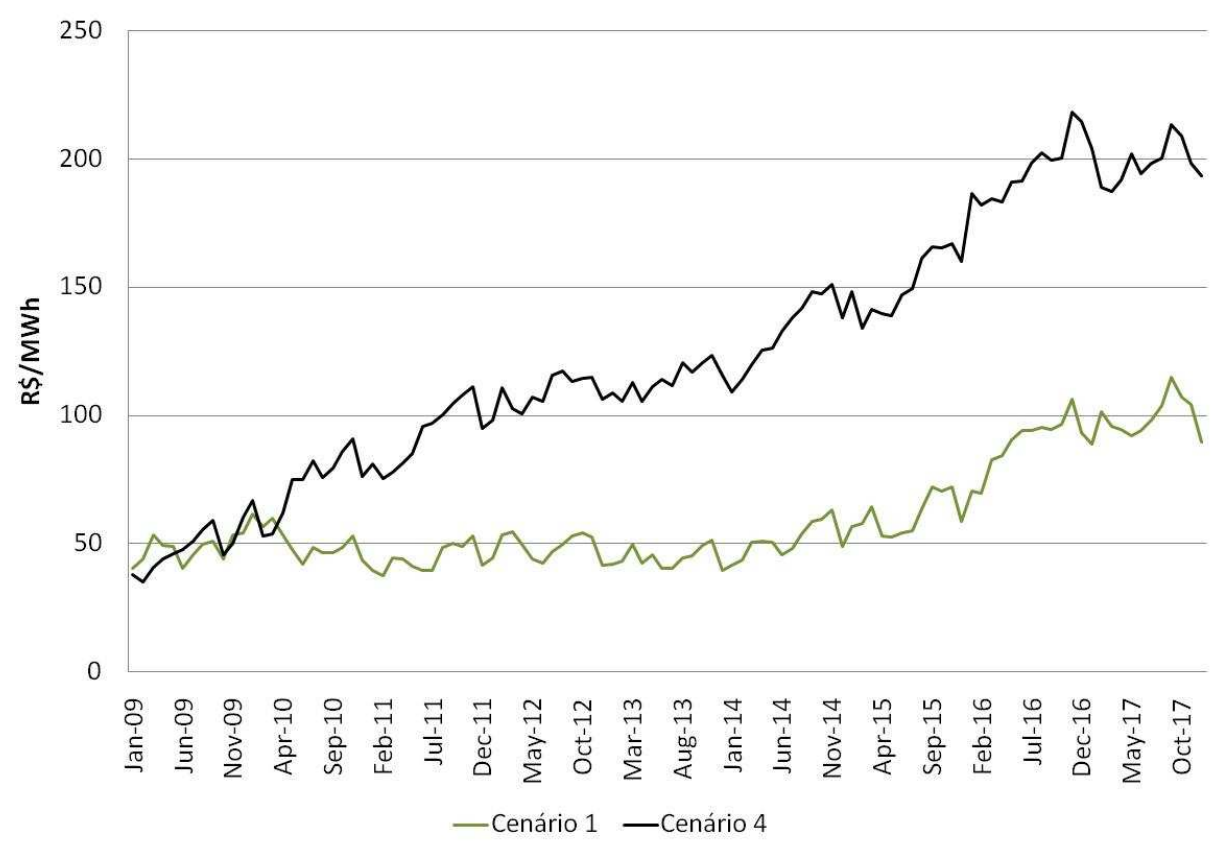

Figura 21 - PLD médio SE/CO para os Cenários 1 e 4 
A partir dos resultados apresentados, pode-se concluir que, embora realizados ajustes na oferta, a redução da carga trouxe alívio ao sistema, culminando na expectativa de preços baixos para o horizonte de estudo, principalmente entre 2009 e 2014. Após esse período, o atraso realizado na oferta causa elevação nos patamares de preço, porém esses ainda podem ser considerados baixos para 0 Cenário 1.

Como mencionado anteriormente, a partir da definição do Cenário 1 são criados outros dois cenários a fim de verificar o impacto dos Leilões de Energia Eólica nos custos dos contratos por disponibilidade, e, por consequência, na Tarifa de Energia. A tabela a seguir traz os acréscimos anuais de potência considerados no subsistema Nordeste para construção dos Cenários 2 e 3.

Tabela 15 - Acréscimos Anuais de Potência Eólica

\begin{tabular}{|c|c|c|}
\hline Ano & Cenário 2 & Cenário 3 \\
\hline 2012 & $300 \mathrm{MW}$ & $700 \mathrm{MW}$ \\
\hline 2013 & $300 \mathrm{MW}$ & $700 \mathrm{MW}$ \\
\hline 2014 & $400 \mathrm{MW}$ & $900 \mathrm{MW}$ \\
\hline Total & $1.000 \mathrm{MW}$ & $2.500 \mathrm{MW}$ \\
\hline
\end{tabular}

Dado que o perfil de geração das usinas eólicas localizadas na região Nordeste apresenta caráter complementar ao regime hidrológico, adotou-se o seguinte perfil de disponibilidade para as usinas utilizadas nos Cenários 2 e 3.

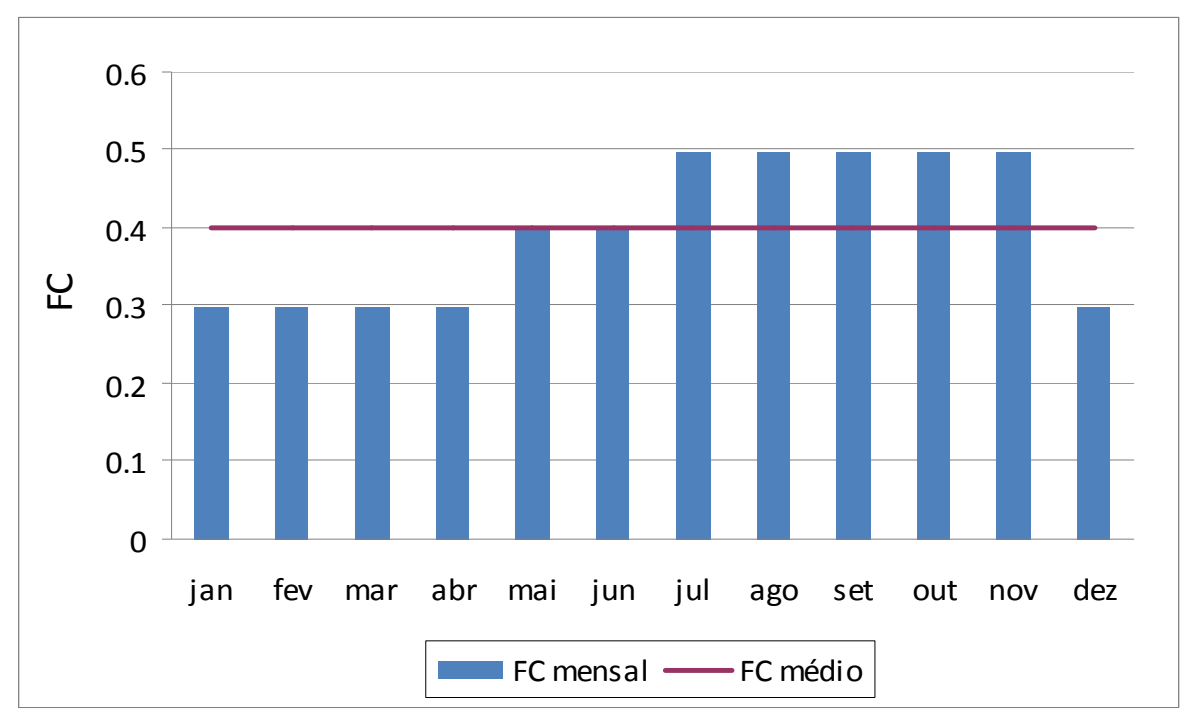

Figura 22 - Fator de Capacidade adotado para as usinas eólicas 
Embora seja possível definir um perfil de geração para as usinas eólicas ao longo do ano, sabe-se que a geração real dessas não apresenta valores fixos, dada a natureza da fonte. Para conferir caráter variável à produção de energia das usinas eólicas, optou-se por modelá-las como usinas termelétricas que apresentam Custo Variável Unitário (CVU) relativamente baixo, que foi definido em $\mathrm{R} \$ 50$ por MWh. Os resultados obtidos para os Cenários 2 e 3 são apresentados na Figura 22.

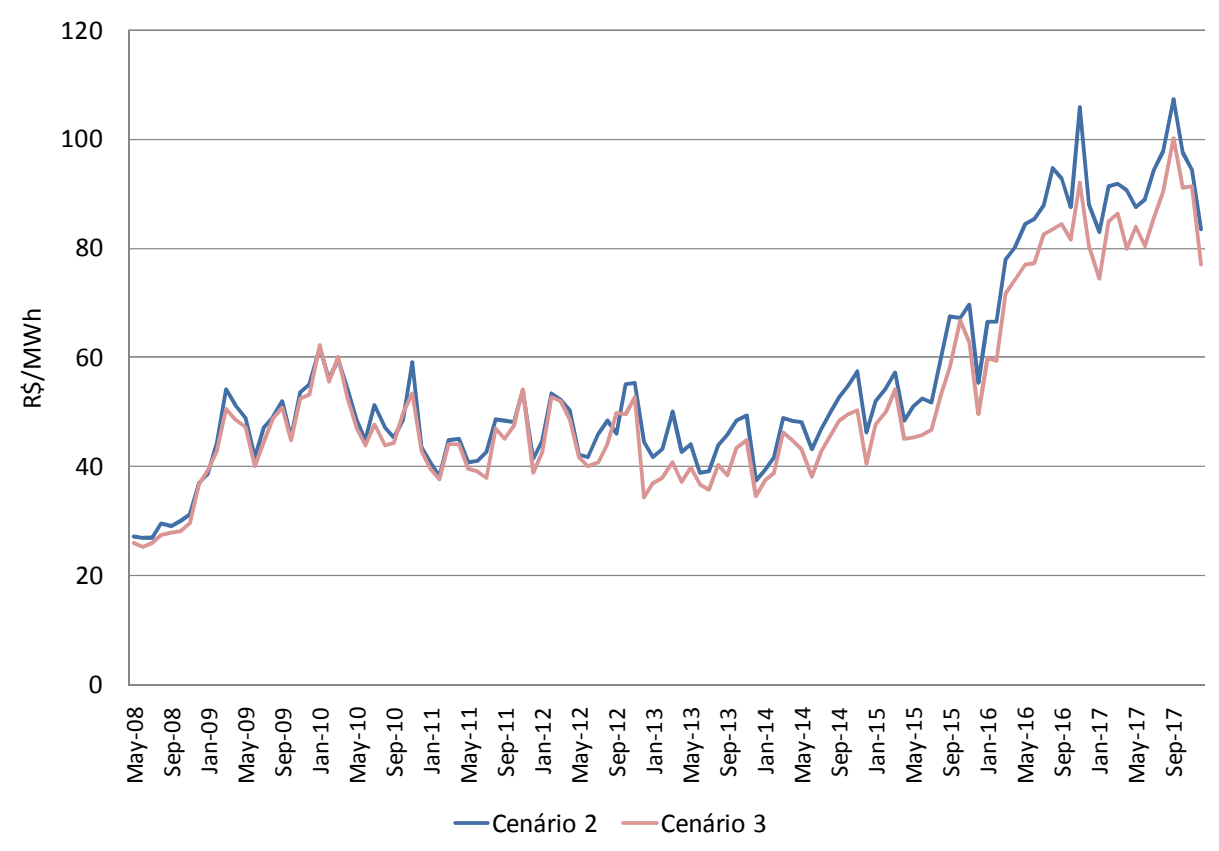

Figura 23 - PLD médio SE/CO para os Cenários 2 e 3

Como esperado, a inserção de usinas eólicas reduz consideravelmente a previsão de PLD, principalmente a partir de 2012, data em que essas iniciam sua operação, o que deve refletir para a redução do custo dos contratos por disponibilidade.

A aplicação das correlações definidas aos cenários de PLD produz os cenários de preços dos contratos por disponibilidade que serão utilizados para projeção da TE. A Figura 24 traz os custos previstos do contrato por disponibilidade com início de suprimento em 2009, referentes ao 1ํ LEN. 


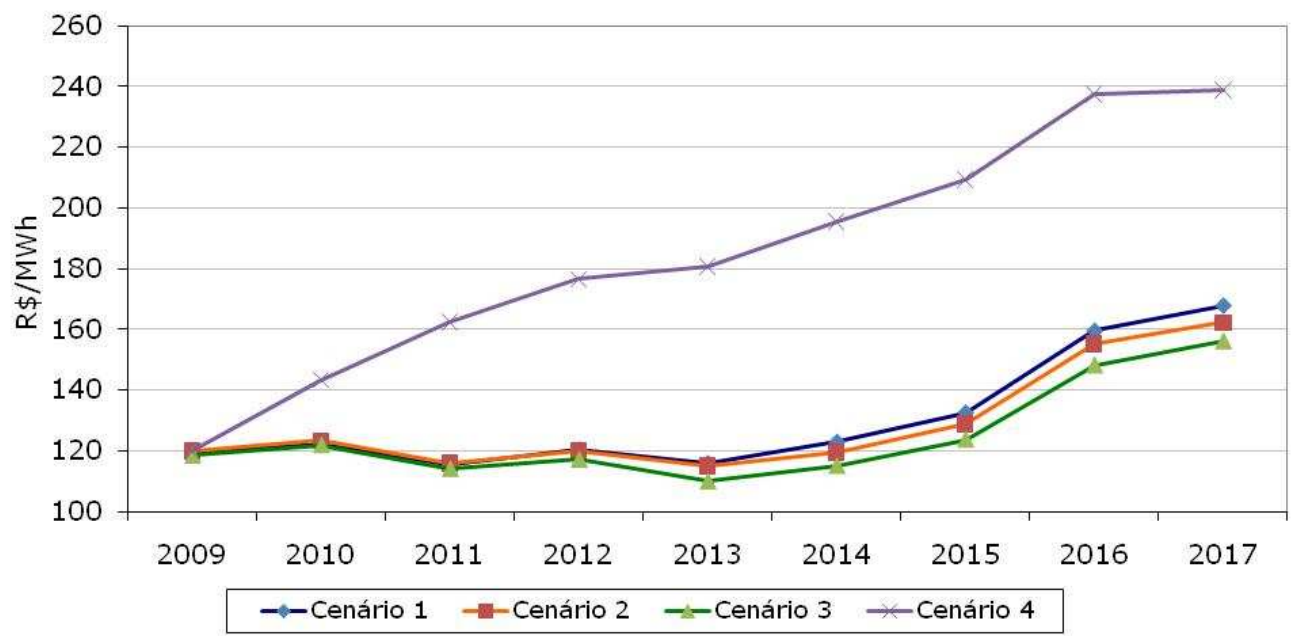

Figura 24 - Custo Esperado do Produto com entrega em 2009 do 1 LEN

\subsection{RESULTADOS DA TARIFA DE ENERGIA}

Para definir-se a Tarifa de Energia que permita a comparação com os preços praticados no $\mathrm{ACL}$, há necessidade de considerar as características do consumidor. Assim, foram considerados dois perfis de consumo, levando em conta que ambos estão conectados ao nível de 138 kV e consequentemente são enquadrados na tarifação azul. A tabela abaixo contém as informações a respeito dos perfis de consumo utilizados para projeção da TE.

Tabela 16 - Perfis de Consumo Adotados

\begin{tabular}{|c|c|c|c|}
\hline Perfis & $\begin{array}{c}\text { Demanda } \\
\text { Ponta }\end{array}$ & $\begin{array}{c}\text { Demanda } \\
\text { Fora de Ponta }\end{array}$ & $\begin{array}{c}\text { Fator de } \\
\text { Carga }\end{array}$ \\
\hline Consumidor 1 & $100 \mathrm{MW}$ & $100 \mathrm{MW}$ & $95 \%$ \\
\hline Consumidor 2 & $30 \mathrm{MW}$ & $100 \mathrm{MW}$ & $95 \%$ \\
\hline
\end{tabular}

Além das premissas já abordadas anteriormente, deve-se quantificar as outras componentes da Tarifa de Energia. Assim, adotou-se o que segue: 
- Transporte e conexão de Itaipu: Com base nos valores históricos evidenciados por essa componente, adotou-se o valor fixo constante da revisão tarifária de 2008, que, por exemplo, representa um acréscimo de $\mathrm{R} \$$ 9,1 por MWh no horário de ponta do período seco.

- Perdas na Rede Básica: As perdas na Rede Básica são calculadas pela Câmara de Comercialização de Energia Elétrica (CCEE) e definidas como percentual aplicado sobre o consumo verificado. Assim, definiu-se o valor de $2,24 \%$ a ser acrescido ao custo de compra de energia.

- P\&D: Por meio da análise dos valores evidenciados por essa componente, assumiu-se o valor de $1,21 \%$ a ser acrescido ao custo de compra de energia.

- Componentes Financeiros: Pode-se considerar que os Subsídios aos Irrigantes e aos consumidores baixa renda, descontos cedidos na TUSD aos consumidores e geradores que comercializam fontes incentivadas e 0 Programa Luz para Todos são os principais componentes financeiros aplicáveis à Tarifa de Energia. Logo, através da análise histórica dos valores, considera-se que seus impactos são de $4,2 \%$ no custo de compra de energia.

A figura a seguir ilustra a composição da Tarifa de Energia projetada para período de abril de 2011 a março de 2012, considerando o Cenário 1 para o Consumidor 1. 


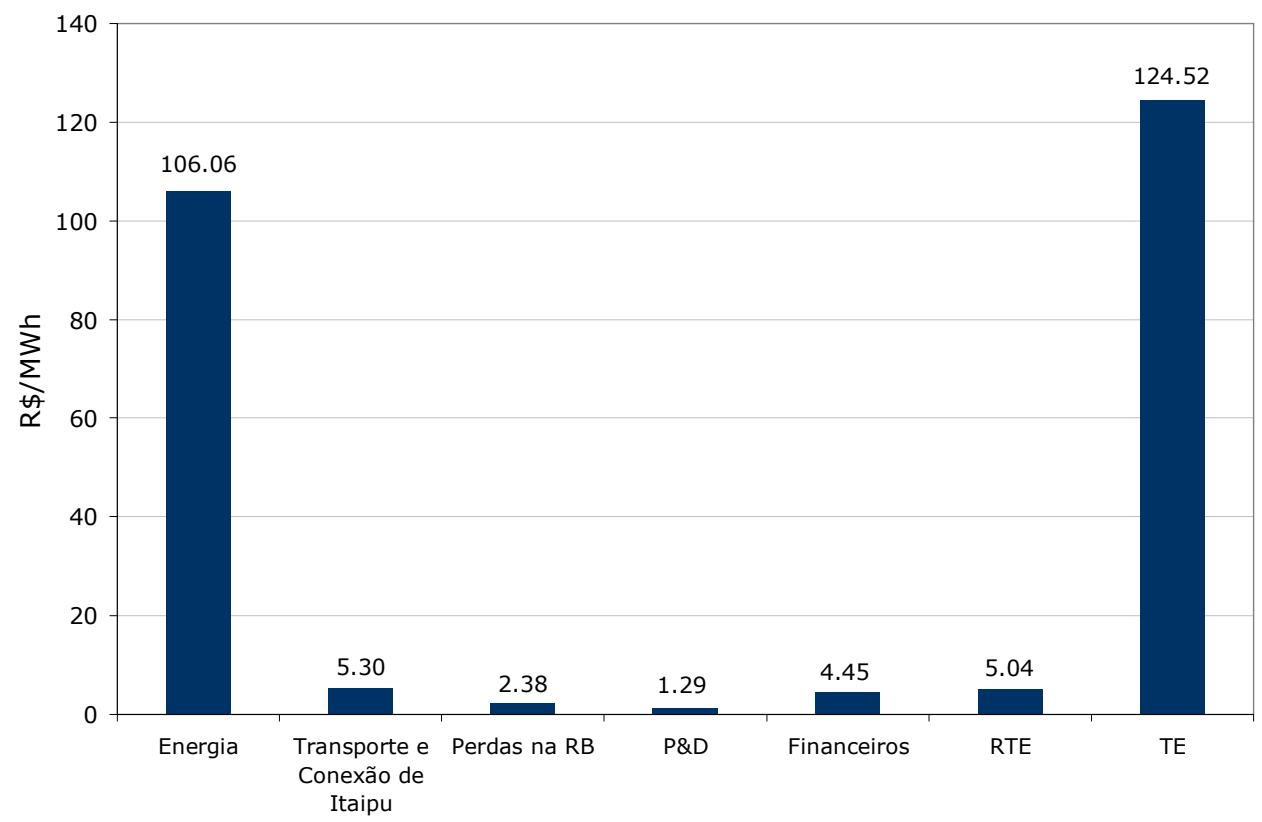

Figura 25 - Composição da TE no Cenário 1 para o Consumidor 1

Considerando os quatro cenários de oferta definidos anteriormente e as diretrizes estabelecidas, obtém-se a evolução da Tarifa de Energia, como ilustrado nas figuras a seguir:

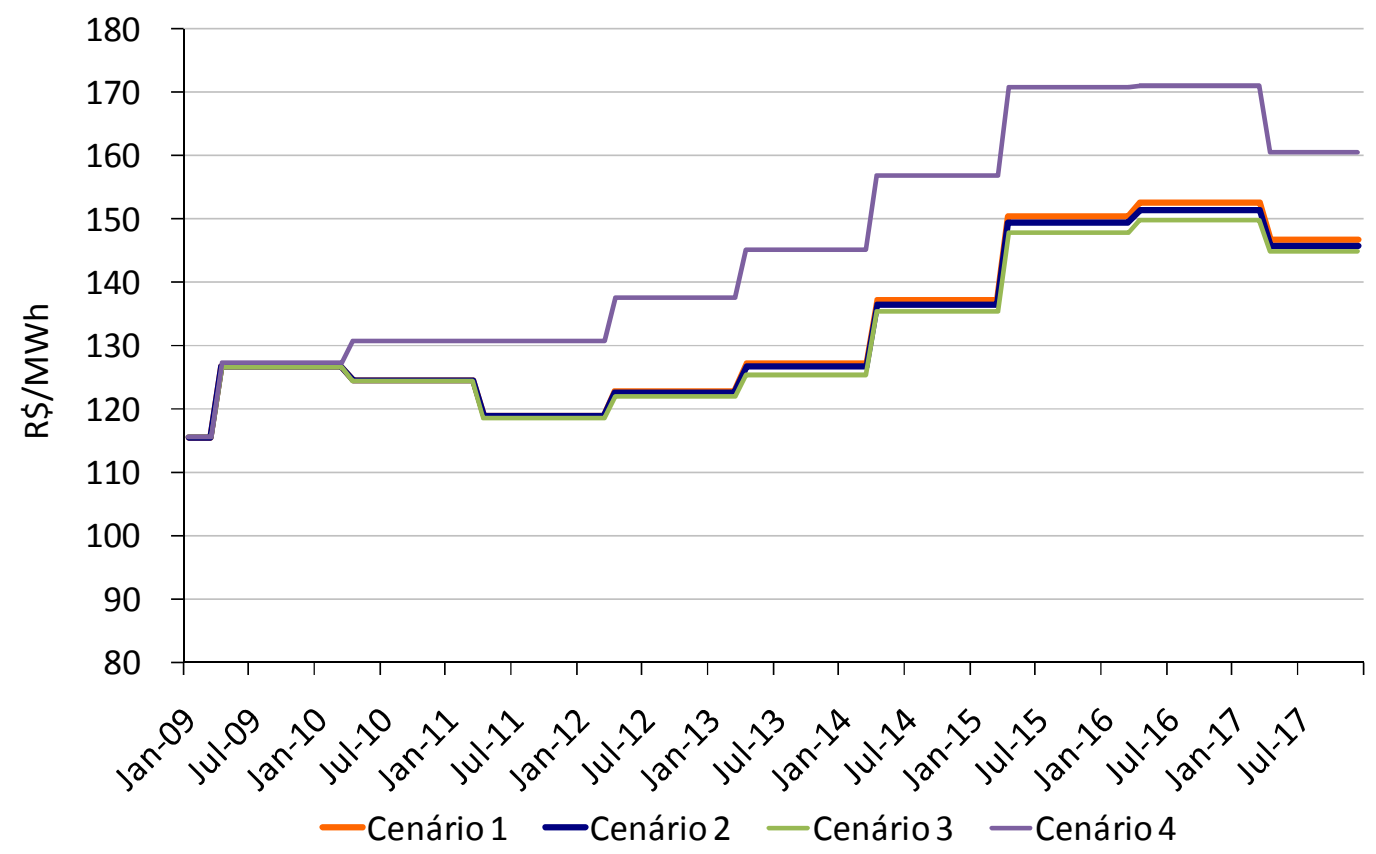

Figura 26 - Projeção da TE para o Consumidor 1 


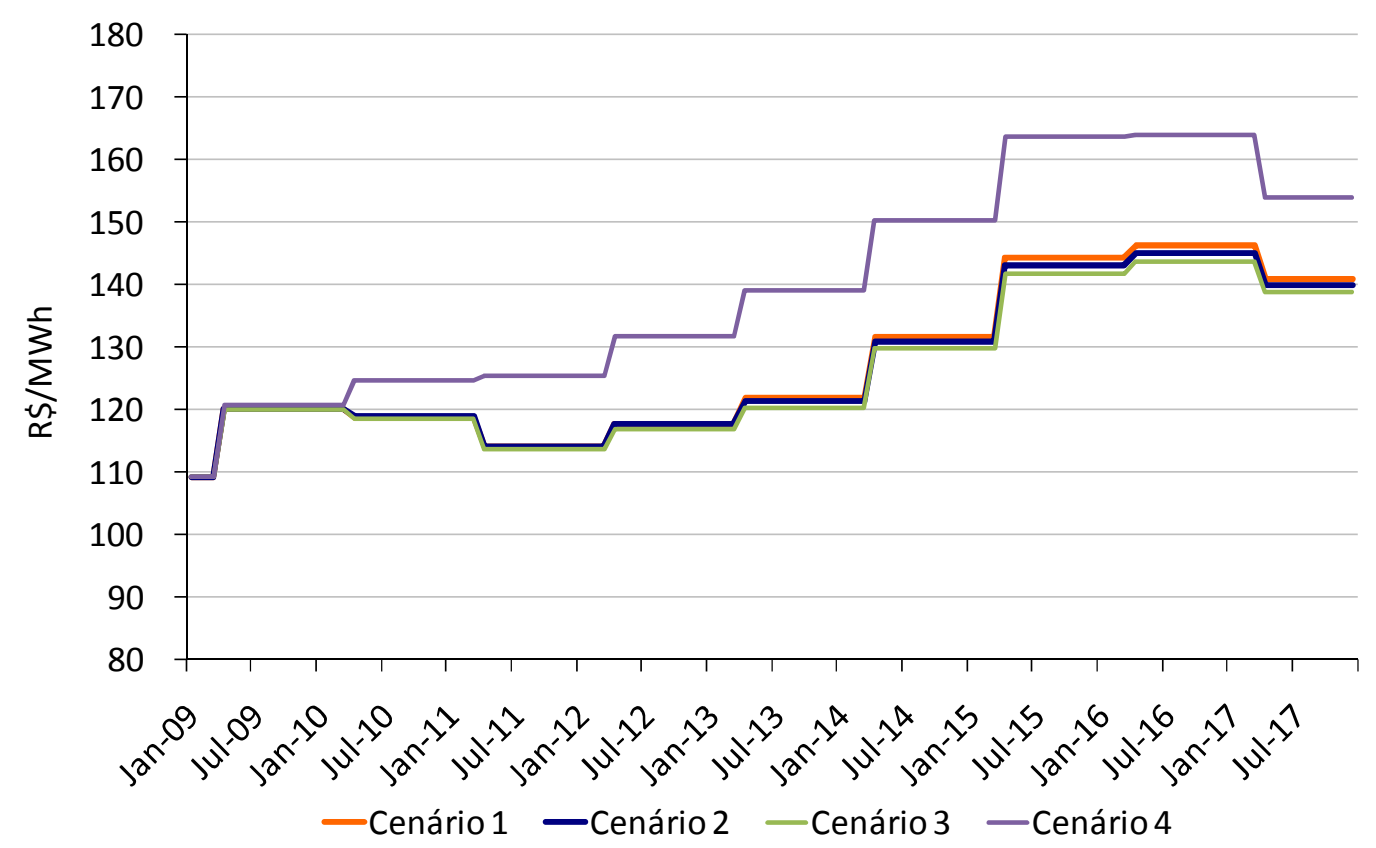

Figura 27 - Projeção da TE para o Consumidor 2

Conforme se observa nas figuras apresentadas, pode-se esperar um aumento na ordem de $30 \%$ nas Tarifas de Energia dos consumidores cativos ao longo de todo horizonte para os Cenários 1, 2, e 3, chegando a $40 \%$ no Cenário 4. Para abril/2009, havia uma grande expectativa de aumento da TE para ambos os consumidores, o que de fato ocorreu. Isso deveu-se principalmente ao aumento da participação dos contratos por disponibilidade no portfólio de compra da distribuidora em questão (Figura 19), bem como à elevação da tarifa de Itaipu, justificável em função de sua recente revisão ${ }^{8}$ e da expectativa de aumento da taxa de câmbio.

Devido à previsão de término da cobrança da Recomposição Tarifária Extraordinária, pode-se notar uma redução de cerca de $5 \%$ nas tarifas no primeiro semestre de 2011 para os Cenário de 1 a 3. Após esse período, é esperada uma elevação gradual até 2013, e logo após uma escalada dos preços em função da recontratação da energia existente e do elevado custo dos contratos por disponibilidade.

\footnotetext{
${ }^{8}$ A Resolução Homologatória oㅜ 749, de 9 de dezembro de 2008, estabeleceu a tarifa de repasse da potência (US $\$ \mathrm{~kW}$.mês) oriunda de Itaipu para o ano de 2009. Nessa ocasião, ocorreu um aumento de $8,70 \%$ quando comparado aos valores de estabelecidos para 2008.
} 
Como esperado, o Consumidor 1, que tem perfil de carga "flat", apresenta Tarifa de Energia Média superior ao Consumidor 2, uma vez que as tarifas de energia no horário de ponta são superiores às do horário fora de ponta.

Para ambos consumidores, os cenários de inclusão de oferta eólica reduzem as tarifas sensivelmente após 2015, tendo em vista que a perspectiva de oferta encontra-se mais restrita nesse horizonte.

Outra forma de apresentar os resultados obtidos é por meio do preço médio de compra de energia da distribuidora, chamado "preço mix". Nesse caso, não são avaliados os componentes financeiros que compõem as tarifas de energia e os componentes relativos a: (i) ao custo de conexão e uso da Rede Básica por Itaipu; (ii) perdas elétricas na Rede Básica; (iii) P\&D, (iv) RTE e (v) Componentes Financeiros.

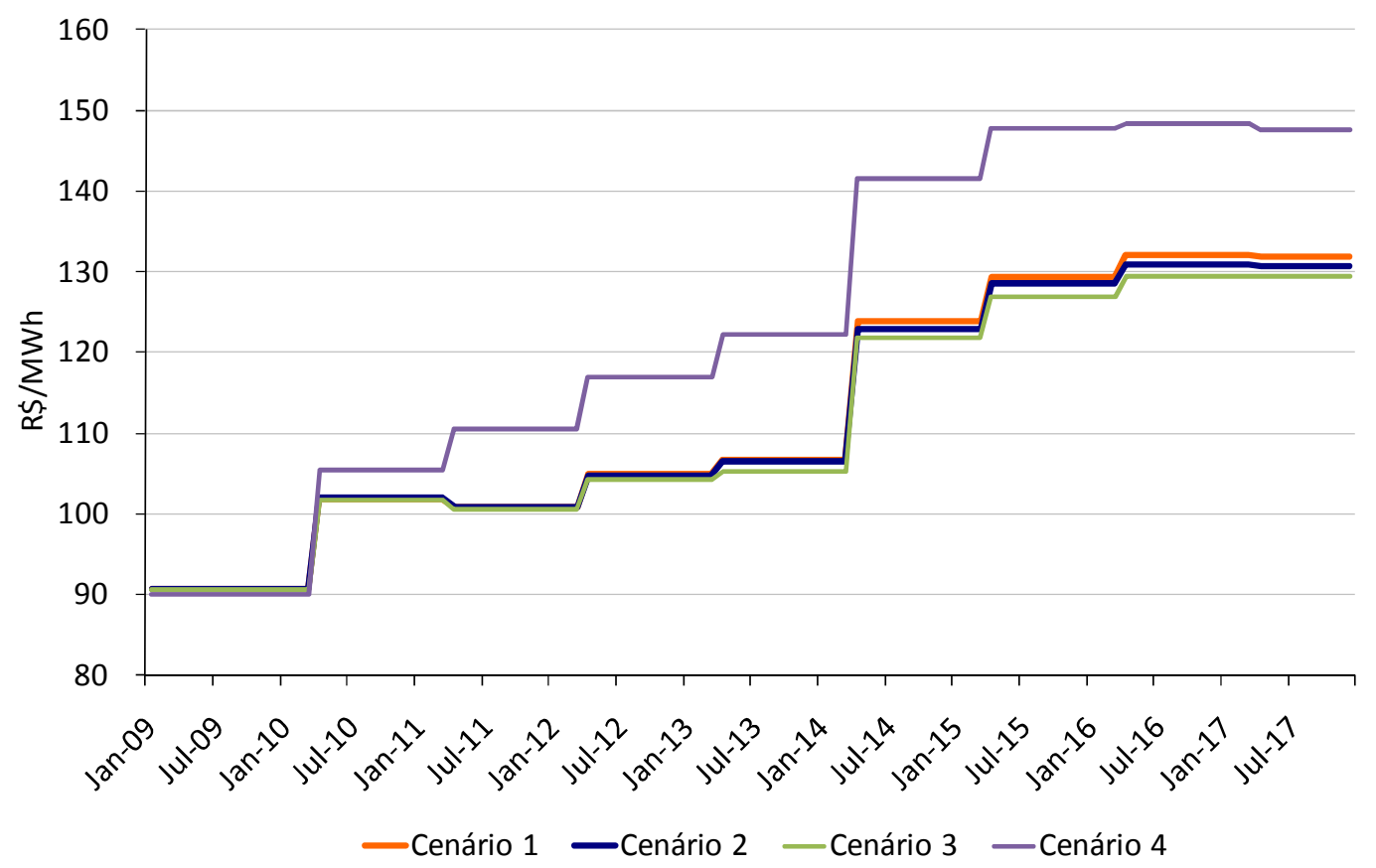

Figura 28 - Projeção do preço médio de compra da CEMIG 


\section{EXPECTATIVA DOS PREÇOS DOS CONTRATOS BILATERAIS DE ENERGIA}

Como abordado no Capítulo 2, no ACL os contratos são livremente negociados entre os agentes através da definição dos seguintes parâmetros: preços, prazos e volumes. Assim, de modo geral, os consumidores livres estão sujeitos às seguintes modalidades contratuais:

- Contratação a Médio e Longo Prazo: a partir da data de início de suprimento é estabelecido um preço para o contrato de energia a vigorar durante todo o prazo contratual, sendo os preços dos contratos ponderados pelo preço da energia de novos empreendimentos de geração e pouco influenciados pela conjuntura hidrológica vigente no instante de início da contratação.

- Contratação a Curto Prazo: a partir da data de início de suprimento é estabelecido um primeiro contrato, que na sequência passa a ser constantemente renovado, de tal forma a cobrir o mesmo horizonte temporal analisado na contratação anterior, sendo os preços dos contratos negociados segundo as condições de mercado vigentes durante a assinatura dos mesmos.

Tendo em mente os conceitos abordados acima, o presente capítulo tem por objetivo detalhar a metodologia de formação de preço dos contratos bilaterais e apresentar o Software desenvolvido para obtenção dos resultados. 


\subsection{MODELAGEM DOS CONTRATOS BILATERAIS}

\subsubsection{Contratos de Curto Prazo}

Para fins desse trabalho, serão considerados como contratos de curto prazo, os contratos com duração de um e dois anos. Nessa modalidade, o valor dos contratos $\left(P_{\text {mercado }}\right.$ (i) $)$ são fortemente influenciados pela conjuntura hidrológica

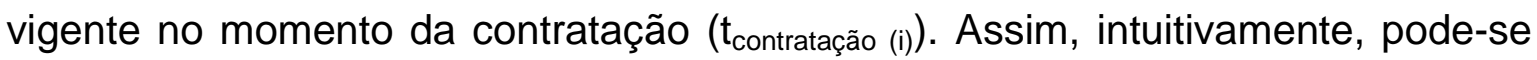
assumir que se a situação hidrológica encontrar-se adversa no momento de contratação, o preço do contrato de curto prazo será substancialmente maior que quando comparado ao preço em um momento de afluências elevadas e de armazenamentos dos principais reservatórios do sistema em níveis confortáveis.

A figura a seguir ilustra o comportamento hipotético dos preços dos contratos de curto prazo ao longo do período de estudo (T).

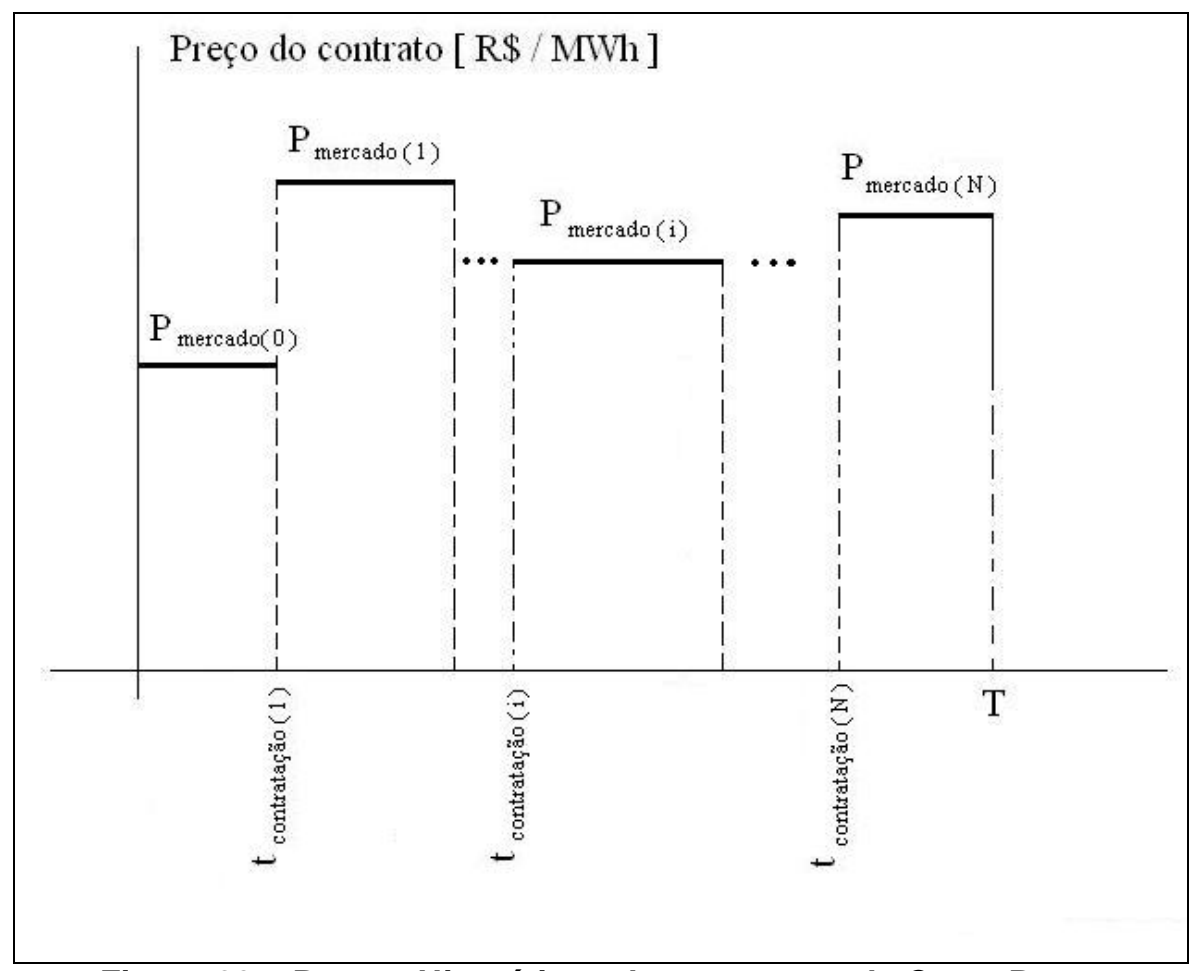

Figura 29 - Preços Hipotéticos dos contratos de Curto Prazo 
Tendo em vista as características retro definidas para os contratos de curto prazo, podem-se definir as seguintes fórmulas empíricas para formação de seus preços para uma única série de PLD:

$$
\begin{aligned}
& \operatorname{preçolano}\left(\mathrm{t}_{0}\right)=\left[\frac{\sum_{1}^{12} \mathrm{p}_{\mathrm{n}}\left(\mathrm{T}_{1}\right)}{12}\right] * \mathrm{M}
\end{aligned}
$$

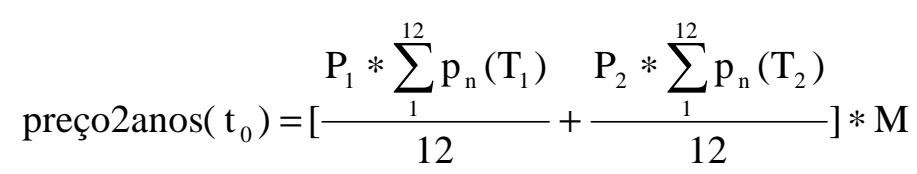

Onde:

preço1ano(t0): preço do contrato de um ano no instante da contratação (R\$/MWh).

preço2anos(t0): preço do contrato de dois anos no instante da contratação ( $\mathrm{R} \$ / \mathrm{MWh})$.

pn(T1): valor presente do preço mensal da energia para o mês " $n$ " no primeiro ano do contrato e determinada série hidrológica de vazões ( $\mathrm{R} \$ / \mathrm{MWh})$.

pn(T2): valor presente do preço mensal da energia para o mês " $n$ " no segundo ano do contrato e determinada série hidrológica de vazões $(\mathrm{R} \$ / \mathrm{MWh})$.

P1 e P2: Ponderação do $1^{\circ}$ e $2^{\circ}$ ano do contrato respectivamente.

M: margem para comercialização.

n: variável que caracteriza o mês do ano.

Uma vez definido o valor do contrato para uma série de PLD, pode-se estender a metodologia para $(\mathrm{N})$ possíveis séries. Após situar "N" valores contratuais para o instante de contratação ( $\left.t_{\text {contratação (i) }}\right)$, determina-se que o valor do contrato para o instante ( $t_{\text {contratação (i) }}$ ) será estabelecido através do cálculo da média aritmética dos contratos resultantes de todas as séries. 
Para conferir maior consistência aos resultados dos contratos de dois anos, determina-se que para uma dada série hidrológica $(\mathrm{N})$ e instante de contratação $\left(\mathrm{t}_{\text {contratação (i) }}\right)$, deve-se calcular a média dos preços da energia do primeiro ano a

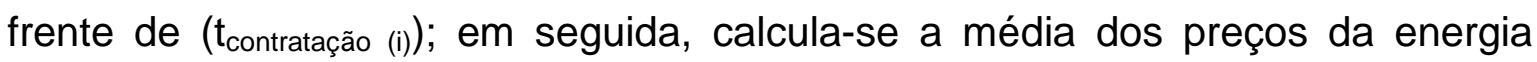
referente ao segundo ano a frente de ( $\left.t_{\text {contratação (i) }}\right)$. A partir da média dos preços da energia para o segundo ano, cria-se uma faixa de valores de preços possíveis para o segundo ano, de acordo a expressão:

$$
(1-\mathrm{f}) * \text { mps } \leq \text { preçospossíveis } \leq(1+\mathrm{f}) * \mathrm{mps}
$$

Onde,

f: valor percentual que define a variação em torno dos preços possíveis para o segundo ano na série $(\mathrm{N})$.

mps: média dos preços da energia referente ao primeiro ano a frente de ( $\left.\mathrm{t}_{\text {contratação (i) }}\right)$ na série $(\mathrm{N}),(\mathrm{R} \$ / \mathrm{MWh})$.

preçospossíveis: preços da energia que atendam a condição imposta por eq (4), ( $\mathrm{R} \$ / M W h)$.

Após definida a faixa de valores aceitáveis para o segundo ano (faixa de ocorrências restrita, simulando uma distribuição de probabilidades condicionada, que por simplicidade não foi aqui estabelecida), percorre-se todas as séries de preço selecionando os valores encontrados que atendam a condição imposta pela expressão eq.(4) e, então, admitindo cada realização da amostra restrita de ocorrências como equiprovável, calcula-se a média de preços de cada mês e de cada série hidrológica, permitindo definir o valor do contrato para o segundo ano da série hidrológica $\mathrm{N}$, iniciada no primeiro ano do período. Ao final, após a aplicação do procedimento descrito para todas as séries de preço, é aplicada a fórmula eq.(3) e calculada a média aritmética das séries hidrológicas para definição do preço do contrato. As figuras a seguir ilustram a formação de preços dos contratos de curto prazo de um e dois anos. 


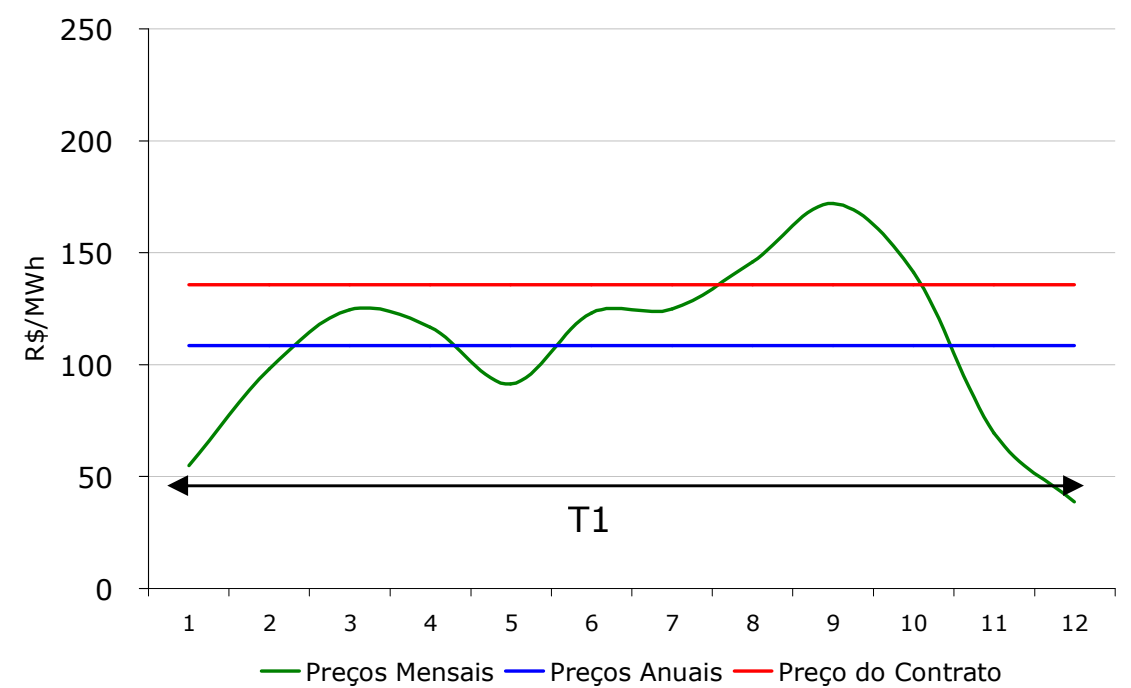

Figura 30 - Formação do preço dos contratos de um ano

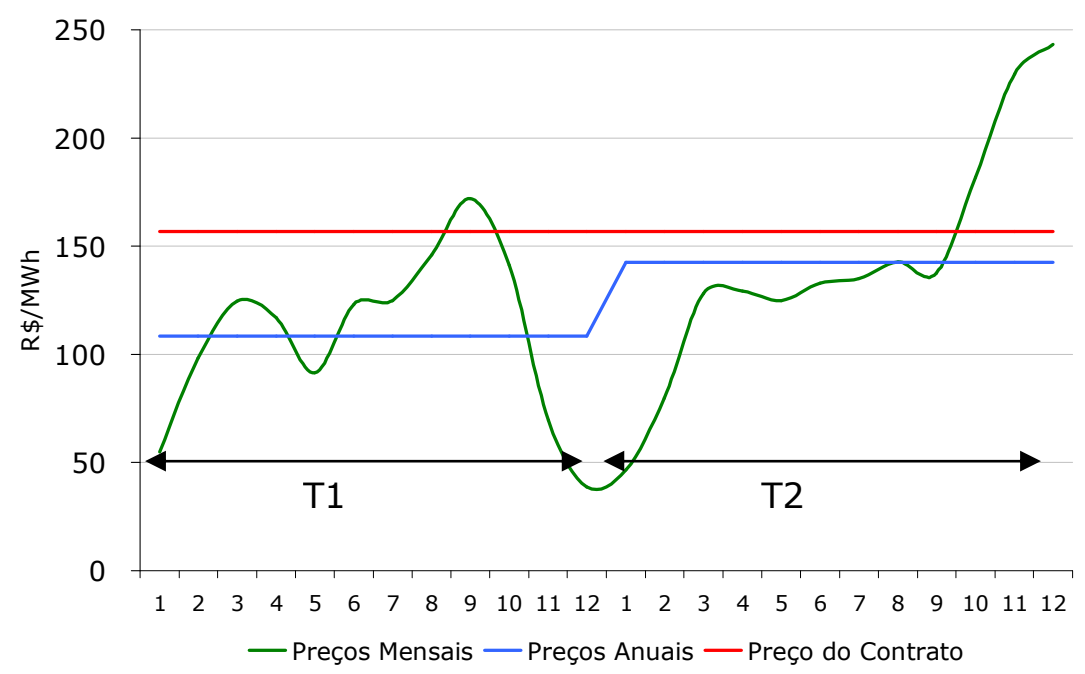

Figura 31 - Formação do preço dos contratos de dois anos

\subsubsection{Contratos de Médio e Longo Prazo}

Os contratos de médio e longo prazo trazem em sua formação de preço tanto a perspectiva da conjuntura hidrológica no momento de sua realização, como o Custo Marginal de Expansão ( $\mathrm{CME}$ ), que é caracterizado pelo preço resultante dos empreendimentos dos leilões de energia nova. 
Para fins desse trabalho somente serão considerados os contratos de médio prazo. Assim, foram definidos que os contratos de médio prazo são aqueles com vigência de três e quatro anos. A partir da definição exposta acima, buscou-se reproduzir suas características através das equações (5) e (6) para um única série de PLD:

$$
\text { preço3anos }\left(\mathrm{t}_{0}\right)=\left[\frac{\mathrm{P}_{1} * \sum_{1}^{12} \mathrm{p}_{\mathrm{n}}\left(\mathrm{T}_{1}\right)}{12}+\frac{\mathrm{P}_{2} * \sum_{1}^{12} \mathrm{p}_{\mathrm{n}}\left(\mathrm{T}_{2}\right)}{12}+\frac{\mathrm{P}_{3} * \sum_{1}^{12} \text { pnova }{ }_{\mathrm{n}}\left(\mathrm{T}_{3}\right)}{12}\right] * \mathrm{M}
$$

$$
\operatorname{preço4anos}\left(\mathrm{t}_{0}\right)=\left[\frac{\mathrm{P}_{1} * \sum_{1}^{12} \mathrm{p}_{\mathrm{n}}\left(\mathrm{T}_{1}\right)}{12}+\frac{\mathrm{P}_{2} * \sum_{1}^{12} \mathrm{p}_{\mathrm{n}}\left(\mathrm{T}_{2}\right)}{12}+\frac{\mathrm{P}_{3} * \sum_{1}^{12} \operatorname{pnova}_{\mathrm{n}}\left(\mathrm{T}_{3}\right)}{12}+\frac{\mathrm{P}_{4} * \sum_{1}^{12} \text { pnova }_{\mathrm{n}}\left(\mathrm{T}_{4}\right)}{12}\right] * \mathrm{M}
$$

Onde:

preço3anos(t0): preço do contrato de três anos no instante da contratação $(\mathrm{R} \$ / \mathrm{MWh})$.

preço4anos(t0): preço do contrato de quatro anos no instante da contratação ( $\mathrm{R} \$ / M W h)$.

pn(T1): valor presente dos preços mensais da energia no primeiro ano do contrato $(\mathrm{R} \$ / \mathrm{MWh})$.

pn(T2): valor presente dos preços mensais da energia no segundo ano do contrato $(\mathrm{R} \$ / \mathrm{MWh})$.

pnova(T3): valor presente dos preço da energia nova no terceiro ano do contrato $(\mathrm{R} \$ / \mathrm{MWh})$.

pnova(T4): valor presente dos preço da energia nova no quarto ano do contrato $(\mathrm{R} \$ / \mathrm{MWh})$.

$\mathrm{P} 1, \mathrm{P} 2, \mathrm{P} 3$ e P4: Ponderação do $1^{\circ}, 2^{\circ}, 3^{\circ}$ e $4^{\circ}$ ano do contrato respectivamente.

M: margem para comercialização.

n: variável que caracteriza o mês do ano. 
Vale lembrar que a definição do preço para o segundo ano dos contratos de três e quatro anos passa pelo mesmo procedimento estabelecido para o contrato de dois anos.

De forma análoga aos contratos de curto prazo, são calculados os valores de preço3anos(t0) e preço4anos(t0) para todas as séries de preço e, em seguida, calculada a média aritmética para determinação do preço médio desses contratos.

As figuras a seguir ilustram a formação de preços dos contratos de médio prazo de três e quatro anos.

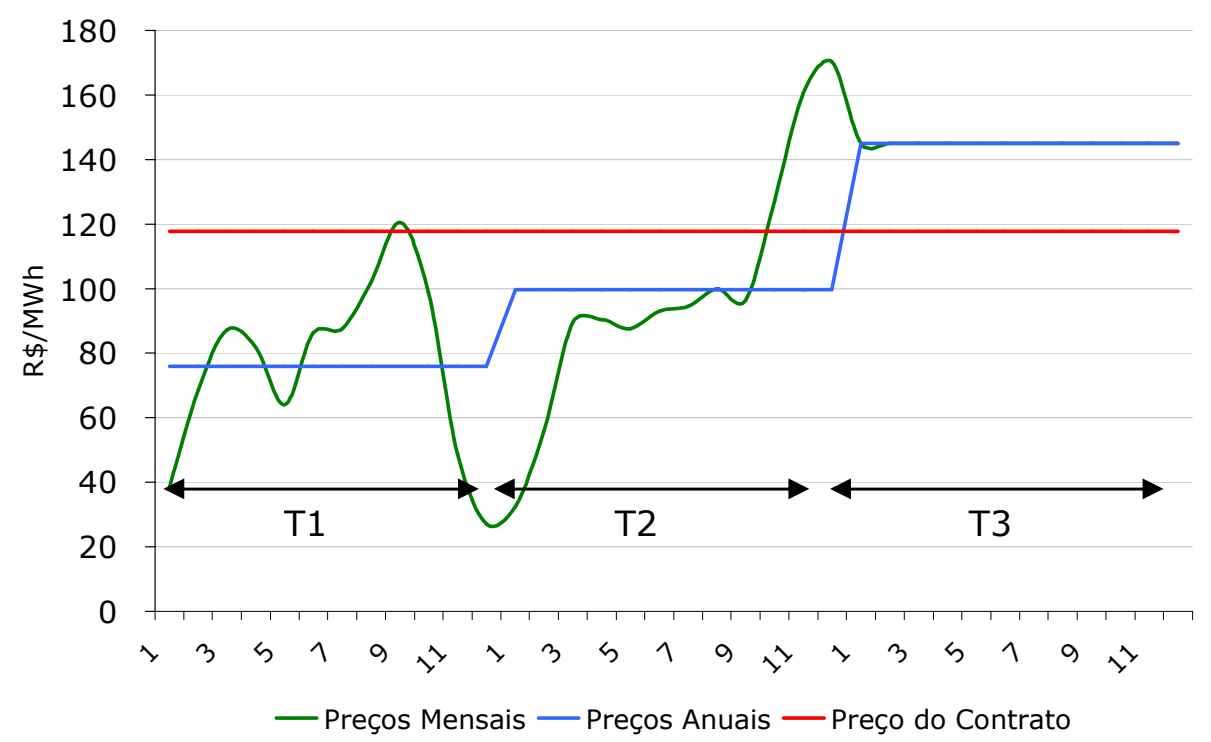

Figura 32 - Formação do preço dos contratos de três anos

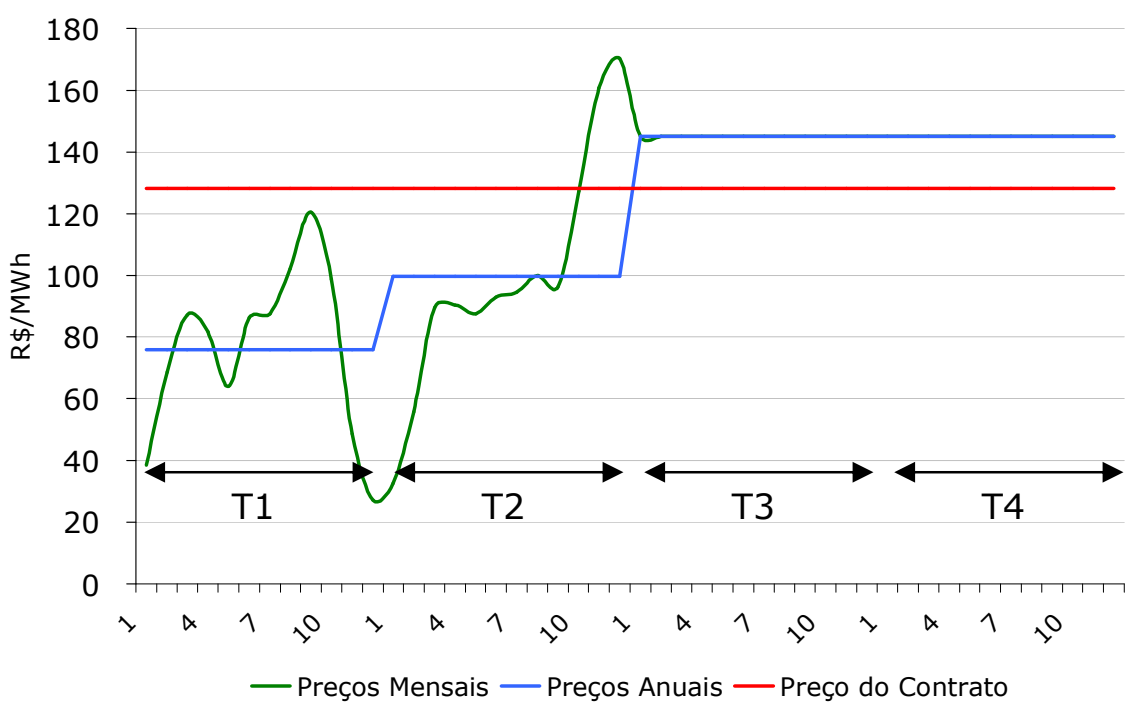

Figura 33 - Formação do preço dos contratos de quatro anos 


\subsection{CARACTERÍSTICAS DO MODELO DE SIMULAÇÃO}

O modelo de simulação, que tem por objetivo determinar o preço dos contratos bilaterais, foi desenvolvido no software Microsoft Office Excel utilizando a ferramenta "Visual Basic for Applications" para edição de rotinas computacionais.

Os dados de entrada podem ser resumidos em: séries de preços, período de análise, duração dos contratos, ponderação dos anos, margem de comercialização e preço da energia nova. As figuras a seguir ilustram a tela contendo a seleção dos parâmetros de entrada e as séries de preço.

Após a aplicação das fórmulas descritas na seção anterior é disponibilizado o custo total da estratégia de contratação selecionada, que tem por objetivo aferir a estratégia mais promissora para o balanço financeiro de um Consumidor Livre.

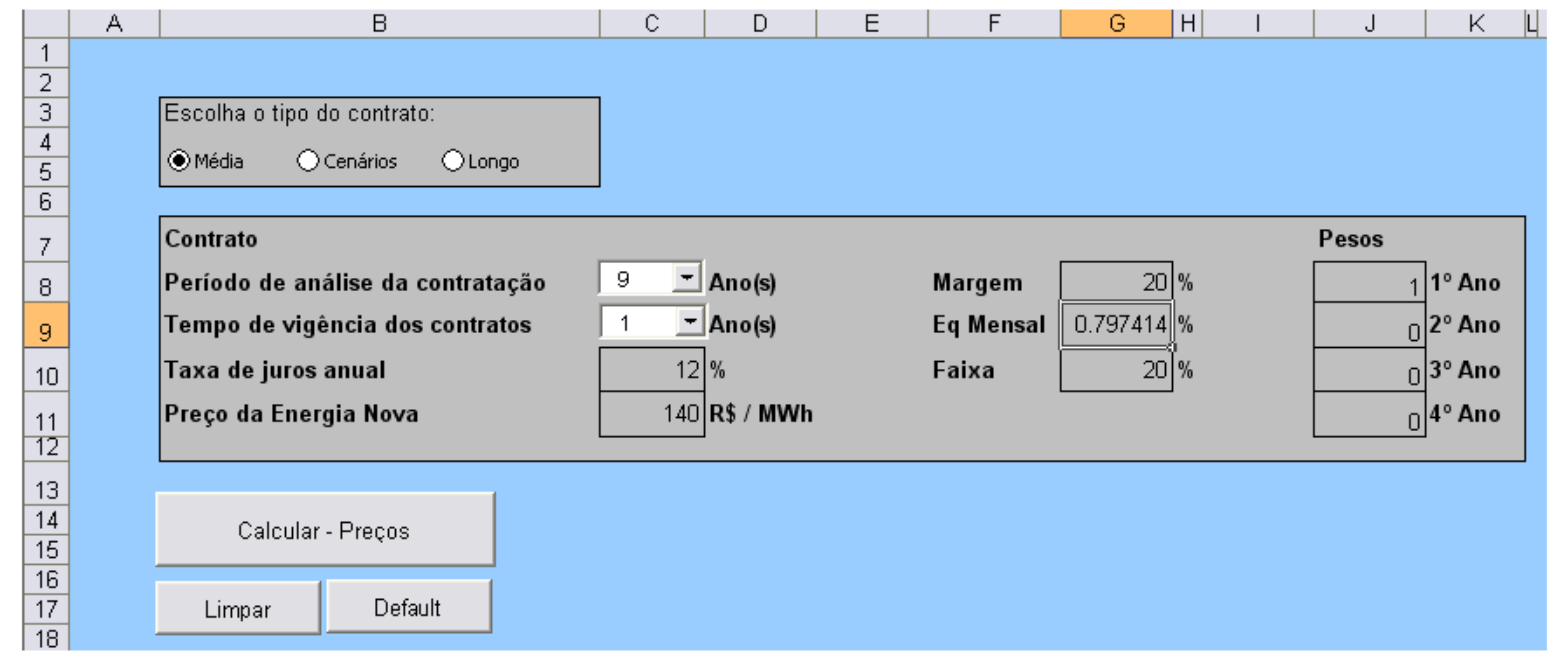

Figura 34 - Dados de Entrada do Modelo de Simulação 


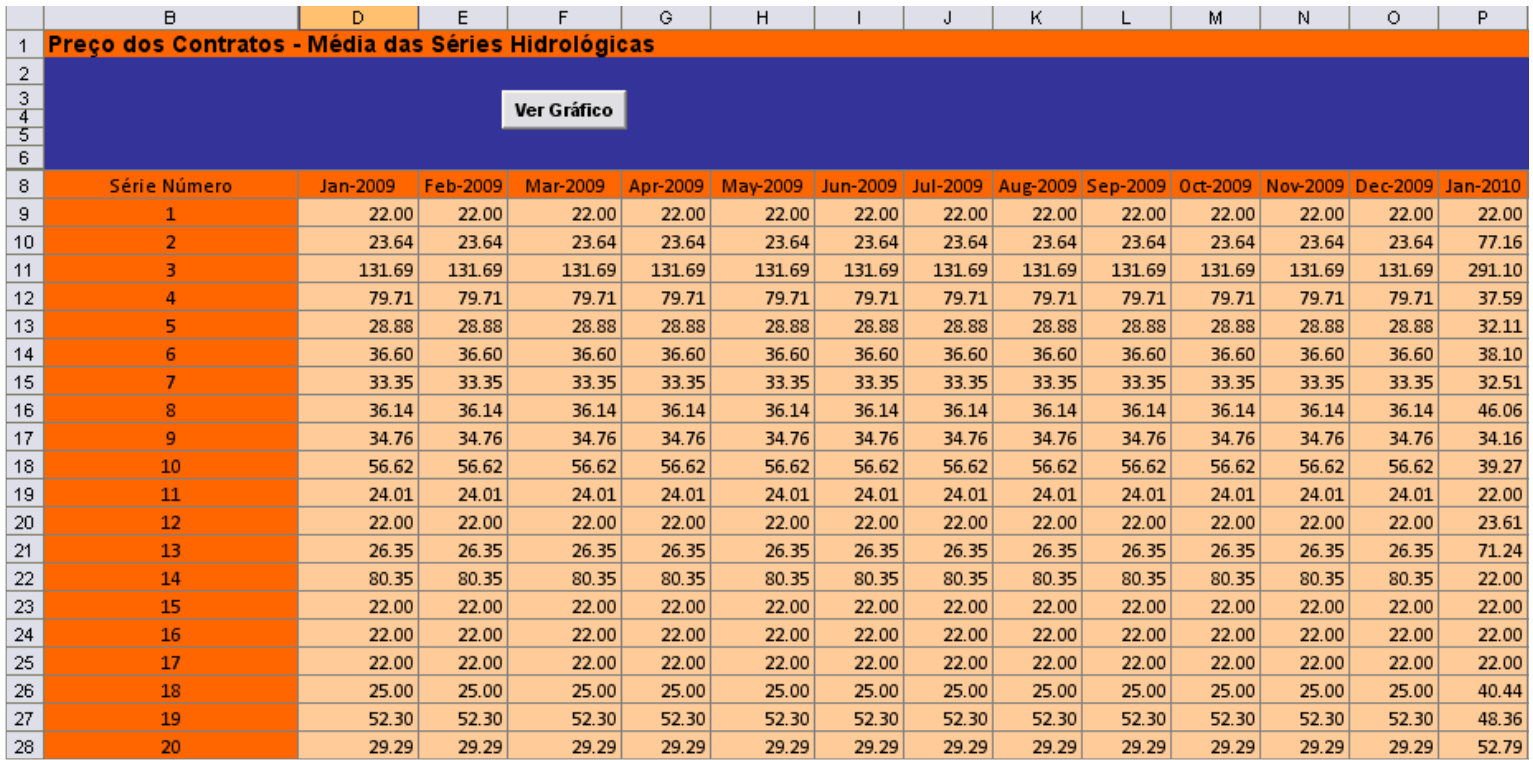

Figura 35 - Séries de preços utilizadas pelo modelo de simulação

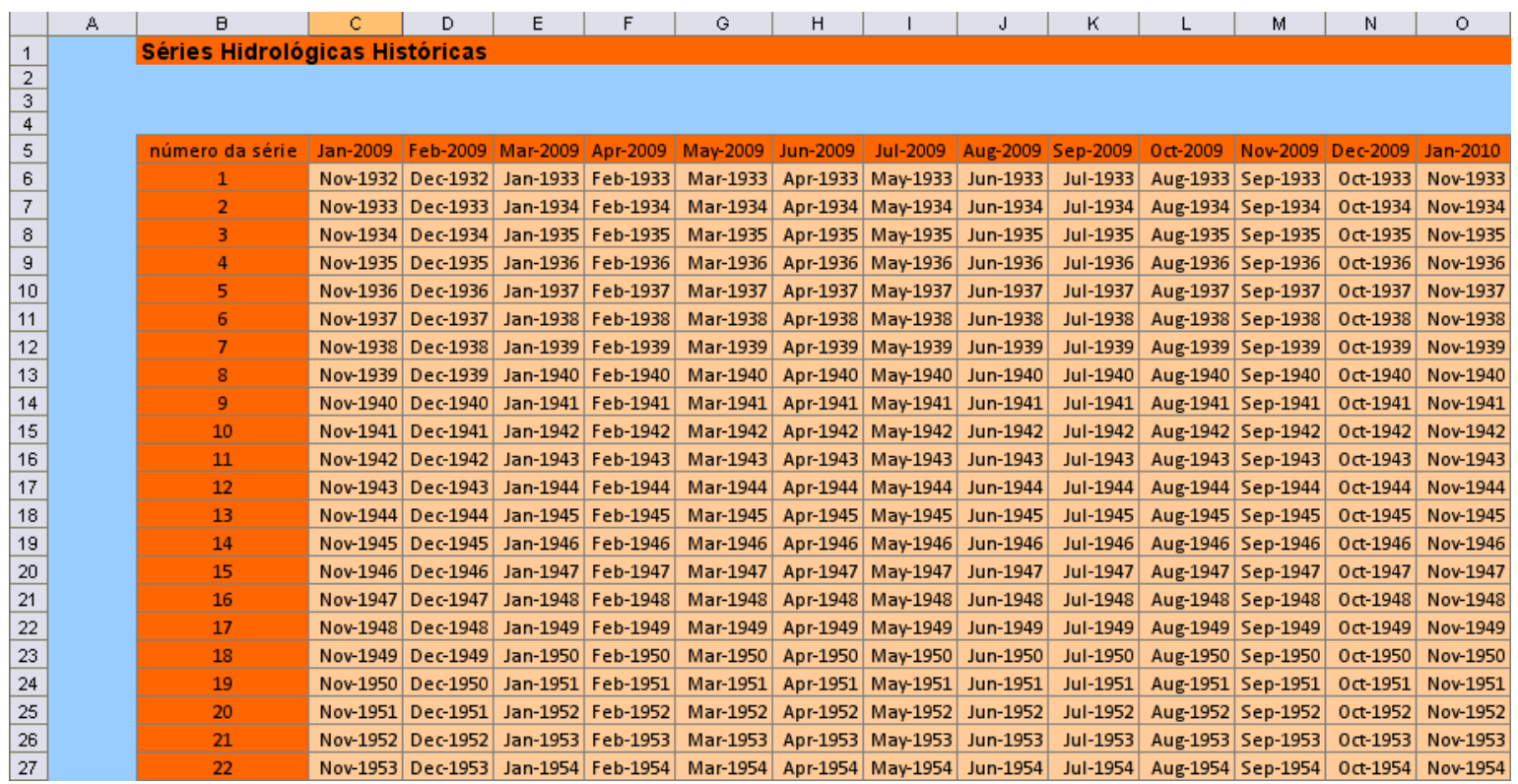

Figura 36 - Séries Hidrológicas vinculadas às séries de preços

\subsection{RESULTADOS}

Visando sintetizar os preços dos contratos nas diversas modalidades descritas no item 7.1, tendo em vista os quatro cenários definidos em 6.1.6, foram utilizados os seguintes parâmetros para aplicação das formulações propostas: 
- Preço da Energia Nova, $145 \mathrm{R} \$$ / $\mathrm{MWh}$, valor este que exprime o preço da energia para o terceiro ano e para o quarto ano à frente do instante de início da contratação ( to ).

- Margem para comercialização, $M=20 \%$.

- Valor percentual que define a variação em torno dos preços possíveis para o segundo ano a frente de ( to ( $i)$ ) na série $(N), f=40 \%$.

Pesos para ponderar o valor dos contratos:

Tabela 17 - Ponderações anuais para os contratos bilaterais

\begin{tabular}{|l|c|c|c|c|}
\hline & $\mathbf{1 0}^{\circ}$ ano & $\mathbf{2}^{\circ}$ ano & $\mathbf{3}^{\circ}$ ano & $\mathbf{4}^{\circ}$ ano \\
\hline Contrato 2 anos & 0.6 & 0.4 & - & - \\
\hline Contrato 3 Anos & 0.4 & 0.3 & 0.3 & - \\
\hline Contrato 4 Anos & 0.3 & 0.3 & 0.2 & 0.2 \\
\hline
\end{tabular}

Para o período de análise de jan/2009 a dez/2016 as simulações obtidas apresentaram os seguintes resultados com relação ao comportamento dos preços dos contratos para as quatro possibilidades de contratação enunciadas anteriormente. 


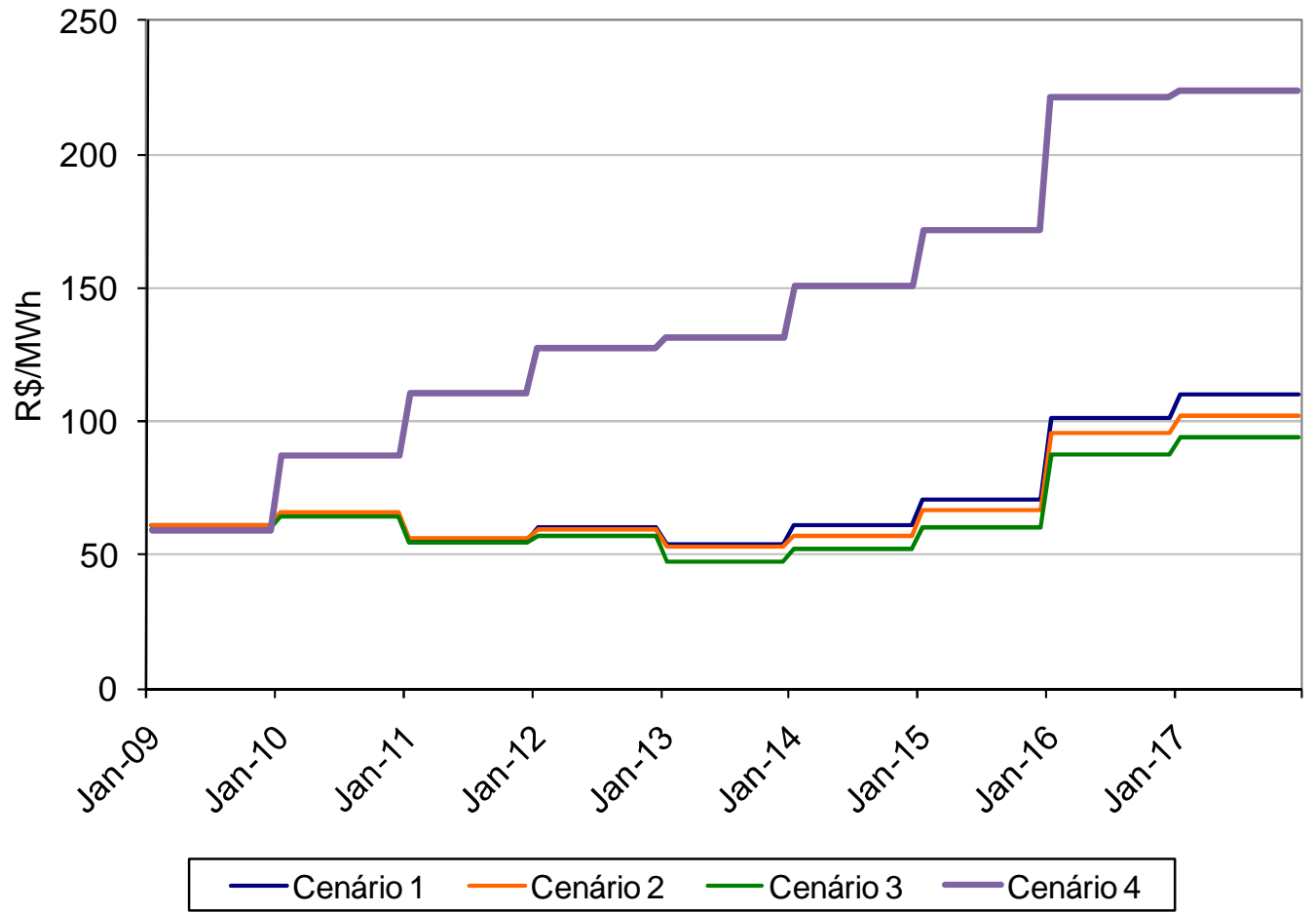

Figura 37 - Comportamentos dos contratos bilaterais de 1 ano

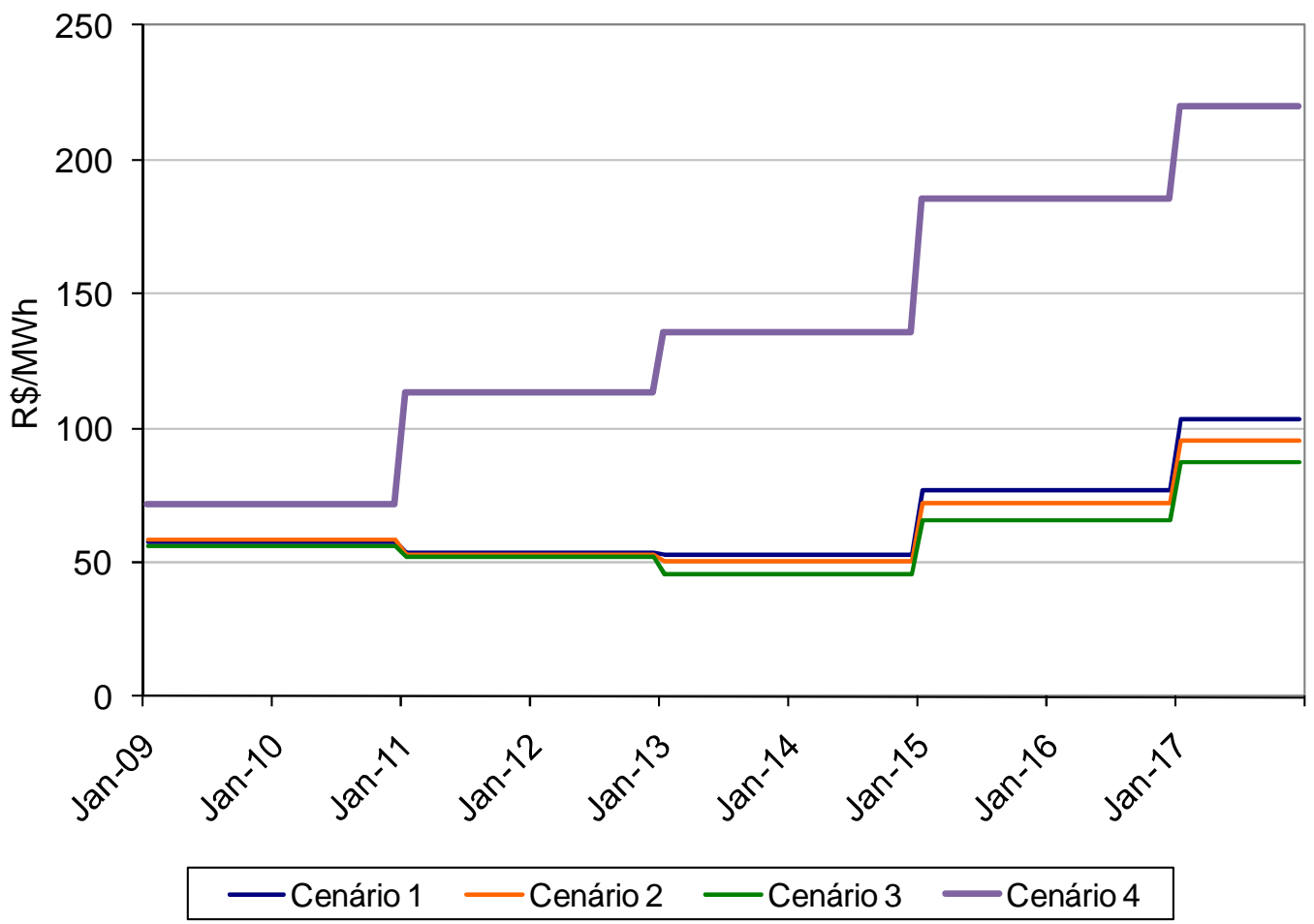

Figura 38 - Comportamentos dos contratos bilaterais de 2 anos 


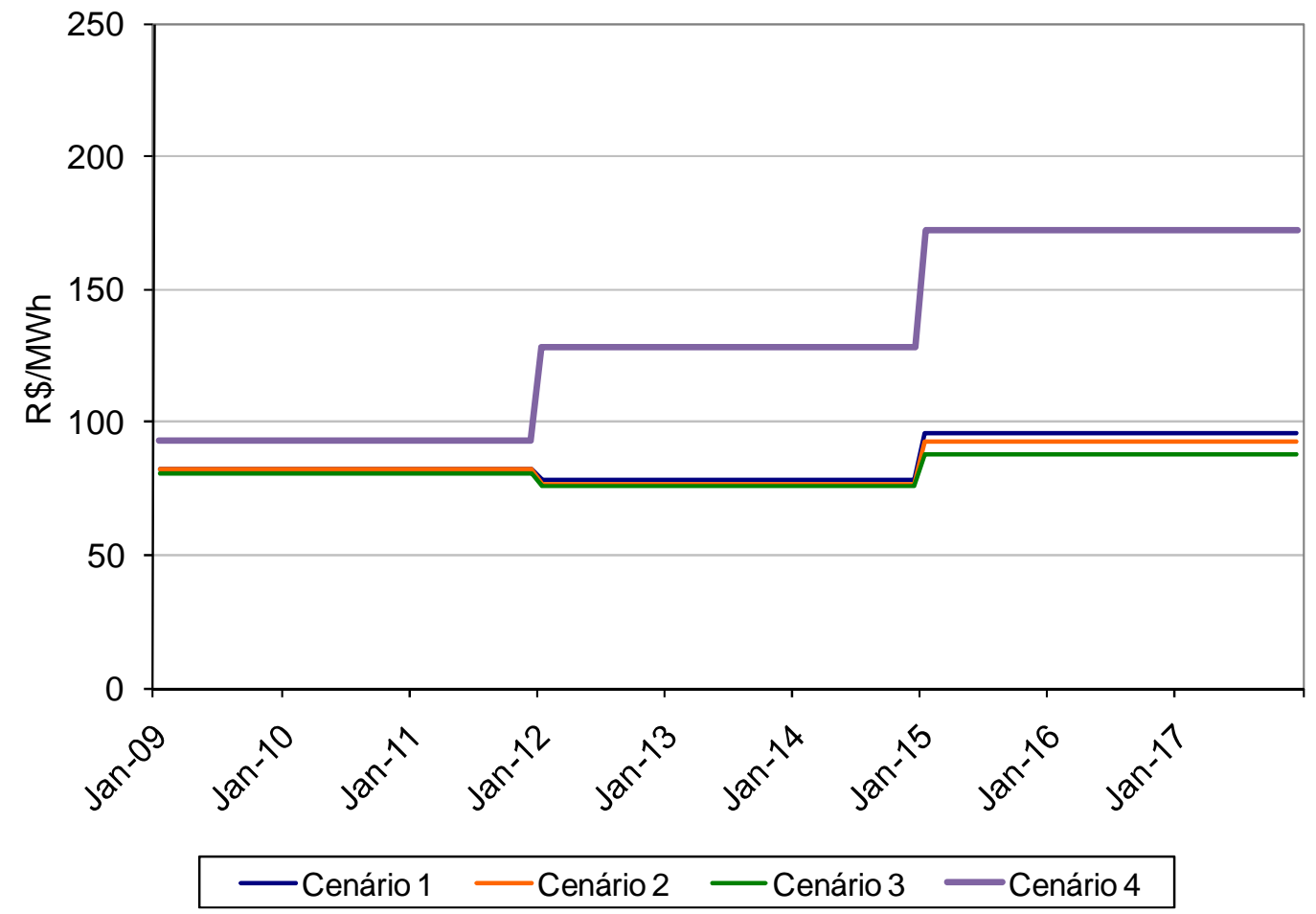

Figura 39 - Comportamentos dos contratos bilaterais de 3 anos

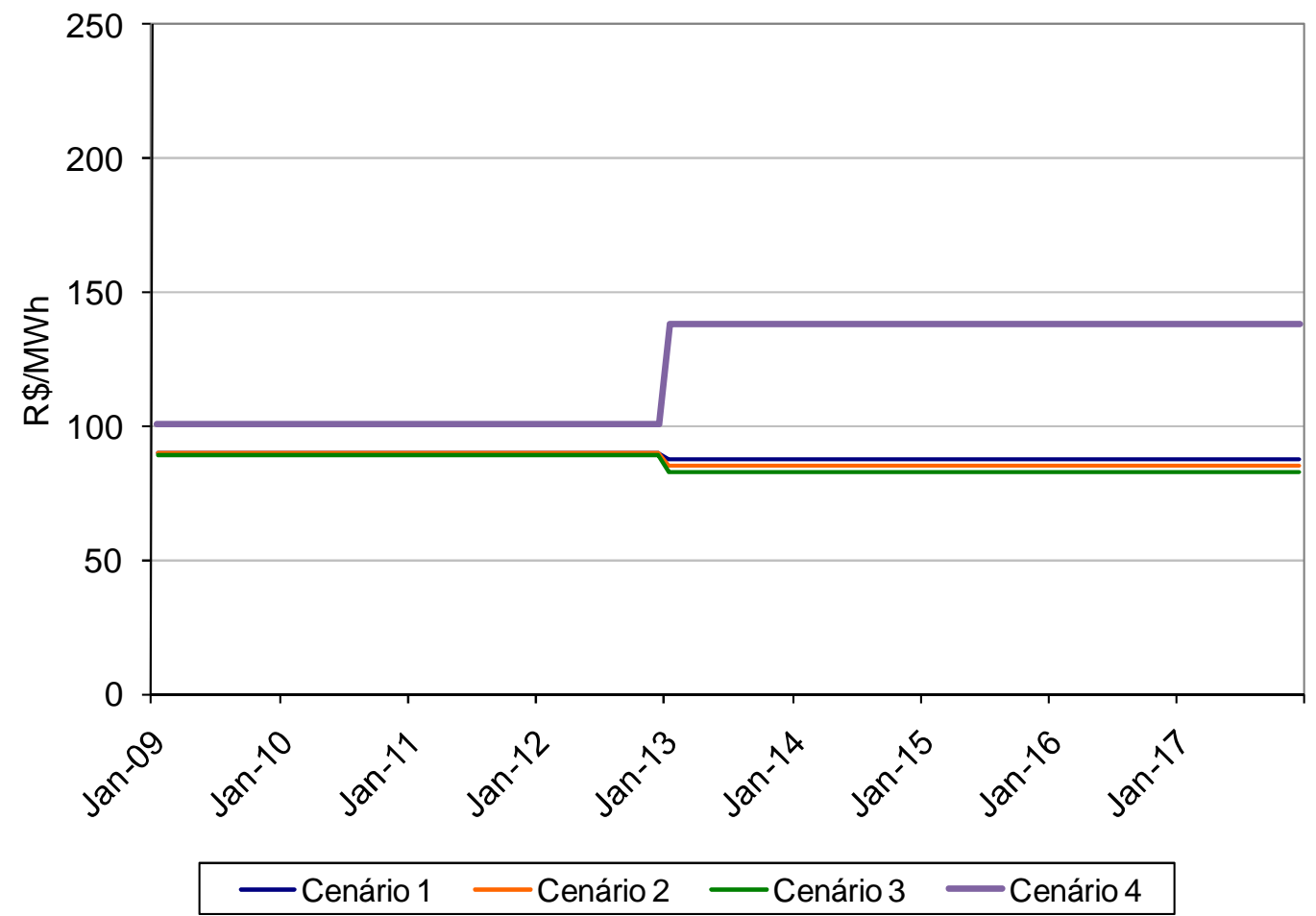

Figura 40 - Comportamentos dos contratos bilaterais de 4 anos

Os resultados obtidos encontram-se na forma numérica no Anexo 3. 


\section{ANÁLISES DOS RESULTADOS}

Buscando quantificar os custos de aquisição da energia elétrica referente aos quatro cenários sistêmicos definidos em 6.1.5, no período de jan/09 a dez/17, para os consumidores cujos perfis estão descritos na Tabela 16, foram comparados os custos totais nas diferentes estratégias de contratação a valores presentes, o que se demonstra a seguir.

Tabela 18 - Resultado Financeiro para o Consumidor I (bilhões)

\begin{tabular}{|l|c|c|c|c|}
\hline $\begin{array}{c}\text { Estratégia de } \\
\text { Contratação }\end{array}$ & Cenário 1 & Cenário 2 & Cenário 3 & Cenário 4 \\
\hline ACR & $\mathrm{R} \$ 7,382$ & $\mathrm{R} \$ 7,362$ & $\mathrm{R} \$ 7,321$ & $\mathrm{R} \$ 8,039$ \\
\hline Contrato - 1 Ano & $\mathrm{R} \$ 3,802$ & $\mathrm{R} \$ 3,722$ & $\mathrm{R} \$ 3,506$ & $\mathrm{R} \$ 7,233$ \\
\hline Contrato - 2 Anos & $\mathrm{R} \$ 3,515$ & $\mathrm{R} \$ 3,400$ & $\mathrm{R} \$ 3,214$ & $\mathrm{R} \$ 6,997$ \\
\hline Contrato - 3 Anos & $\mathrm{R} \$ 4,764$ & $\mathrm{R} \$ 4,691$ & $\mathrm{R} \$ 4,579$ & $\mathrm{R} \$ 6,923$ \\
\hline Contrato - 4 Anos & $\mathrm{R} \$ 5,031$ & $\mathrm{R} \$ 4,988$ & $\mathrm{R} \$ 4,890$ & $\mathrm{R} \$ 6,606$ \\
\hline
\end{tabular}

Tabela 19 - Resultado Financeiro para o Consumidor II (bilhões)

\begin{tabular}{|l|c|c|c|c|}
\hline $\begin{array}{c}\text { Estratégia de } \\
\text { Contratação }\end{array}$ & Cenário 1 & Cenário 2 & Cenário 3 & Cenário 4 \\
\hline ACR & $\mathrm{R} \$ 6,614$ & $\mathrm{R} \$ 6,596$ & $\mathrm{R} \$ 6,559$ & $\mathrm{R} \$ 7,205$ \\
\hline Contrato - 1 Ano & $\mathrm{R} \$ 3,565$ & $\mathrm{R} \$ 3,490$ & $\mathrm{R} \$ 3,287$ & $\mathrm{R} \$ 6,781$ \\
\hline Contrato - 2 Anos & $\mathrm{R} \$ 3,295$ & $\mathrm{R} \$ 3,188$ & $\mathrm{R} \$ 3,013$ & $\mathrm{R} \$ 6,560$ \\
\hline Contrato - 3 Anos & $\mathrm{R} \$ 4,466$ & $\mathrm{R} \$ 4,397$ & $\mathrm{R} \$ 4,293$ & $\mathrm{R} \$ 6,490$ \\
\hline Contrato - 4 Anos & $\mathrm{R} \$ 4,716$ & $\mathrm{R} \$ 4,676$ & $\mathrm{R} \$ 4,584$ & $\mathrm{R} \$ 6,193$ \\
\hline
\end{tabular}

Conforme disponibilizado, para os Cenários 1, 2 e 3 a estratégia que minimiza o custo na compra da energia ao longo do período de análise é a contratação de curto prazo com renovação contratual a cada dois anos, posto que as séries de preço encontram-se bem comportadas, pois o sistema encontra-se equilibrado. 
Já para o Cenário 4, onde o sistema encontra-se com limitação de oferta, a melhor estratégia passa a ser a contratação de médio prazo com renovação contratual a cada quatro anos.

Pode ser observado também que a variação de preços na estratégia de contratos de um ano expõe de forma demasiada ambos os consumidores à volatilidade dos preços de mercado (Fig. 37).

Embora a inserção de usinas eólicas reduza a probabilidade de ocorrência de valores elevados de PLD, cabe salientar os riscos inerentes ao optar-se por contratos mais curtos. Uma vez que na eventualidade de hidrologias desfavoráveis o consumidor ficaria exposto a preços contratuais atrelados às conjunturas vigentes no mercado, sendo, neste caso, afetado negativamente quando comparado com a contratação de longo prazo no ACL ou no ACR. As figuras a seguir ilustram as distribuições de preços nos instantes de contratação das estratégias que se mostraram mais promissoras.

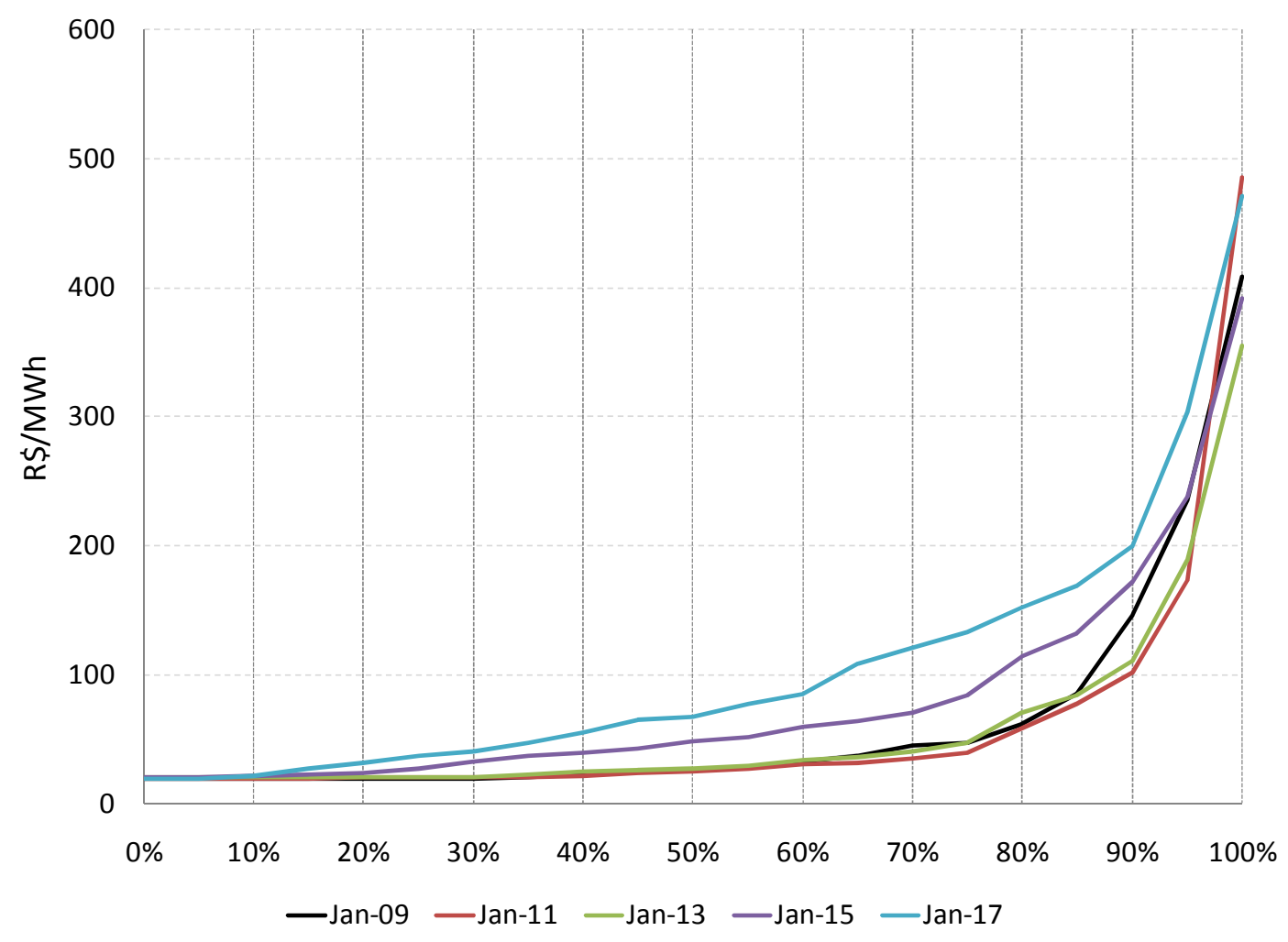

Figura 41 - Distribuições de Preços de Renovação - Cenário 1 


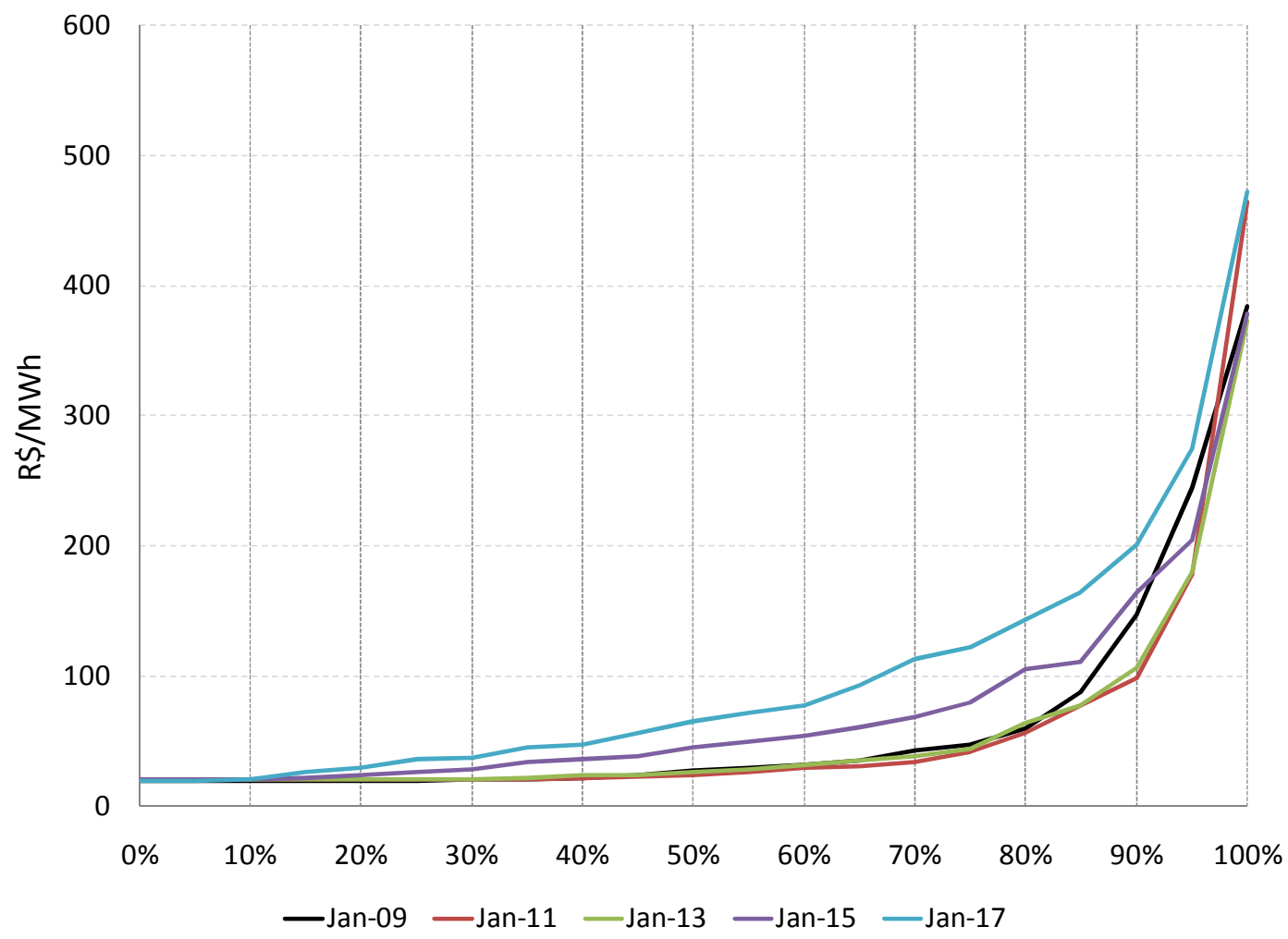

Figura 42 - Distribuições de Preços de Renovação - Cenário 2

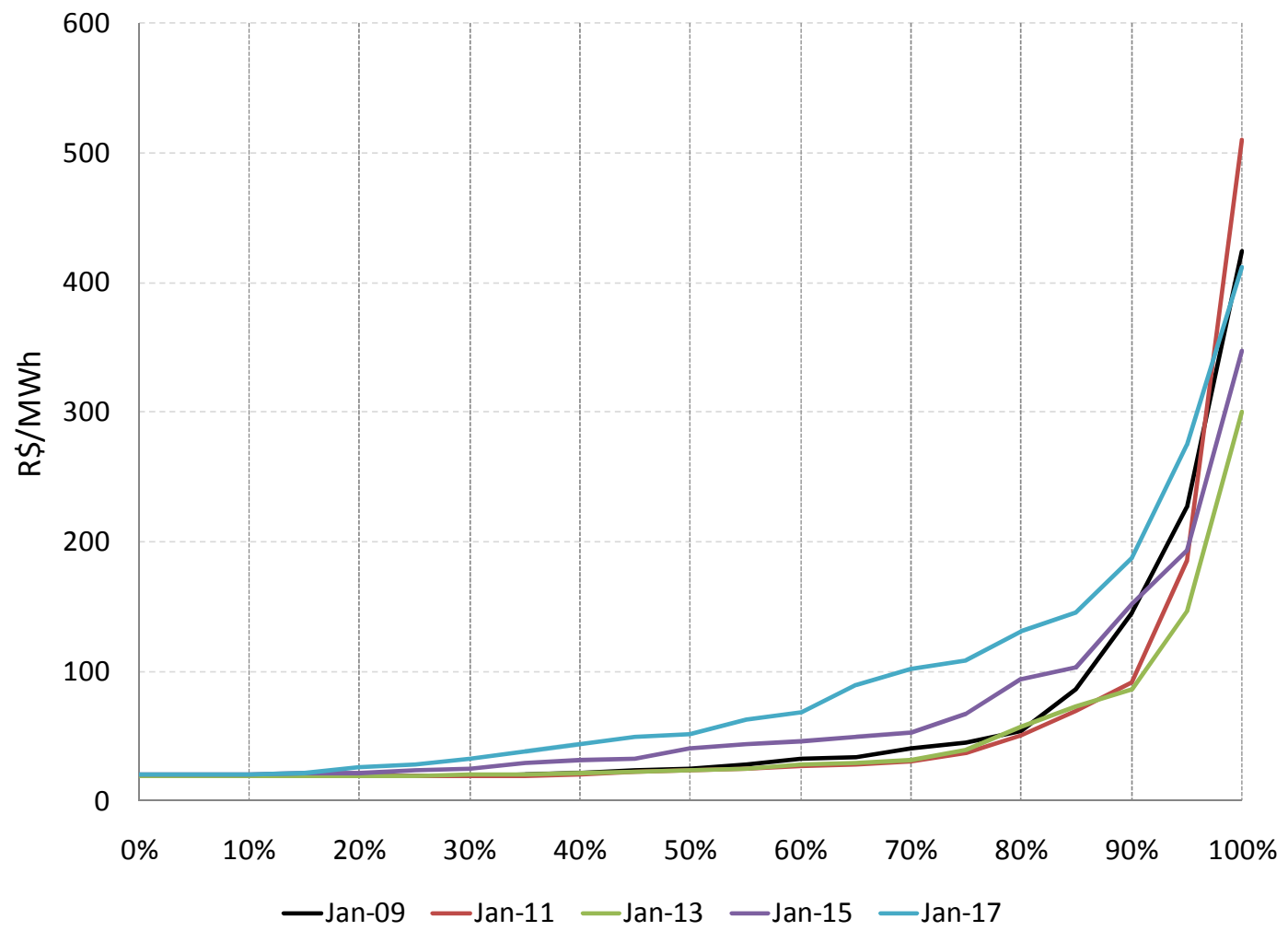

Figura 43 - Distribuições de Preços de Renovação - Cenário 3 


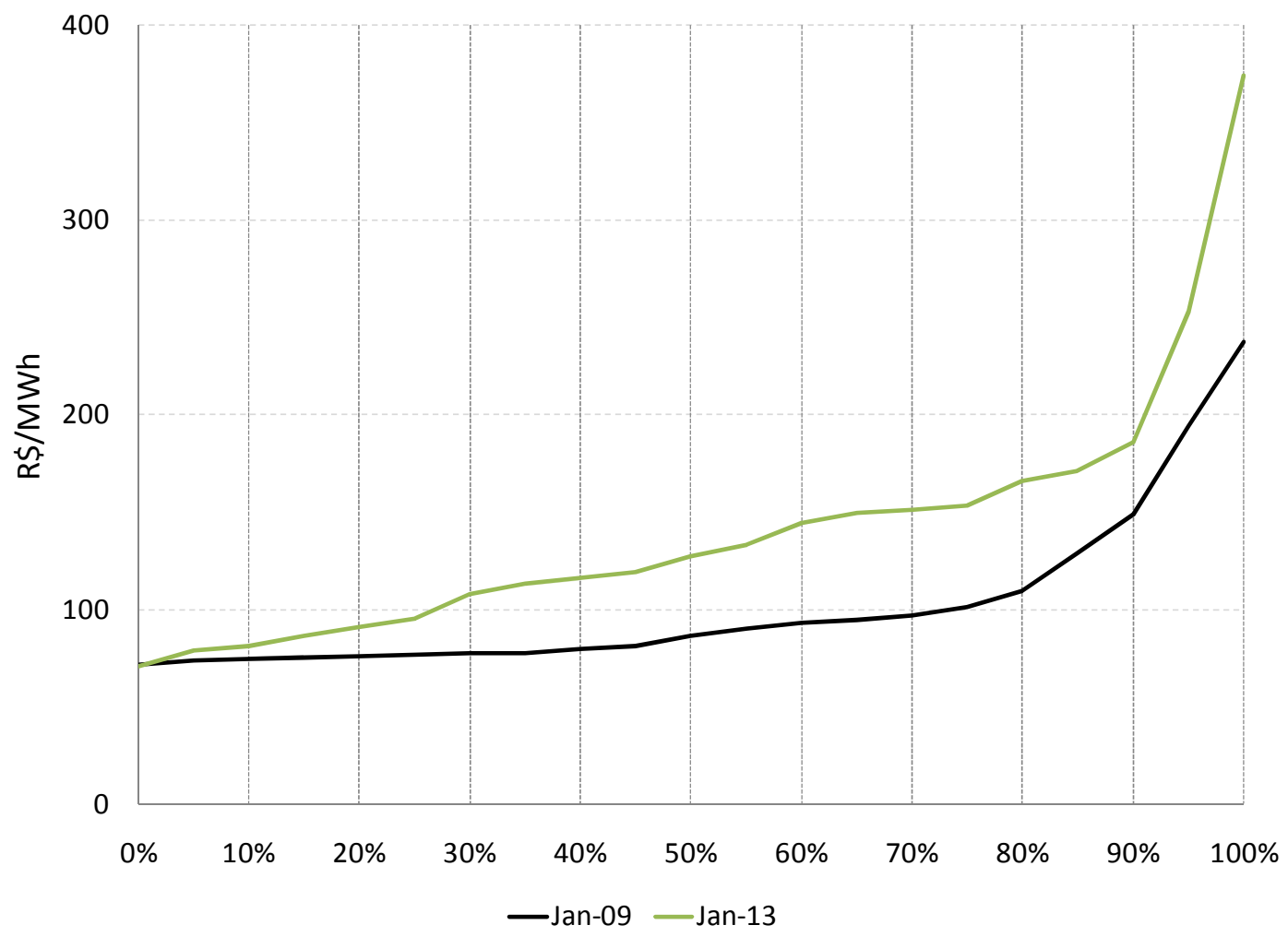

Figura 44 - Distribuições de Preços de Renovação - Cenário 4

A partir das distribuições de probabilidade apresentadas, é possível inferir que a probabilidade de ocorrência dos valores acima de $\mathrm{R} \$ 150$ por $\mathrm{MWh}$ para os contratos a serem firmados em janeiro de 2013 é de $7 \%, 8 \%, 5 \%$ e $35 \%$, respectivamente, para os Cenários 1, 2, 3 e 4.

Ainda a respeito das estratégias de contratação, o atual modelo do setor elétrico possibilita ao consumidor livre definir sua maneira de contratação de acordo com seu "apetite de risco". Assim, aqueles que dispõem de um perfil de risco mais agressivo podem optar por contratos mais curtos, beneficiando-se de preços reduzidos quando ocorrem afluências próximas ou superiores à média histórica, sendo penalizados do contrário. Já para os consumidores com perfil conservador as estratégias de contratação de médio e longo prazo trazem maior previsibilidade ao custo com aquisição de energia, porém, por outro lado, não permitem a esse auferir ganhos nos momentos de preços baixos. 
Também merece destaque que, uma vez que a estrutura tarifária vigente no ACR impõe tarifas mais elevadas no horário de ponta, os contratos no âmbito do ACL tornam-se mais atrativos.

Quanto à inserção de usinas eólicas no parque gerador por meio dos Leilões de Energia de Reserva, cumpre destacar que essa apresenta várias características atraentes, como abundante disponibilidade e complementaridade com a geração hidrelétrica. Tais características tornam a geração eólica uma alternativa para a expansão da capacidade de geração renovável do país, complementando a energia hidrelétrica e a bioeletricidade.

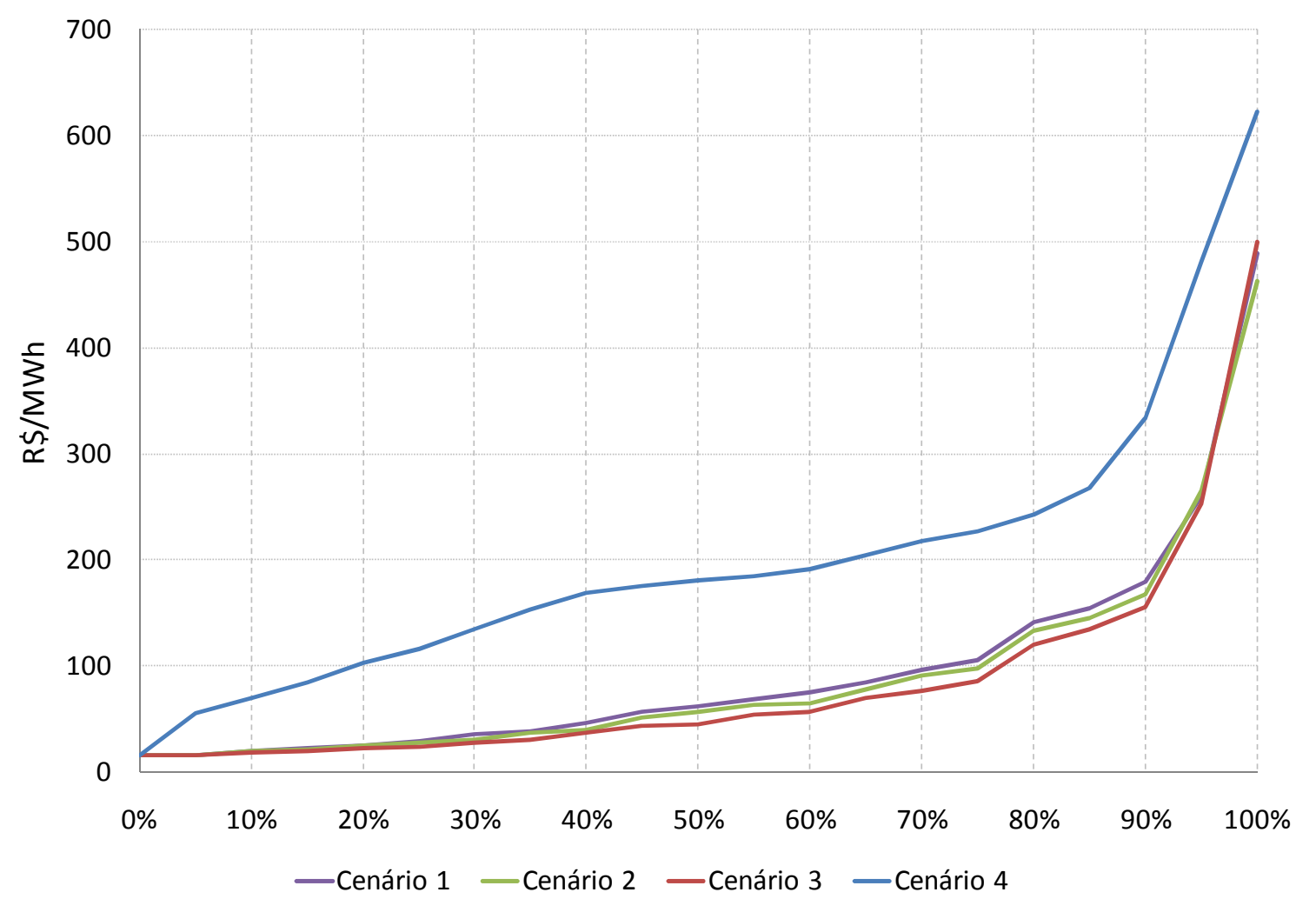

Figura 45 - Distribuições do PLD médio em 2016

O grande questionamento quanto à inserção da energia eólica na matriz nacional diz respeito ao seu preço, que atualmente encontra-se na ordem de $\mathrm{R} \$ 200$ por MWh. No entanto, segundo estimativas da Associação Brasileira de Energia Eólica (ABEEOLICA), quando adicionados os benefícios econômicos referentes à 
redução dos custos operativos termelétricos e à melhoria da operação das usinas hidrelétricas devido ao padrão de geração "anti-sazonal" da energia eólica, que levaria a reduções adicionais dos custos de operação, chega-se ao custo de cerca de $\mathrm{R} \$ 150$ por MWh. Além desses benefícios, também há de mencionar-se a redução da volatilidade das tarifas devido à variação dos preços internacionais dos combustíveis e da taxa de câmbio. 


\section{CONSIDERAÇÕES FINAIS}

O presente trabalho apresentou os aspectos teóricos envolvidos na definição dos preços praticados tanto no Ambiente de Contratação Regulado, quanto no Ambiente de Contratação Livre.

Dentro do escopo da previsão de preços para o $\mathrm{ACR}$, foram abordados os aspectos regulatórios que determinam a construção da Tarifa de Energia, com destaque para o custo dos contratos provenientes de novos empreendimentos de fonte térmica.

Para previsão dos preços praticados no $A C L$ foi elaborado um modelo de simulação, cujas premissas foram definidas com base no comportamento observado dos agentes de mercado.

Definidas as premissas que determinam os custos de contratação no ACR e ACL, foram realizadas simulações partindo de quatro cenários de PLD definidos a partir de análises críticas do Plano Decenal de Expansão de Energia (PDE) 2008/2017.

De posse dos resultados obtidos foram realizadas considerações sobre a estratégia de contratação de um grande consumidor de energia, tendo foco tanto no custo total, quanto nos riscos associados. Assim, entende-se que as ferramentas desenvolvidas colaboram na definição da estratégia de contratação de um grande consumidor de energia.

A respeito das recomendações de trabalhos futuros, sugere-se a implementação de um simulador que utilize Algoritmos Genéticos que objetivem a minimização do custo de contratação e o risco inerente, utilizando, por exemplo, a métrica do Value at Risk (VaR). 
Além disso, recomenda-se o desenvolvimento de metodologia para precificação dos contratos bilaterais de médio prazo que contemple a expectativa de PLD e/ou balanço de garantia firme. 


\section{REFERÊNCIAS}

ASSOCIAÇÃO BRASILEIRA DOS GRANDES CONSUMIDORES INDUSTRIAIS DE ENERGIA E DE CONSUMIDORES LIVRES - ABRACE. Expectativa de Evolução da Tarifa de Energia no Ambiente de Contratação Regulada - ACR, 2008.

AGÊNCIA NACIONAL DE ENERGIA ELÉTRICA - ANEEL. Brasília. Apresenta informações sobre regulamentação e fiscalização do setor elétrico. Disponível em: $<$ http://www.aneel.gov.br/>.

ANEEL - Agência Nacional de Energia Elétrica. Nota Técnica no 302/2005, "Estabelecimento das disposições relativas ao cálculo da tarifa de uso dos sistemas de distribuição - TUSD e tarifa de energia - TE" - Brasília, 2005.

ANEEL - Agência Nacional de Energia Elétrica. Nota Técnica no 092/2008SRE/ANEEL, que trata da segunda revisão tarifária periódica da empresa CEMIG - Brasília, 2008.

ANEEL - Agência Nacional de Energia Elétrica. Nota Técnica no 355/2008SRE/ANEEL, "Tarifa de repasse da potência oriunda de ITAIPU Binacional, com vigência a partir de 1ํ de janeiro de 2009." - Brasília, 2005.

BRASIL. Decreto $n^{\circ}$ 5.163, de 30 de julho de 2004. Regulamenta a comercialização de energia elétrica, o processo de outorga de concessões e de autorizações de geração de energia elétrica, e dá outras providências.

BRASIL. Decreto $n^{\circ} 5.177$, de 12 de agosto de 2004. Dispõe sobre a Câmara de Comercialização de Energia Elétrica - CCEE.

BRASIL. Lei $n^{\circ} 10.847$, de 15 de março de 2004. Auto riza a criação da Empresa de Pesquisa Energética - EPE.

BRASIL. Lei $\mathrm{n}^{\circ} 10.848$, de 15 de março de 2004. Dispõe sobre a comercialização de energia elétrica, altera as Leis nos 5.655, de 20 de maio de 1971, 8.631, de 4 de março de 1993, 9.074, de 7 de julho de 1995, 9.427, de 26 de dezembro de 1996, 9.478, de 6 de agosto de 1997, 9.648, de 27 de maio de 1998, 9.991, de 24 de julho de 2000, 10.438, de 26 de abril de 2002, e dá outras providências.

BRASIL. Resolução Normativa no 166, de 04 de Outubro de 2005. Estabelece as disposições consolidadas relativas ao cálculo da tarifa de uso dos sistemas de distribuição (TUSD) e da tarifa de energia elétrica (TE). 
CÂMARA DE COMERCIALIZAÇÃO DE ENERGIA ELÉTRICA - CCEE. São Paulo. Apresenta informações acerca do funcionamento do mercado de energia elétrica. Disponível em: <http://www.ccee.org.br/>.

CYRINO, R. A. S.; CAMPOS, C. E. N. Z. M. Gerenciamento de Risco da Compra de Energia no Novo Modelo do Setor Elétrico. Universidade de São Paulo. São Paulo, 2005.

EMPRESA DE PESQUISA ENERGÉTICA - EPE. Plano Decenal de Expansão de Energia 2008/2017. Rio de Janeiro, 2008.

KELMAN, R. Exemplo da Cadeia de Modelos de Planejamento Operativo. In: "A Nova Operação do Sistema Elétrico Brasileiro". 3a ed. DEE/CEE, PUCRio, 1999.

MEDEIROS, L. Previsão do Preço Sopt no Mercado de Energia Elétrica. Pontifícia Universidade Católica do Rio de Janeiro. Rio de Janeiro, 2004.

OPERADOR NACIONAL DO SISTEMA - ONS. Rio de Janeiro. Apresenta informações sobre a operação do Sistema Interligado Nacional - SIN. Disponível em: <http://www.ons.org.br/>.

PSR, Inserção da Energia Eólica Desafios e Oportunidades. Rio de Janeiro, 2009.

RAMOS, D. S. Reestruturação do Setor Elétrico Brasileiro. Material utilizado na disciplina Formação de Preços e Comercialização de Energia no Novo Ambiente do Setor em disciplina de pós-graduação da Escola Politécnica da USP, 2007, São Paulo.

SUSTERAS, G.L., RAMOS, D.S. Aplicação de Algoritmos Genéticos Para Previsão do Comportamento das Distribuidoras Como Apoio à Estratégia de Comercialização de Energia de Agentes Geradores. Universidade de São Paulo. São Paulo, 2006.

VITORINO, R.N., RAMOS, D.S. Análise de Estratégias de Comercialização de Energia para Consumidores Livres no Novo Ambiente Institucional do Setor Elétrico Brasileiro. Universidade de São Paulo. São Paulo, 2005. 
ANEXO 1 - DADOS UTILIZADOS NA PROJEÇÃO DA TARIFA DE ENERGIA 
Montantes Contratuais Considerados (MWh)

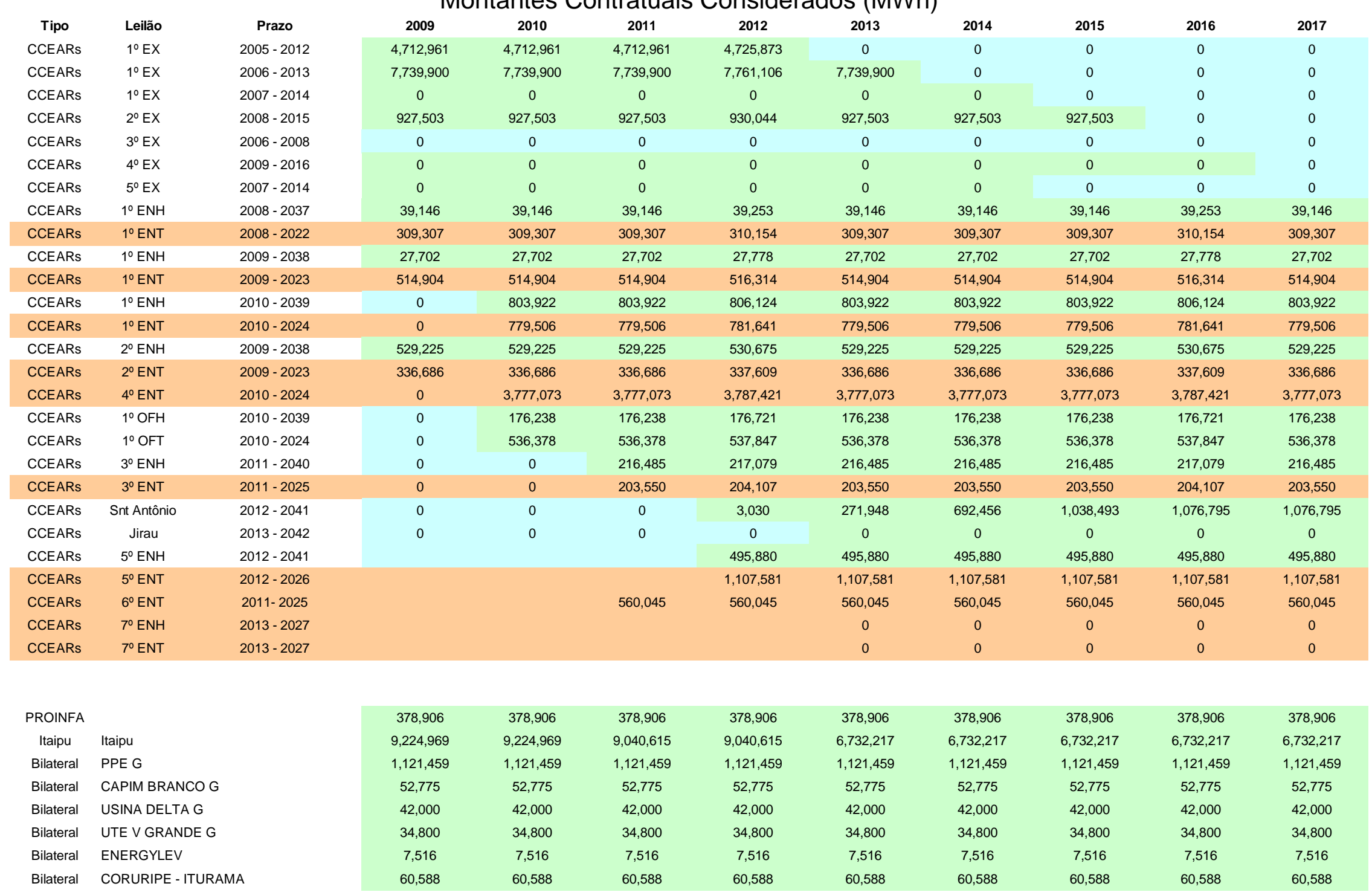




\begin{tabular}{|c|c|c|c|c|c|c|c|c|c|c|c|}
\hline \multicolumn{12}{|c|}{ Preços Contratuais Considerados ( $\mathrm{R} \$ / \mathrm{MWh})$} \\
\hline Tipo & Leiйо & Prazo & 2009 & 2010 & 2011 & 2012 & 2013 & 2014 & 2015 & 2016 & 2017 \\
\hline CCEAR & $10 \mathrm{EX}$ & $2005-2012$ & 66.85 & 66.85 & 66.85 & 66.85 & & & & & \\
\hline CCEAR & $1^{\circ} \mathrm{EX}$ & $2006-2013$ & 78.26 & 78.26 & 78.26 & 78.26 & 78.26 & & & & \\
\hline CCEAR & $1^{\circ} \mathrm{EX}$ & $2007-2014$ & & & & & & & & & \\
\hline CCEAR & $2^{\circ} \mathrm{EX}$ & $2008-2015$ & 91.84 & 91.84 & 91.84 & 91.84 & 91.84 & 91.84 & 91.84 & & \\
\hline CCEAR & $3^{\circ} \mathrm{EX}$ & $2006-2008$ & & & & & & & & & \\
\hline CCEAR & $4^{\circ} \mathrm{EX}$ & $2009-2016$ & & & & & & & & & \\
\hline CCEAR & $5^{\circ} \mathrm{EX}$ & $2007-2014$ & & & & & & & & & \\
\hline CCEAR & $1^{\circ} \mathrm{ENH}$ & $2008-2037$ & 117.62 & 117.62 & 117.62 & 117.62 & 117.62 & 117.62 & 117.62 & 117.62 & 117.62 \\
\hline CCEAR & $1^{\circ} \mathrm{ENT}$ & $2008-2022$ & 103.42 & 107.03 & 98.39 & 104.81 & 99.03 & 107.90 & 119.81 & 151.42 & 160.60 \\
\hline CCEAR & $1^{\circ} \mathrm{ENH}$ & $2009-2038$ & 125.68 & 125.68 & 125.68 & 125.68 & 125.68 & 125.68 & 125.68 & 125.68 & 125.68 \\
\hline CCEAR & 1ํ ENT & $2009-2023$ & 119.41 & 122.29 & 115.44 & 120.52 & 115.94 & 122.98 & 132.62 & 159.52 & 167.82 \\
\hline CCEAR & $1^{\circ} \mathrm{ENH}$ & $2010-2039$ & & 126.52 & 126.52 & 126.52 & 126.52 & 126.52 & 126.52 & 126.52 & 126.52 \\
\hline CCEAR & $1^{\circ} \mathrm{ENT}$ & $2010-2024$ & & 67.28 & 57.99 & 64.91 & 58.69 & 68.19 & 80.66 & 111.55 & 119.71 \\
\hline CCEAR & $2^{\circ} \mathrm{ENH}$ & $2009-2038$ & 137.30 & 137.30 & 137.30 & 137.30 & 137.30 & 137.30 & 137.30 & 137.30 & 137.30 \\
\hline CCEAR & $2^{\circ} \mathrm{ENT}$ & $2009-2023$ & 138.34 & 140.81 & 134.98 & 139.29 & 135.40 & 141.40 & 149.83 & 174.87 & 183.12 \\
\hline CCEAR & $4^{\circ} \mathrm{ENT}$ & $2010-2024$ & & 141.96 & 135.50 & 140.27 & 135.97 & 142.61 & 151.96 & 179.71 & 188.86 \\
\hline CCEAR & $1^{\circ} \mathrm{OFH}$ & $2010-2039$ & & 141.40 & 141.40 & 141.40 & 141.40 & 141.40 & 141.40 & 141.40 & 141.40 \\
\hline CCEAR & $1 \%$ OFT & $2010-2024$ & & 145.44 & 145.44 & 145.44 & 145.44 & 145.44 & 145.44 & 145.44 & 145.44 \\
\hline CCEAR & 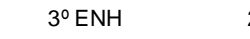 & $2011-2040$ & & & 129.89 & 129.89 & 129.89 & 129.89 & 129.89 & 129.89 & 129.89 \\
\hline CCEAR & $3^{\circ}$ ENT & $2011-2025$ & & & 125.82 & 130.73 & 126.30 & 133.14 & 142.76 & 171.32 & 180.73 \\
\hline CCEAR & Snt Antônio & $2012-2041$ & & & & 79.30 & 79.30 & 79.30 & 79.30 & 79.30 & 79.30 \\
\hline CCEAR & Jirau & $2013-2042$ & & & & & 70.81 & 70.81 & 70.81 & 70.81 & 70.81 \\
\hline CCEARs & 5 $\mathrm{ENH}$ & $2012-2041$ & & & & 133.30 & 133.30 & 133.30 & 133.30 & 133.30 & 133.30 \\
\hline CCEARs & $5^{\circ}$ ENT & $2012-2026$ & & & & 170.82 & 168.75 & 171.94 & 176.42 & 189.74 & 194.12 \\
\hline CCEARS & $6^{\circ}$ ENT & $2011-2025$ & & & 95.58 & 103.99 & 96.42 & 108.03 & 123.63 & 165.13 & 177.21 \\
\hline CCEARs & $7^{\circ} \mathrm{ENH}$ & $2013-2027$ & & & & & 96.45 & 96.45 & 96.45 & 96.45 & 96.45 \\
\hline CCEARs & $7^{\circ}$ ENT & $2013-2027$ & & & & & 96.42 & 108.03 & 123.63 & 165.13 & 177.21 \\
\hline PROINFA & & & 0.00 & 0.00 & 0.00 & 0.00 & 0.00 & 0.00 & 0.00 & 0.00 & 0.00 \\
\hline Itaipu & Itaipu & & 114.78 & 114.78 & 114.78 & 114.78 & 114.78 & 114.78 & 114.78 & 114.78 & 114.78 \\
\hline Bilateral & PPE G & & 126.26 & 126.26 & 126.26 & 126.26 & 126.26 & 126.26 & 126.26 & 126.26 & 126.26 \\
\hline Bilateral & CAPIM BRANCO G & & 141.78 & 141.78 & 141.78 & 141.78 & 141.78 & 141.78 & 141.78 & 141.78 & 141.78 \\
\hline Bilateral & USINA DELTA G & & 156.82 & 156.82 & 156.82 & 156.82 & 156.82 & 156.82 & 156.82 & 156.82 & 156.82 \\
\hline Bilateral & UTE V GRANDE G & & 156.82 & 156.82 & 156.82 & 156.82 & 156.82 & 156.82 & 156.82 & 156.82 & 156.82 \\
\hline Bilateral & ENERGYLEV & & 132.07 & 132.07 & 132.07 & 132.07 & 132.07 & 132.07 & 132.07 & 132.07 & 132.07 \\
\hline Bilateral & CORURIPE - ITURAM & & 140.86 & 140.86 & 140.86 & 140.86 & 140.86 & 140.86 & 140.86 & 140.86 & 140.86 \\
\hline
\end{tabular}


Preços dos Contratos por Disponibilidade $(\mathrm{R} \$ / \mathrm{MWh})$

\begin{tabular}{|c|c|c|c|c|c|c|c|c|c|c|c|c|}
\hline & Leilão & Produto & 2008 & 2009 & 2010 & 2011 & 2012 & 2013 & 2014 & 2015 & 2016 & 2017 \\
\hline \multirow{9}{*}{ Cenário 1} & $1^{\circ}$ & $2008-15$ & 134.51 & 103.42 & 107.03 & 98.39 & 104.81 & 99.03 & 107.90 & 119.81 & 151.42 & 160.60 \\
\hline & $1^{0}$ & 2009-15 & & 119.41 & 122.29 & 115.44 & 120.52 & 115.94 & 122.98 & 132.62 & 159.52 & 167.82 \\
\hline & $1^{0}$ & 2010-15 & & & 67.28 & 57.99 & 64.91 & 58.69 & 68.19 & 80.66 & 111.55 & 119.71 \\
\hline & $2^{0}$ & 2009-15 & & 138.34 & 140.81 & 134.98 & 139.29 & 135.40 & 141.40 & 149.83 & 174.87 & 183.12 \\
\hline & $3^{\circ}$ & 2011-15 & & & & 125.82 & 130.73 & 126.30 & 133.14 & 142.76 & 171.32 & 180.73 \\
\hline & $4^{\circ}$ & 2010-15 & & & 141.96 & 135.50 & 140.27 & 135.97 & 142.61 & 151.96 & 179.71 & 188.86 \\
\hline & $5^{\circ}$ & 2012-15 & & & & & 170.82 & 168.75 & 171.94 & 176.42 & 189.74 & 194.12 \\
\hline & $6^{\circ}$ & 2011-15 & & & & 95.58 & 103.99 & 96.42 & 108.03 & 123.63 & 165.13 & 177.21 \\
\hline & $7^{0}$ & 2013-15 & & & & & & 96.42 & 108.03 & 123.63 & 165.13 & 177.21 \\
\hline
\end{tabular}

\begin{tabular}{|c|c|c|c|c|c|c|c|c|c|c|c|c|}
\hline & Leiăo & Produto & 2008 & 2009 & 2010 & 2011 & 2012 & 2013 & 2014 & 2015 & 2016 & 2017 \\
\hline \multirow{9}{*}{ Cenário 2} & 1 & $2008-15$ & 134.51 & 104.16 & 108.33 & 98.89 & 104.00 & 97.90 & 103.67 & 115.27 & 146.73 & 154.43 \\
\hline & 1 & $2009-15$ & & 120.00 & 123.32 & 115.83 & 119.87 & 115.05 & 119.61 & 128.92 & 155.38 & 162.21 \\
\hline & 1 & 2010-15 & & & 68.65 & 58.54 & 64.03 & 57.46 & 63.68 & 75.96 & 107.22 & 114.27 \\
\hline & 2 & $2009-15$ & & 138.84 & 141.70 & 135.31 & 138.73 & 134.66 & 138.51 & 146.56 & 170.86 & 177.52 \\
\hline & 3 & $2011-15$ & & & & 126.20 & 130.10 & 125.45 & 129.85 & 139.03 & 166.74 & 174.34 \\
\hline & 4 & $2010-15$ & & & 142.94 & 135.87 & 139.66 & 135.14 & 139.41 & 148.34 & 175.27 & 182.65 \\
\hline & 5 & 2012-15 & & & & & 170.52 & 168.35 & 170.40 & 174.68 & 187.60 & 191.14 \\
\hline & 6 & 2011-15 & & & & 96.24 & 102.92 & 94.95 & 102.49 & 117.68 & 158.97 & 169.09 \\
\hline & 7 & $2013-15$ & & & & & & 94.95 & 10249 & 11768 & 158.97 & 16909 \\
\hline
\end{tabular}

\begin{tabular}{|c|c|c|c|c|c|c|c|c|c|c|c|c|}
\hline & Leilão & Produto & 2008 & 2009 & 2010 & 2011 & 2012 & 2013 & 2014 & 2015 & 2016 & 2017 \\
\hline \multirow{9}{*}{ Cenário 3} & 1 & $2008-15$ & 134.51 & 102.19 & 106.54 & 96.73 & 100.59 & 91.39 & 98.02 & 108.80 & 138.40 & 147.47 \\
\hline & 1 & $2009-15$ & & 118.44 & 121.90 & 114.13 & 117.17 & 109.96 & 115.15 & 123.70 & 148.16 & 156.03 \\
\hline & 1 & $2010-15$ & & & 66.76 & 56.19 & 60.37 & 50.36 & 57.59 & 69.15 & 99.28 & 107.90 \\
\hline & 2 & 2009-15 & & 137.52 & 140.47 & 133.88 & 136.44 & 130.40 & 134.73 & 142.02 & 164.00 & 171.48 \\
\hline & 3 & 2011-15 & & & & 124.56 & 127.49 & 120.60 & 125.54 & 133.85 & 158.92 & 167.45 \\
\hline & 4 & 2010-15 & & & 141.59 & 134.28 & 137.12 & 130.43 & 135.23 & 143.31 & 167.67 & 175.95 \\
\hline & 5 & 2012-15 & & & & & 169.30 & 166.09 & 168.39 & 172.27 & 183.96 & 187.93 \\
\hline & 6 & 2011-15 & & & & 93.41 & 98.46 & 86.43 & 95.10 & 109.21 & 148.02 & 159.93 \\
\hline & 7 & 2013-15 & & & & & & 86.43 & 95.10 & 109.21 & 148.02 & 159.93 \\
\hline
\end{tabular}

\begin{tabular}{|c|c|c|c|c|c|c|c|c|c|c|c|c|}
\hline & Leião & Produto & 2008 & 2009 & 2010 & 2011 & 2012 & 2013 & 2014 & 2015 & 2016 & 2017 \\
\hline \multirow{9}{*}{ Cenário 4} & 1 & $2008-15$ & 134.51 & 84.53 & 132.76 & 154.78 & 169.88 & 174.20 & 188.72 & 200.82 & 219.54 & 220.18 \\
\hline & 1 & $2009-15$ & & 104.65 & 143.37 & 162.53 & 176.53 & 180.70 & 195.57 & 209.34 & 237.39 & 238.76 \\
\hline & 1 & $2010-15$ & & & 93.76 & 114.59 & 127.45 & 130.83 & 140.89 & 146.96 & 145.23 & 144.47 \\
\hline & 2 & $2009-15$ & & 126.03 & 159.56 & 177.83 & 192.10 & 196.53 & 213.06 & 229.63 & 268.82 & 271.00 \\
\hline & 3 & 2011-15 & & & & 174.70 & 190.98 & 196.03 & 214.88 & 233.79 & 278.49 & 280.97 \\
\hline & 4 & 2010-15 & & & 162.74 & 183.00 & 198.82 & 203.73 & 222.04 & 240.42 & 283.86 & 286.27 \\
\hline & 5 & $2012-15$ & & & & & 198.90 & 201.25 & 210.04 & 218.86 & 239.69 & 240.85 \\
\hline & 6 & 2011-15 & & & & 169.56 & 189.46 & 195.16 & 214.40 & 230.52 & 255.94 & 256.83 \\
\hline & 7 & 2013-15 & & & & & & 195.16 & 214.40 & 230.52 & 255.94 & 256.83 \\
\hline
\end{tabular}


Resultados da Tarifa de Energia ( $\mathrm{R} \$ \mathrm{MWh}$ )

Consumidor 1

\begin{tabular}{|c|c|c|c|c|c|c|c|c|c|c|}
\hline TE & $2008 / 2009$ & 2009 / 2010 & 2010 / 2011 & $2011 / 2012$ & 2012 / 2013 & $2013 / 2014$ & 2014 / 2015 & 2015 / 2016 & $2016 / 2017$ & 2017 / 2018 \\
\hline Cenário 1 & 115.65 & 126.79 & 124.52 & 118.97 & 122.93 & 127.15 & 137.39 & 145.13 & 150.54 & 152.71 \\
\hline Cenário 2 & 115.65 & 126.88 & 124.67 & 118.98 & 122.73 & 126.74 & 136.50 & 144.16 & 149.41 & 151.34 \\
\hline Cenário 3 & 115.65 & 126.70 & 124.42 & 118.59 & 122.00 & 125.54 & 135.41 & 142.83 & 147.79 & 149.95 \\
\hline Cenário 4 & 115.65 & 127.49 & 130.75 & 130.73 & 137.54 & 145.14 & 156.92 & 165.44 & 170.80 & 171.15 \\
\hline
\end{tabular}

Consumidor 2

\begin{tabular}{|c|c|c|c|c|c|c|c|c|c|c|}
\hline TE & 2008 / 2009 & 2009 / 2010 & $2010 / 2011$ & $2011 / 2012$ & 2012 / 2013 & 2013 / 2014 & 2014 / 2015 & 2015 / 2016 & $2016 / 2017$ & 2017 / 2018 \\
\hline Cenário 1 & 109.29 & 120.13 & 118.72 & 114.06 & 117.86 & 121.91 & 131.72 & 139.14 & 144.33 & 146.41 \\
\hline Cenário 2 & 109.29 & 120.22 & 118.87 & 114.07 & 117.67 & 121.51 & 130.87 & 138.21 & 143.24 & 145.10 \\
\hline Cenário 3 & 109.29 & 120.05 & 118.63 & 113.70 & 116.96 & 120.36 & 129.82 & 136.94 & 141.69 & 143.76 \\
\hline Cenário 4 & 109.29 & 120.81 & 124.69 & 125.33 & 131.86 & 139.15 & 150.44 & 158.61 & 163.76 & 164.09 \\
\hline
\end{tabular}


ANEXO 2 - CARACTERÍSTICAS DAS USINAS TÉRMICAS 
Características das Usinas Térmicas vencedoras dos Leilões de Energia Nova

\begin{tabular}{|c|c|c|c|c|c|c|c|c|c|}
\hline Proprietário & Usina & Tipo & Submercado & Leilão & Produto & $\begin{array}{l}\text { Venda Total } \\
\text { (MW médio) }\end{array}$ & $\begin{array}{l}\text { Receita Fixa } \\
\text { (R\$/ano) }\end{array}$ & $\begin{array}{l}\text { Inflexibilidade } \\
\text { (MW médio) }\end{array}$ & $\begin{array}{l}\text { Custo Variável } \\
\text { (R\$/MWh) }\end{array}$ \\
\hline ENGUIA GEN PI & Altos & Diesel & $\mathrm{NE}$ & 1 & $2008-15$ & 7.000 & $2,344,035$ & 0.00 & 567.18 \\
\hline ENGUIA GEN CE & Aracati & Diesel & $\mathrm{NE}$ & 1 & $2008-15$ & 6.000 & $2,236,109$ & 0.00 & 567.18 \\
\hline ENGUIA GEN CE & Baturité & Diesel & $\mathrm{NE}$ & 1 & $2008-15$ & 6.000 & $2,236,109$ & 0.00 & 567.18 \\
\hline ENGUIA GEN PI & Campo Maior & Diesel & $\mathrm{NE}$ & 1 & $2008-15$ & 7.000 & $2,344,035$ & 0.00 & 567.18 \\
\hline UTE COCAL & COCAL & Biomassa & SE & 1 & $2008-15$ & 10.000 & $4,624,772$ & 0.00 & 127.58 \\
\hline ENGUIA GEN CE & Crato & Diesel & $\mathrm{NE}$ & 1 & $2008-15$ & 7.000 & $2,344,035$ & 0.00 & 567.18 \\
\hline ENGEBRA & Daia & Oleo & SE & 1 & $2008-15$ & 19.000 & $7,767,294$ & 0.00 & 617.56 \\
\hline ENGUIA GEN CE & Iguatu & Diesel & $\mathrm{NE}$ & 1 & $2008-15$ & 8.000 & $3,116,814$ & 0.00 & 567.18 \\
\hline USINA INTERLAGOS & Interlagos & Biomassa & SE & 1 & $2008-15$ & 6.000 & $7,500,130$ & 0.00 & 0.00 \\
\hline ENGUIA GEN BA & Jaguarari & Diesel & $\mathrm{NE}$ & 1 & $2008-15$ & 59.000 & $21,767,757$ & 0.00 & 558.67 \\
\hline ENGUIA GEN CE & Juazeiro do Norte & Diesel & NE & 1 & $2008-15$ & 8.000 & $3,116,814$ & 0.00 & 567.18 \\
\hline ENGUIA GEN PI & Marambaia & Diesel & $\mathrm{NE}$ & 1 & $2008-15$ & 7.000 & $2,344,035$ & 0.00 & 567.18 \\
\hline ENGUIA GEN PI & Nazária & Diesel & $\mathrm{NE}$ & 1 & $2008-15$ & 7.000 & $2,344,035$ & 0.00 & 567.18 \\
\hline ENGUIA GEN CE & Pecem & Diesel & $\mathrm{NE}$ & 1 & $2008-15$ & 8.000 & $3,116,814$ & 0.00 & 567.18 \\
\hline PIE-RP TERMELÉTRICA & PIE - RP & Biomassa & SE & 1 & $2008-15$ & 9.000 & $4,199,211$ & 0.00 & 138.67 \\
\hline UTE QUIRINOPÓLIS & Quirinópolis & Biomassa & SE & 1 & $2008-15$ & 6.000 & $7,616,527$ & 0.00 & 0.00 \\
\hline TERMORIO & Termorio & Gas & SE & 1 & $2008-15$ & 352.000 & $227,698,465$ & 62.75 & 118.30 \\
\hline ARUANÃ ENERGIA & Xavante Aruanã & Diesel & SE & 1 & $2008-15$ & 21.000 & $5,778,913$ & 0.00 & 895.43 \\
\hline UTE COCAL & COCAL & Biomassa & SE & 1 & $2009-15$ & 9.000 & $5,481,022$ & 0.00 & 127.58 \\
\hline COSAN BIOENERGIA & Costa Pinto & Biomassa & SE & 1 & $2009-15$ & 19.000 & $30,683,250$ & \#N/D & 0.00 \\
\hline SFE & Eletrobolt & Gas & SE & 1 & $2009-15$ & 278.000 & $146,894,032$ & 0.00 & 161.34 \\
\hline BENCO ENGENHARIA (4)/PETROBRA & Goiânia II & Diesel & SE & 1 & $2009-15$ & 65.000 & $29,225,280$ & 0.00 & 662.09 \\
\hline PIE-RP TERMELÉTRICA & PIE - RP & Biomassa & SE & 1 & $2009-15$ & 10.000 & $5,639,966$ & 0.00 & 138.67 \\
\hline COSAN BIOENERGIA & Rafard & Biomassa & SE & 1 & $2009-15$ & 12.000 & $19,163,580$ & $\# N / D$ & 0.00 \\
\hline TERMOCEARA & Termoceará & Gas & $\mathrm{NE}$ & 1 & $2009-15$ & 64.000 & $28,502,633$ & 0.00 & 177.45 \\
\hline PETROBRAS PIE & Três Lagoas (Expansão) & Gas & SE & 1 & $2009-15$ & 127.000 & $64,875,306$ & 0.00 & 108.80 \\
\hline ARUANÃ ENERGIA & Xavante Aruanã & Diesel & SE & 1 & $2009-15$ & 1.000 & 275,186 & 0.00 & 895.43 \\
\hline CGTEE & Candiota III & Carvao & $\mathrm{s}$ & 1 & $2010-15$ & 292.000 & $377,422,719$ & 0.00 & 41.28 \\
\hline SANTISTA & Cubatão & Gas & SE & 1 & $2010-15$ & 141.000 & $97,316,553$ & 0.00 & 159.31 \\
\hline TERMOCEARA & Termoceará & Gas & NE & 1 & $2010-15$ & 77.000 & $30,334,251$ & 0.00 & 177.45 \\
\hline TERMORIO & Termorio & Gas & SE & 1 & $2010-15$ & 352.000 & $189,016,779$ & 62.75 & 118.30 \\
\hline BRMDC & Camacari Muricy I & Oleo & $\mathrm{NE}$ & 2 & $2009-15$ & 101.000 & $61,102,262.93$ & 0.00 & 429.05 \\
\hline BRGEC & Camacari Polo de Apoio I & Oleo & NE & 2 & $2009-15$ & 101.000 & $60,983,317.07$ & 0.00 & 429.05 \\
\hline CISFRAMA & Cisframa & Biomassa & $\mathrm{s}$ & 2 & $2009-15$ & 2.000 & $1,656,264.97$ & 0.00 & 150.00 \\
\hline ACUCAR RIBEIRO & Colorado & Biomassa & SE & 2 & $2009-15$ & 8.000 & $10,663,058.56$ & 16.02 & 36.00 \\
\hline TERMOMANAUS & Pau Ferro I & Diesel & $\mathrm{NE}$ & 2 & $2009-15$ & 46.000 & $28,176,702.83$ & 0.00 & 705.00 \\
\hline CIA. PETROLINA & Petrolina & Oleo & $\mathrm{NE}$ & 2 & $2009-15$ & 84.000 & $50,962,689.59$ & 0.00 & 470.73 \\
\hline TEP & Potiguar & Diesel & $\mathrm{NE}$ & 2 & $2009-15$ & 27.000 & $16,387,076.63$ & 0.00 & 635.90 \\
\hline TEP & Potiguar III & Diesel & $\mathrm{NE}$ & 2 & $2009-15$ & 29.000 & $17,716,339.23$ & 0.00 & 635.89 \\
\hline USJ - UTE QUIRI & Quirinopolis & Biomassa & SE & 2 & $2009-15$ & 11.000 & $14,800,904$ & \#N/D & 0.00 \\
\hline SANTA ISABEL & Santa Isabel & Biomassa & $\mathrm{SE}$ & 2 & $2009-15$ & 11.000 & $14,830,613$ & \#N/D & 0.00 \\
\hline ACUCAREIRA ZILLO & Sao Jose & Biomassa & SE & 2 & $2009-15$ & 28.000 & $37,022,459$ & \#N/D & 0.00 \\
\hline SJEABIOGAS & São João Biogás & Biomassa & SE & 2 & $2009-15$ & 10.000 & $12,977,442$ & \#N/D & 0.00 \\
\hline TERMOMANAUS & Termomanaus & Diesel & $\mathrm{NE}$ & 2 & $2009-15$ & 70.000 & $42,865,394.18$ & 0.00 & 705.00 \\
\hline
\end{tabular}




\begin{tabular}{|c|c|c|c|c|c|c|c|c|c|}
\hline Proprietário & Usina & Tipo & Submercado & Leilão & Produto & $\begin{array}{l}\text { Venda Total } \\
\text { (MW médio) }\end{array}$ & $\begin{array}{l}\text { Receita Fixa } \\
\text { (R\$/ano) }\end{array}$ & $\begin{array}{l}\text { Inflexibilidade } \\
\text { (MW médio) }\end{array}$ & $\begin{array}{l}\text { Custo Variável } \\
\text { (R\$/MWh) }\end{array}$ \\
\hline UTE BAHIA I & Bahia I & Oleo & $\mathrm{NE}$ & 3 & 2011-15 & 5.000 & $2,827,584.27$ & 0.00 & 430.19 \\
\hline VALE VERDE & Baia Formosa & Biomassa & $\mathrm{NE}$ & 3 & 2011-15 & 11.000 & $15,609,888$ & $\# N / D$ & 0.00 \\
\hline USINA BOA VISTA & Boa Vista & Biomassa & SE & 3 & 2011-15 & 11.000 & $14,874,658$ & $\# N / D$ & 0.00 \\
\hline THYSSENKRUPP CSA & Do Atlantico & Residuos I & SE & 3 & 2011-15 & 200.000 & $266,189,638.47$ & 0.00 & 94.00 \\
\hline FERRARI AGRO & Ferrari & Biomassa & SE & 3 & 2011-15 & 8.000 & $10,941,010$ & $\# N / D$ & 0.00 \\
\hline TERMOMACAE & Macae Merchant & Gas & SE & 3 & 2011-15 & 200.000 & $122,749,050.12$ & 0.00 & 281.27 \\
\hline ENGEBRA & Palmeiras de Goias & Diesel & SE & 3 & 2011-15 & 69.000 & $34,028,805.30$ & 0.00 & 515.79 \\
\hline ACUCAREIRA QUATA & Quata & Biomassa & SE & 3 & 2011-15 & 10.000 & $13,725,962$ & $\# N / D$ & 0.00 \\
\hline CORONA BIOENERGIA & Usina Bonfim & Biomassa & SE & 3 & 2011-15 & 21.000 & $28,772,156$ & $\# N / D$ & 0.00 \\
\hline BORBOREMA & Campina Grande & Oleo & $\mathrm{NE}$ & 4 & $2010-15$ & 119.000 & $71,368,215.18$ & 0.00 & 287.86 \\
\hline GLOBAL & Global I & Oleo & $\mathrm{NE}$ & 4 & 2010-15 & 105.000 & $66,094,595.01$ & 0.00 & 287.42 \\
\hline GLOBAL & Global II & Oleo & $\mathrm{NE}$ & 4 & $2010-15$ & 109.000 & $68,568,165.94$ & 0.00 & 287.42 \\
\hline SOUTHBAHIA & Itapebi & Oleo & $\mathrm{NE}$ & 4 & 2010-15 & 103.000 & $62,306,653.84$ & 0.00 & 286.33 \\
\hline THERMES & Maracanau I & Oleo & $\mathrm{NE}$ & 4 & 2010-15 & 119.000 & $71,886,759.54$ & 0.00 & 277.39 \\
\hline SOUTHBAHIA & Monte Pascoal & Oleo & $\mathrm{NE}$ & 4 & 2010-15 & 104.000 & $62,387,746.19$ & 0.00 & 280.49 \\
\hline SOBRAL & Nova Olinda & Oleo & $\mathrm{N}$ & 4 & 2010-15 & 120.000 & $75,023,927.08$ & 0.00 & 287.85 \\
\hline TERMOCABO & Termocabo & Oleo & $\mathrm{NE}$ & 4 & 2010-15 & 38.000 & $23,418,100.65$ & 0.00 & 284.44 \\
\hline TERMOMANAUS & Termonordeste & Oleo & $\mathrm{NE}$ & 4 & 2010-15 & 123.000 & $77,269,719.63$ & 0.00 & 287.28 \\
\hline TERMOMANAUS & Termoparaiba & Oleo & $\mathrm{NE}$ & 4 & 2010-15 & 123.000 & $77,196,888.07$ & 0.00 & 287.28 \\
\hline SOBRAL & Tocantinopolis & Oleo & $\mathrm{N}$ & 4 & 2010-15 & 120.000 & $74,908,311.64$ & 0.00 & 287.85 \\
\hline WBR & Viana & Oleo & SE & 4 & 2010-15 & 121.000 & $69,839,994.72$ & 0.00 & 291.62 \\
\hline THERMES & Maracanau II & Oleo & $\mathrm{NE}$ & 5 & $2012-15$ & 51.000 & $29,685,529.23$ & 0.00 & 299.51 \\
\hline MPX & MPX & Carvao & $\mathrm{NE}$ & 5 & 2012-15 & 615.000 & $455,404,492.74$ & 0.00 & 106.30 \\
\hline FURNAS & Santa Cruz Nova - unidades 1 e 2 & Gas & SE & 5 & 2012-15 & 351.000 & $197,031,434.01$ & 0.00 & 150.60 \\
\hline SUAPE II & Suape II & Oleo & $\mathrm{NE}$ & 5 & 2012-15 & 265.000 & $154,592,830.74$ & 0.00 & 311.77 \\
\hline DIFERENCIAL & Termomaranhao & Carvao & $\mathrm{N}$ & 5 & 2012-15 & 315.000 & $240,756,026.06$ & 0.00 & 106.16 \\
\hline CONS.AGROENERGIA & Jose Alencar & GNL & $\mathrm{NE}$ & 6 & 2011-15 & 169.000 & $87,990,002.70$ & 0.00 & 195.27 \\
\hline CONS.LINHARES & Linhares & GNL & SE & 6 & 2011-15 & 96.000 & $46,993,348.62$ & 0.00 & 237.87 \\
\hline CONS. MC2 EB BA1 & MC2 Camacari 1 & Oleo & $\mathrm{NE}$ & 6 & 2011-15 & 102.000 & $56,833,010.70$ & 0.00 & 185.57 \\
\hline CONS. MC2 EB BA1 & MC2 Catu & Oleo & $\mathrm{NE}$ & 6 & 2011-15 & 102.000 & $57,735,040.19$ & 0.00 & 185.57 \\
\hline CONS. MC2 EB BA2 & MC2 Dias Davila 1 & Oleo & $\mathrm{NE}$ & 6 & 2011-15 & 102.000 & $57,284,025.44$ & 0.00 & 185.57 \\
\hline CONS. MC2 EB BA2 & MC2 Dias Davila 2 & Oleo & $\mathrm{NE}$ & 6 & 2011-15 & 102.000 & $56,381,995.95$ & 0.00 & 185.57 \\
\hline CONS. MC2 EB BA3 & MC2 Senhor do Bonfim & Oleo & $\mathrm{NE}$ & 6 & 2011-15 & 102.000 & $58,628,049.59$ & 0.00 & 185.57 \\
\hline CONS. MC2 EB RS BA & MC2 Feira de Santana & Oleo & $\mathrm{NE}$ & 6 & 2011-15 & 101.000 & $58,128,109.29$ & 0.00 & 186.04 \\
\hline CONS. PERNAMBUCO IV & Pernambuco IV & Oleo & $\mathrm{NE}$ & 6 & 2011-15 & 107.000 & $63,602,824.13$ & 0.00 & 204.00 \\
\hline CONS. SANTA RITA DE CASSIA & Santa Rita de Cassia & Oleo & $\mathrm{NE}$ & 6 & 2011-15 & 93.000 & $54,293,921.41$ & 0.00 & 204.00 \\
\hline
\end{tabular}


ANEXO 3 - RESULTADOS DOS CONTRATOS BILATERAIS 
Resultados dos Contratos Bilaterais ( $\mathrm{R} \$ \mathrm{MWh})$

Cenário 1

\begin{tabular}{|l|c|c|c|c|c|c|c|c|c|}
\hline Vigência de cada contrato & $\mathbf{2 0 0 9}$ & $\mathbf{2 0 1 0}$ & $\mathbf{2 0 1 1}$ & $\mathbf{2 0 1 2}$ & $\mathbf{2 0 1 3}$ & $\mathbf{2 0 1 4}$ & $\mathbf{2 0 1 5}$ & $\mathbf{2 0 1 6}$ & $\mathbf{2 0 1 7}$ \\
\hline 1 Ano & 60.99 & 64.86 & 55.83 & 60.24 & 53.89 & 60.94 & 70.63 & 100.97 & 109.80 \\
\hline 2 Ano & 58.03 & 58.03 & 53.88 & 53.88 & 53.08 & 53.08 & 77.17 & 77.17 & 102.97 \\
\hline 3 Ano & 82.14 & 82.14 & 82.14 & 78.59 & 78.59 & 78.59 & 95.99 & 95.99 & 95.99 \\
\hline 4 Ano & 90.03 & 90.03 & 90.03 & 90.03 & 87.36 & 87.36 & 87.36 & 87.36 & 87.36 \\
\hline
\end{tabular}

Cenário 2

\begin{tabular}{|l|l|l|l|l|l|l|l|r|r|}
\hline Vigência de cada contrato & $\mathbf{2 0 0 9}$ & $\mathbf{2 0 1 0}$ & $\mathbf{2 0 1 1}$ & $\mathbf{2 0 1 2}$ & $\mathbf{2 0 1 3}$ & $\mathbf{2 0 1 4}$ & $\mathbf{2 0 1 5}$ & $\mathbf{2 0 1 6}$ & $\mathbf{2 0 1 7}$ \\
\hline 1 Ano & 61.47 & 66.15 & 56.37 & 59.62 & 53.23 & 57.34 & 66.36 & 95.64 & 102.24 \\
\hline A Ano & 58.21 & 58.21 & 52.65 & 52.65 & 50.57 & 50.57 & 72.50 & 72.50 & 95.37 \\
\hline 3 Ano & 82.21 & 82.21 & 82.21 & 76.80 & 76.80 & 76.80 & 92.69 & 92.69 & 92.69 \\
\hline 4 Ano & 90.05 & 90.05 & 90.05 & 90.05 & 85.58 & 85.58 & 85.58 & 85.58 & 85.58 \\
\hline
\end{tabular}

Cenário 3

\begin{tabular}{|l|l|l|l|l|l|l|l|l|l|}
\hline Vigência de cada contrato & $\mathbf{2 0 0 9}$ & $\mathbf{2 0 1 0}$ & $\mathbf{2 0 1 1}$ & $\mathbf{2 0 1 2}$ & $\mathbf{2 0 1 3}$ & $\mathbf{2 0 1 4}$ & $\mathbf{2 0 1 5}$ & $\mathbf{2 0 1 6}$ & $\mathbf{2 0 1 7}$ \\
\hline 1 Ano & 59.83 & 64.60 & 54.53 & 56.85 & 47.45 & 52.64 & 60.44 & 87.32 & 94.28 \\
\hline 2 Anos & 56.48 & 56.48 & 52.25 & 52.25 & 45.74 & 45.74 & 65.51 & 65.51 & 87.35 \\
\hline 3 Anos & 81.05 & 81.05 & 81.05 & 75.79 & 75.79 & 75.79 & 87.76 & 87.76 & 87.76 \\
\hline 4 Anos & 89.05 & 89.05 & 89.05 & 89.05 & 82.85 & 82.85 & 82.85 & 82.85 & 82.85 \\
\hline
\end{tabular}

Cenário 4

\begin{tabular}{|c|c|c|c|c|c|c|c|c|c|}
\hline Vigência de cada contrato & 2009 & 2010 & 2011 & 2012 & 2013 & 2014 & 2015 & 2016 & 2017 \\
\hline 1 Ano & 59.07 & 87.55 & 110.74 & 127.10 & 131.10 & 150.80 & 171.44 & 221.61 & 224.15 \\
\hline 2 Anos & 71.94 & 71.94 & 113.78 & 113.78 & 135.92 & 135.92 & 185.19 & 185.19 & 219.71 \\
\hline 3 Anos & 92.72 & 92.72 & 92.72 & 128.45 & 128.45 & 128.45 & 172.03 & 172.03 & 172.03 \\
\hline 4 Anos & 100.77 & 100.77 & 100.77 & 100.77 & 137.83 & 137.83 & 137.83 & 137.83 & 137.83 \\
\hline
\end{tabular}


Frequência acumulada dos preços dos contratos de dois anos no momento de renovação $(\mathrm{R} \$ / M W h)$ - Cenário 1

\begin{tabular}{|c|c|c|c|c|c|}
\hline & Jan-09 & Jan-11 & Jan-13 & Jan-15 & Jan-17 \\
\hline $0 \%$ & 20 & 20 & 20 & 20 & 20 \\
\hline $5 \%$ & 20 & 20 & 20 & 21 & 20 \\
\hline $10 \%$ & 20 & 20 & 20 & 21 & 22 \\
\hline $15 \%$ & 20 & 20 & 20 & 22 & 27 \\
\hline $20 \%$ & 20 & 20 & 20 & 24 & 31 \\
\hline $25 \%$ & 20 & 20 & 20 & 27 & 38 \\
\hline $30 \%$ & 20 & 20 & 20 & 32 & 40 \\
\hline $35 \%$ & 20 & 20 & 22 & 37 & 47 \\
\hline $40 \%$ & 23 & 22 & 24 & 39 & 55 \\
\hline $45 \%$ & 24 & 24 & 26 & 42 & 65 \\
\hline $50 \%$ & 26 & 25 & 27 & 49 & 67 \\
\hline $55 \%$ & 29 & 27 & 29 & 52 & 77 \\
\hline $60 \%$ & 33 & 30 & 33 & 60 & 85 \\
\hline $65 \%$ & 37 & 32 & 36 & 64 & 109 \\
\hline $70 \%$ & 44 & 35 & 40 & 71 & 121 \\
\hline $75 \%$ & 47 & 39 & 47 & 84 & 133 \\
\hline $80 \%$ & 61 & 58 & 71 & 114 & 152 \\
\hline $85 \%$ & 85 & 77 & 84 & 132 & 168 \\
\hline $90 \%$ & 147 & 102 & 111 & 172 & 200 \\
\hline $95 \%$ & 236 & 173 & 188 & 238 & 304 \\
\hline $100 \%$ & 408 & 485 & 355 & 392 & 471 \\
\hline
\end{tabular}

Frequência acumulada dos preços dos contratos de dois anos no momento de renovação $(R \$ / M W h)$ - Cenário 2

\begin{tabular}{|c|c|c|c|c|c|}
\hline & Jan-09 & Jan-11 & Jan-13 & Jan-15 & Jan-17 \\
\hline $0 \%$ & 20 & 20 & 20 & 20 & 20 \\
\hline $5 \%$ & 20 & 20 & 20 & 20 & 20 \\
\hline $10 \%$ & 20 & 20 & 20 & 21 & 21 \\
\hline $15 \%$ & 20 & 20 & 20 & 22 & 25 \\
\hline $20 \%$ & 20 & 20 & 20 & 23 & 29 \\
\hline $25 \%$ & 20 & 20 & 20 & 26 & 36 \\
\hline $30 \%$ & 20 & 20 & 20 & 28 & 38 \\
\hline $35 \%$ & 20 & 20 & 21 & 34 & 44 \\
\hline $40 \%$ & 22 & 22 & 23 & 36 & 47 \\
\hline $45 \%$ & 24 & 23 & 24 & 38 & 57 \\
\hline $50 \%$ & 27 & 24 & 26 & 45 & 65 \\
\hline $55 \%$ & 30 & 26 & 29 & 49 & 72 \\
\hline $60 \%$ & 32 & 29 & 32 & 53 & 77 \\
\hline $65 \%$ & 35 & 30 & 35 & 60 & 93 \\
\hline $70 \%$ & 43 & 33 & 38 & 68 & 113 \\
\hline $75 \%$ & 47 & 41 & 44 & 79 & 122 \\
\hline $80 \%$ & 59 & 56 & 64 & 105 & 143 \\
\hline $85 \%$ & 88 & 77 & 78 & 111 & 164 \\
\hline $90 \%$ & 147 & 99 & 106 & 165 & 201 \\
\hline $95 \%$ & 245 & 177 & 180 & 205 & 274 \\
\hline $100 \%$ & 384 & 464 & 372 & 378 & 472 \\
\hline
\end{tabular}


Frequência acumulada dos preços dos contratos de dois anos no momento de renovação $(\mathrm{R} \$ / M W h)$ - Cenário 3

\begin{tabular}{|c|c|c|c|c|c|}
\hline & Jan-09 & Jan-11 & Jan-13 & Jan-15 & Jan-17 \\
\hline $0 \%$ & 20 & 20 & 20 & 20 & 20 \\
\hline $5 \%$ & 20 & 20 & 20 & 20 & 20 \\
\hline $10 \%$ & 20 & 20 & 20 & 21 & 20 \\
\hline $15 \%$ & 20 & 20 & 20 & 21 & 22 \\
\hline $20 \%$ & 20 & 20 & 20 & 22 & 26 \\
\hline $25 \%$ & 20 & 20 & 20 & 24 & 28 \\
\hline $30 \%$ & 20 & 20 & 20 & 25 & 33 \\
\hline $35 \%$ & 20 & 20 & 20 & 29 & 39 \\
\hline $40 \%$ & 22 & 20 & 21 & 32 & 44 \\
\hline $45 \%$ & 23 & 23 & 22 & 32 & 49 \\
\hline $50 \%$ & 24 & 23 & 24 & 41 & 51 \\
\hline $55 \%$ & 28 & 25 & 25 & 44 & 63 \\
\hline $60 \%$ & 33 & 27 & 28 & 46 & 68 \\
\hline $65 \%$ & 34 & 29 & 29 & 49 & 90 \\
\hline $70 \%$ & 41 & 30 & 31 & 53 & 101 \\
\hline $75 \%$ & 45 & 37 & 39 & 67 & 108 \\
\hline $80 \%$ & 54 & 51 & 57 & 94 & 131 \\
\hline $85 \%$ & 86 & 70 & 73 & 103 & 146 \\
\hline $90 \%$ & 145 & 91 & 86 & 152 & 188 \\
\hline $95 \%$ & 227 & 185 & 146 & 193 & 274 \\
\hline $100 \%$ & 424 & 510 & 300 & 347 & 411 \\
\hline
\end{tabular}

Frequência acumulada dos preços dos contratos de quatro anos no momento de renovação $(R \$ / M W h)$ - Cenário 4

\begin{tabular}{|c|c|c|}
\hline & Jan-09 & Jan-13 \\
\hline $0 \%$ & 71 & 71 \\
\hline $5 \%$ & 74 & 79 \\
\hline $10 \%$ & 74 & 81 \\
\hline $15 \%$ & 75 & 86 \\
\hline $20 \%$ & 76 & 91 \\
\hline $25 \%$ & 77 & 95 \\
\hline $30 \%$ & 77 & 108 \\
\hline $35 \%$ & 78 & 114 \\
\hline $40 \%$ & 79 & 116 \\
\hline $45 \%$ & 81 & 119 \\
\hline $50 \%$ & 86 & 127 \\
\hline $55 \%$ & 90 & 133 \\
\hline $60 \%$ & 93 & 144 \\
\hline $65 \%$ & 95 & 149 \\
\hline $70 \%$ & 97 & 151 \\
\hline $75 \%$ & 101 & 154 \\
\hline $80 \%$ & 110 & 166 \\
\hline $85 \%$ & 129 & 171 \\
\hline $90 \%$ & 149 & 186 \\
\hline $95 \%$ & 194 & 253 \\
\hline $100 \%$ & 237 & 374 \\
\hline
\end{tabular}

